Cahiers Charlevoix

Études franco-ontariennes
Cahiers Charlevoix Études franco-ontariennes

or Crevenerix of

\title{
Inégalités ethniques, disparités socioculturelles et hiérarchie de la terre à Hawkesbury et à Alfred en 1871
}

\section{Fernand Ouellet}

Volume 4, 2000

URI : https://id.erudit.org/iderudit/1039358ar

DOI : https://doi.org/10.7202/1039358ar

Aller au sommaire du numéro

\section{Éditeur(s)}

Société Charlevoix

Presses de l’Université d'Ottawa

ISSN

1203-4371 (imprimé)

2371-6878 (numérique)

Découvrir la revue

Citer cet article

Ouellet, F. (2000). Inégalités ethniques, disparités socioculturelles et hiérarchie de la terre à Hawkesbury et à Alfred en 1871. Cahiers Charlevoix, 4, 51-148. https://doi.org/10.7202/1039358ar
Résumé de l'article

Fernand Ouellet poursuit son étude du profil socio-économique des communautés de langue française de l'est du Canada avant 1911. Utilisant la méthode comparative, il a jusqu'ici mis en rapport, entre elles et avec les autres populations de leurs provinces et régions, ces diverses collectivités à des points de vue divers - la démographie, l'agriculture, l'urbanisation, l'industrialisation, l'alphabétisation et la scolarisation -; il a montré que leur appartenance religieuse et linguistique constituent des facteurs de distinction et qu'elles forment partout des communautés désavantagées. Le présent article lui permet de tester la validité de ses conclusions sur la communauté française du comté de Prescott, celles des cantons de Hawkesbury-Est, de Hawkesbury-Ouest et d'Alfred, à partir du recensement nominatif de 1871. Il commente les thèses courantes, certaines fantaisistes, sur l'estimation du nombre des migrants canadiens-français et les motivations qui les poussent à migrer, montrant que les considérations socio-économiques devancent de loin le besoin de se reproduire. Il explique enfin les inégalités ethniques des Franco-Ontariens par la hiérarchie de la terre, leur arrivée tardive justifiant la moindre étendue de leurs possessions foncières et les rendant disponibles pour le travail forestier.
Ce document est protégé par la loi sur le droit d'auteur. L'utilisation des services d'Érudit (y compris la reproduction) est assujettie à sa politique d'utilisation que vous pouvez consulter en ligne.

https://apropos.erudit.org/fr/usagers/politique-dutilisation/ 


\section{INÉGALITÉS ETHNIQUES, DISPARITÉS SOCIOCULTURELLES ET HIÉRARCHIE DE LA TERRE À HAWKESBURY ET À ALFRED EN 1871*}

Fernand Ouellet

Département d'histoire Université York, Toronto

* Ce texte a été rédigé grâce à l'appui du programme Killam. Cahiers Charlevoix 4, 2000, pp. 51-148. 


\section{SOMMAIRE}

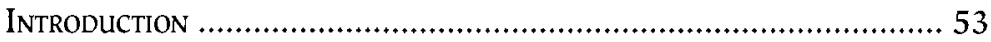

I - Migrants et pionniers : migration et Établissement ................... 57 1- Le profil de l'émigrant dans l'historiographie

2- Les étapes de la migration à Hawkesbury et à Alfred parmi les différents groupes ethniques

II - Diversité DES CONFESSIONS RELIGIEUSES

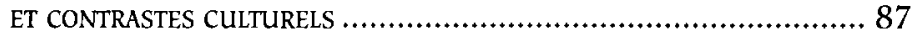

III - LES STRUCTURES SOCIO-ÉCONOMIQUES ………............................ 97

IV - LA HIÉRARCHIE DE LA TERRE: CULTIVATEURS MARGINAUX ET «MIDDLING-CLASS" AGRICOLE ............................................ 117

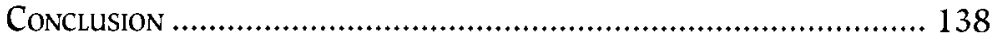




\section{INÉGALITÉS ETHNIQUES, DISPARITÉS} SOCIOCULTURELLES ET HIÉRARCHIE DE LA TERRE À HAWKESBURY ET À ALFRED EN 1871

\section{INTRODUCTION}

Depuis quelques années, nous avons tenté de décrire le contexte dans lequel se sont développées les diverses communautés de langue française de l'est du Canada avant 1911. Utilisant une méthode comparative et mettant largement à profit les données des recensements et les études existantes, nous avons situé ces collectivités non seulement les unes par rapport aux autres, mais aussi en relation avec les autres collectivités de leurs provinces et régions respectives. En analysant leur comportement démographique, leurs rapports à l'agriculture, à l'urbanisation, à l'industrialisation, à l'alphabétisation et à la fréquentation scolaire ${ }^{1}$, il est

\footnotetext{
${ }^{1}$ Fernand Ouellet, «Canadiens français et non-francophones dans les villes québécoises et ontariennes, 1851-1911: une perspective comparative et régionale", dans Jacques Cotnam, Yves Frenette, Agnès Whitfield (dir.), La Francophonie ontarienne: bilan et perspectives de recherche, Ottawa, Le Nordir, 1995, pp. 135-184; "Francophones et Franco-Ontariens dans l'univers agricole canadien, 1851-1911: perspectives comparatives", Cahiers Charlevoix 1. Etudes franco-ontariennes, Sudbury, Prise de parole, 1995, pp. 291-359; "Fréquentation scolaire, alphabétisation et société au Québec et en Ontario jusqu'en 1911 : les francophones et les autres «, Cahiers Charlevoix 2, Etudes franco-ontariennes,
} 
apparu qu'en tous lieux, ce qui les rapprochait et les éloignait les unes des autres et de leur entourage tenait tout autant à leur enracinement géographique et à leur situation à ces égards qu'à leur appartenance religieuse et linguistique. Un peu comme si toutes ces variables possédaient un tel degré d'affinité qu'il devenait impossible d'en aborder une sans faire appel plus ou moins à chacune des autres. Ainsi, le profil qui se dégage de cette exploration est celui de communautés désavantagées à divers égards dans le milieu global où elles étaient enracinées.

Une telle démarche ne peut, en dernier ressort, être pleinement justifiée si elle ne pénètre à l'intérieur des unités géographiques plus petites où les Canadiens français se trouvaient regroupés et en contact direct avec les habitants d'origine britannique, allemande et américaine. Le comté de Prescott dans l'est de l'Ontario, où s'était alors constituée une des communautés de langue française parmi les plus représentatives de ce point de vue, nous a semblé un des lieux les plus propices pour tester la validité de nos conclusions en ce qui concerne leur profil culturel et socioéconomique. En effet, en 1851 , on y dénombrait 3438 francophones $(32,8 \%)$ et 7049 colons de langue anglaise $(67,2 \%)$ sur une population totale de 10487 . Un demisiècle plus tard, les effectifs d'origine française s'y étaient élevés à 20124 (74,6\%), alors que ceux d'origines diverses avaient été réduits à 6844 (25,4\%). Déjà, en 1851, les catholiques de toutes distinctions, au nombre de 5420 , étaient majoritaires. Vingt ans ans plus tard, ce fut au tour des Canadiens français de le devenir. En 1911, la proportion

1997, pp. 263-349; «Aperçus comparatifs sur la démographie des communautés francophones dans l'est du Canada avant 1911 ", Cahiers Charlevoix 3, Etudes franco-ontariennes, 1998, pp. 87-177; «La Colonisation du Saguenay-Lac-SaintJean... en perspective, 1851-1911. La Marche des francophones dans l'est du Canada et vers la Nouvelle-Angleterre", Saguenayensia, 36, 1994, pp. 8-26; "Démographie, développement économique, fréquentation scolaire et alphabétisation dans les populations acadiennes des Maritimes avant 1911: une perspective régionale et comparative", Acadiensis, 26, 1996, pp. 3-31. 
des catholiques avait elle-même grimpé à $81 \%$. Vu à cette échelle, le spectacle était donc celui d'une communauté de langue française en grande expansion et de communautés de langue anglaise apparemment fort mal en point dans une province anglophone en plein développement.

Nous n'entendons pas répondre à toutes les questions soulevées par ces quelques chiffres. La tâche en serait trop lourde. C'est pourquoi nous avons limité notre champ d'observation à seulement trois cantons: ceux de HawkesburyEst, de Hawkesbury-Ouest et d'Alfred. En 1851, ces cantons, pris ensemble, avaient presque tout à fait la même physionomie que celle du comté et ils continuèrent de l'avoir jusqu'en 1911. Au milieu du siècle, les Canadiens français représentaient $32,1 \%$ de la population de ces trois cantons et les habitants de langue anglaise $67,9 \%$. À la veille de la première guerre mondiale, la proportion des premiers atteignait $73,7 \%$ et celle des seconds $26,3 \%$. Le recul en termes absolus des anglophones depuis 1851 y était même plus marqué dans ces trois cantons qu'au niveau du comté: 275 individus contre 205. Étant donné que cette majorité anglophone, devenue minorité dès 1871 au niveau du comté $(45,5 \%)$ et des trois cantons $(46,4 \%)$, fut non seulement, pendant tout ce temps, incapable d'absorber ses surplus des naissances sur les décès et ses immigrants, au point de voir sa population diminuer même par une faible marge, on ne saurait, comme le fait Chad Gaffield, parler des faibles pertes dont la population originaire des îles Britanniques fit l'expérience pour la première fois à la fin du $\mathrm{XIX}^{\mathrm{e}}$ siècle ${ }^{2}$. Pas étonnant alors que la suprématie numérique des catholiques déjà acquise depuis longtemps se soit davantage affirmée dans ces cantons que dans le comté: $88,4 \%$ contre $81,5 \%$. Notons, enfin, que, en 1911 , plus de $80 \%$ des 4400 habitants de la ville de Hawkesbury étaient francophones et

\footnotetext{
${ }^{2}$ Chad Gaffield, Aux origines de l'identité franco-ontarienne. Éducation, culture, économie, Ottawa, PUO, 1993, p. 84.
} 
catholiques. À preuve que la dimension urbaine et industrielle devint un des éléments, même modeste, de cette équation, la ville, dans un comté où l'industrie manufacturière comptait pour peu, regroupait $16 \%$ de la population, $72 \%$ de la main-d'œuvre industrielle et $66,1 \%$ de la valeur des produits manufacturés dans le comté.

Ainsi limitée dans l'espace, cette enquête l'est aussi dans le temps puisqu'elle est confinée à une seule année et à une source principale: le recensement nominatif de $1871^{3}$. Donc, un bloc de 1589 maisonnées, lieu de résidence de 9956 personnes appartenant à 1741 familles. Les habitants d'origine française y représentaient $53,6 \%$ de la population, le reste se départageant entre 619 Anglais, 2268 Irlandais, 1614 Écossais et 120 Allemands. Les catholiques s'y chiffraient à 6439 , soit $64,5 \%$ de la population. Dans le village de Hawkesbury, plus de la moitié des habitants étaient des Canadiens français, alors que plus de soixante pour cent étaient catholiques. Les dynamismes démographiques des communautés canadienne-française et de langue anglaise n'étaient donc pas les mêmes puisque, depuis 1851, les effectifs de la première s'étaient accrus de $165 \%$ alors que ceux de la seconde n'avaient augmenté que de seulement $8,3 \%$, ce qui était certainement fort inférieur à sa croissance naturelle.

Il y avait donc en 1871, à Hawkesbury et à Alfred, à l'époque où progresse la colonisation et s'amorce la transition vers le capitalisme industriel, comme dans le reste de l'Ontario, une société en formation née de mouvements migratoires déclenchés, depuis la Révolution américaine, successivement aux États-Unis, dans les îles Britanniques et dans le Bas-Canada. Elle était composée d'éléments divers nés sur place ou, le plus souvent, venus d'ailleurs, surtout du Québec et des îles Britanniques, qui se rattachaient à des groupes ethniques et religieux. Il a donc fallu identifier les

\footnotetext{
${ }^{3}$ Archives publiques du Canada (APC), bobines c-10010, c-10011.
} 
uns et les autres de façon à dégager les profils démographiques et culturels des immigrants et des gens en place. Ces communautés, bien que toutes fondées sur la famille et toutes désireuses qu'elles aient été de se reproduire, étaient néanmoins différentes sur les plans ethnique et religieux et leurs membres étaient répartis différemment et inégalement dans les activités socio-économiques et culturelles. Où se situaient les Canadiens français dans cet équilibre interethnique et dans le jeu des forces socio-économiques? Peut-être est-il possible de dégager, de la variété des informations du recencement de 1871, des éléments susceptibles d'expliquer éventuellement pourquoi les habitants d'origine britannique devaient quitter la région en si grand nombre et pourquoi les Canadiens français ont persisté au point de la dominer numériquement. Était-ce simplement le fruit d'un différentiel dans les taux de natalité, la conséquence des incompatibilités nationales ou le résultat des complexités de la socio-économie? Sans doute, tout cela à des degrés divers.

\section{Migrants et pionniers:}

\section{MIGRATION ET ÉTABLISSEMENT}

Ces mouvements migratoires, qu'ils aient été d'origine internationale ou québécoise, qu'ils aient eu leur aboutissement au Québec, aux États-Unis, dans le Haut-Canada ou dans l'Ouest canadien ont fait l'objet tantôt de spéculations et tantôt de recherches plus ponctuelles, inspirées davantage par l'émigration vers les États-Unis et par les migrations internes au Québec que par l'émigration vers le Haut-Canada. Pourtant, en 1870, non seulement l'immigration était-elle encore un événement important en Ontario, mais sa population d'origine française s'y chiffrait à 74000 alors qu'elle dépassait à peine les 100000 en NouvelleAngleterre $^{4}$. Cette historiographie des migrations, à cause

${ }^{4}$ R.D. Vicero, «Immigration of French Canadians to New England, 18401900 ", Ph.D. Thesis, University of Wisconsin, 1968, 449 p. 
des perspectives qu'elle apporte et des éléments de comparaison qu'elle suggère, a paru essentielle à notre propos sur ceux qui prirent part aux premières étapes de la colonisation dans l'est de l'Ontario.

\section{LE PROFIL DE L'ÉMIGRANT DANS L'HISTORIOGRAPHIE}

Même si le texte d'Albert Faucher ${ }^{5}$ paru en 1964 sur l'émigration des Canadiens français au XIX ${ }^{e}$ siècle offre peu d'informations sur les premières vagues d'immigrants britanniques et d'émigrants canadiens-français vers les États-Unis et l'Ontario, il constitue néanmoins une mise en perspective de ces mouvements acceptée par bien des historiens. Entre 1846 et 1914, explique-t-il, soixante millions de personnes quittèrent l'Europe, dont $60 \%$ se dirigèrent vers les États-Unis. Ainsi happé par ce tourbillon migratoire international, le Québec, partie marginale d'un espace économique nord-américain, n'était guère plus qu'une «terre de transit» vers les États-Unis et le reste du Canada. Autrement dit, l'émigration des Canadiens français n'était qu'un "cas de migrations parmi d'autres». Pour Faucher, la saturation des terroirs, la pauvreté, la dépossession et l'attachement à un territoire ne pesaient pas lourd sur la décision d'émigrer ou non. Car l'Amérique envisagée par Faucher était avant tout, géographiquement et économiquement, une terre d'opportunités que chacun, selon sa capacité et son désir de réussir, s'efforçait de s'approprier. La lumière qui attira alors les Canadiens français était celle des industries textiles de la NouvelleAngleterre: régions les plus rapprochées de l'émigrant potentiel, au coût minimum de transport. En Nouvelle-Angleterre, les Canadiens français ne déplacèrent pas les Yankees et les Irlandais, ils remplacèrent plutôt les seconds qui avaient

\footnotetext{
${ }^{5}$ Albert Faucher, «L'Émigration des Canadiens français au XIX ${ }^{\mathrm{e}}$ siècle: position du problème et perspectives», Recherches sociographiques, vol. 5, 1964, pp. 277-317.
} 
succédé aux premiers, tous deux étant partis vers de plus verts pâturages en quête de bénéfices plus substantiels: "Le Middle-West, affirme-t-il, promettait plus que la NouvelleAngleterre, la Nouvelle-Angleterre davantage que la province de Québec». Aperçue à l'échelle canadienne, la désertion des campagnes vers l'extérieur de la province par les Canadiens français ne pouvait être autre chose que la manifestation régionale et normale d'un événement national et occidental. Faucher va plus loin puisqu'il assimile les pertes que fit l'Ontario avant, mais surtout après 1880 , en faveur des États-Unis et de l'Ouest canadien, au cas québécois. L'émigrant de Faucher n'est donc pas en mauvaise posture économique ou autre. Il est simplement désireux d'améliorer son sort et, peut-être, de partir vers d'autres cieux par la suite, pour le surmonter abondamment en fin d'expérience migratoire.

Pendant que Faucher formulait sa vision, Gilles Paquet, alors son disciple, se chargea d'en rédiger la justification statistique en ce qui concerne l'émigration des Canadiens français vers la Nouvelle-Angleterre. Il arriva à la conclusion que, tout en étant continues, les migrations canadiennesfrançaises antérieures à 1875 n'avaient eu qu'un caractère temporaire. Par contre, après cette date, elles auraient, selon Paquet, pris l'allure d'un mouvement de masse déclenché par une vigoureuse reprise économique en NouvelleAngleterre. Pas étonnant dans ces conditions que, pendant la décennie 1880-1890, le solde migratoire du Québec francophone et anglophone aurait, selon lui, atteint un niveau astronomique. Mais ce solde migratoire auquel il arrive à la suite de ses calculs au tableau 10 de son texte ${ }^{6}$, soit 344952 départs du Québec vers les États-Unis dont

${ }^{6}$ Gilles Paquet, «L'Émigration des Canadiens français vers la Nouvelle-Angleterre, 1870-1910: prises de vue quantitatives», Recherches sociographiques, vol. 5, 1964, pp. 319-370. Voir le tableau 10 en particulier pp. 343-344. La méthode utilisée est la suivante: la population totale du Québec en 1891 (1 488 535) la population totale du Québec en $1881(1359027)=129508$ - naissances au 
295000 vers la Nouvelle-Angleterre, était basé sur une extraordinaire sous-estimation dans son équation des décès pendant la décennie: un total de seulement 28154 décès pour tout le Québec, alors que les seuls décès de catholiques québécois se chiffraient, selon Jacques Henripin et Péron, à 302981 . Cette erreur capitale vicie toute sa démarche et l'amène à pratiquer une admirable gymnastique intellectuelle qui aboutit à dire, sans preuves à l'appui, "qu'une estimation de l'émigration des Canadiens français vers la Nouvelle-Angleterre de l'ordre de 150000 à 200000 individus pour la décennie, 1881-1891, même si elle est assez vague, demeure très vraisemblable et assez conservatrice». À vrai dire, cela aurait simplifié de beaucoup ses procédés, si Paquet avait utilisé les chiffres sur la croissance de la population catholique de 1881 à 1891 selon les recensements (120 991) et les données alors disponibles sur la croissance naturelle des catholiques (227 204). Le solde net qu'il aurait obtenu aurait été de 106213 pour l'émigration des catholiques. Ce chiffre

Québec 1881-1891 (414 720) + décès au Québec 1881-1891 (28 124) immigration et rapatriement ( 87 909) = émigration nette (344952). Ce chiffre final est un non-sens non seulement à cause de cette immense sous-estimation des décès mais aussi en raison d'une substantielle sous-évaluation des naissances puisque, selon Jacques Henripin et Péron, le niveau des naissances chez les seuls catholiques fut, pendant cette décennie, de 530185 et celui des décès de 302 981. D'ailleurs, pourquoi ces chiffres sur l'immigration et le rapatriement, puisque l'émigration nette est normalement la différence entre la croissance de la population pendant la décennie en question et la croissance naturelle pendant la même période? Il va de soi que le résultat de cette opération tient compte de l'immigration et du rapatriement.

Supposons un instant que Paquet a raison de prétendre que 295000 Québécois de toutes origines ont alors quitté la province vers la Nouvelle-Angleterre et que, parmi eux, il y avait au moins 150000 Canadiens français, ce qui voudrait dire qu'un maximum possible de 145000 non-francophones sur une population totale de 285507 de même origine en 1880 , soit plus de $50 \%$ des effectifs, seraient partis dans cette seule direction. Ainsi, la moitié des nonfrancophones disparaissent vers la Nouvelle-Angleterre alors que seulement $14 \%$ des francophones posent le même geste, et cela ne constituerait pas aux yeux de l'économiste Paquet l'événement démographique majeur de cette décennie. Cela aussi est très curieux. 
est, d'ailleurs, très près de celui qu'il a lui-même obtenu et rejeté pour les Canadiens français à partir des recensements américains, soit 103365 (tableau 5 de son texte), et du solde (102 800) que nous avons tiré des données accumulées par l'historien Ralph Vicero. Notons qu'en 1891 la population catholique représentait $86 \%$ de la population totale de la province et que la population canadiennefrançaise constituait $93 \%$ de la population catholique.

Vingt ans plus tard, Paquet et son collaborateur Wayne Smith examinèrent une fois de plus la question de l'émigration vers les États-Unis afin de proposer «un scénario plausible des forces économiques qui ont engendré les flux et reflux de population entre les différents segments de l'espace économique autour des Grands Lacs ${ }^{7} »$. La méthode employée par les auteurs n'était pas différente de celle utilisée en 1964, excepté qu'ils eurent recours aux données sur les naissances et les décès des catholiques reproduites par Jacques Henripin. Estimée de cette façon, l'émigration aurait, cette fois-ci, augmenté régulièrement jusqu'à la fin de la guerre de Sécession. C'est seulement alors que se serait déclenché le boom migratoire durant les années 1860-1870, plus précisément de la fin de la guerre de Sécession à 1870, avec un maximum de 224252 départs.

La vision de l'émigrant présentée par Paquet et Smith n'était différente de celle de Faucher que par son intensité. Car il s'agissait, ce qui inclut le Canadien français, d'un agent économique ordinaire, pas émotif pour un sou, mais rationnel, sensible au marché et au profit. Sa décision de partir, "de l'Europe» ou d'un "sous-espace marginal de l'espace économique américain, était basée sur un calcul économique", à six variables au moins, toutes centrées en premier lieu sur l'endroit de destination. Essentiellement, la visée de l'émigrant, en conquérant qu'il était, était de

\footnotetext{
${ }^{7}$ Gilles Paquet et Wayne R. Smith, «L'Émigration des Canadiens français vers les États-Unis, 1790-1940: problématique et coups de sonde», L'Actualité économique, vol. 59, 1983, pp. 423-453.
} 
s'approprier sa part des "rentes» disponibles en fin de migration. Même si la "taille de cette rente économique génératrice de migration n'[était] évidemment pas facile à mesurer", la tâche de celui qui s'acheminait vers les régions agricoles était de s'enquérir de la disponibilité de terres et de leur profitabilité à ces endroits. Pour ceux, au contraire, qui se dirigeaient vers les régions commerciales et industrielles, la "rente différencielle» devait être mesurée en termes d'emploi, de salaires, de niveau de vie et de mobilité sociale verticale. Il est évident que, chez Paquet, l'idée de migration est axée sur les facteurs d'attraction et non sur les contraintes qui, au départ, pouvaient pousser le candidat à l'émigration à partir.

L'étude de Yolande Lavoie ${ }^{8}$, parue en 1972, appartient en partie au même courant historiographique, en ce sens qu'il s'agissait de démontrer qu'il existait un synchronisme entre l'émigration des Canadiens français et celle des autres $\mathrm{Ca}$ nadiens vers les États-Unis. Mais cela, dans son cas, à l'encontre de Paquet, avec l'idée d'attirer l'attention sur l'énormité des ravages causés dans la société d'origine par ces départs massifs. Mais elle ne nous apprend rien sur les motifs qui déterminaient les départs et sur les raisons qui incitaient à aller dans telle direction plutôt que dans telle autre. Cependant, il ne fait pas de doute que si les émigrants anglophones, Canadiens de naissance, s'étaient dirigés vers la Nouvelle-Angleterre en grand nombre, Ralph Vicero, qui a rédigé l'œuvre la mieux documentée de l'époque sur l'immigration en Nouvelle-Angleterre, en aurait fait état.

La thèse de Vicero sur l'immigration des Canadiens français en Nouvelle-Angleterre est, contrairement aux travaux précédents, appuyée sur une recherche très exhaustive visant à mesurer à la fois l'émigration nette des

\footnotetext{
${ }^{8}$ Yolande Lavoie, «Les Mouvements migratoires des Canadiens entre leur pays et les États-Unis aux XIX ${ }^{\mathrm{e}}$ et $\mathrm{XX}^{\mathrm{e}}$ siècles: étude quantitative», Hubert Charbonneau (dir.), La Population du Québec: études rétrospectives, Montréal, Boréal, 1973, pp. 73-88.
} 
Canadiens français vers ces États, leurs motifs, leur place dans une économie industrielle en pleine expansion, ainsi que l'évolution de leur population de 1840 à 1900 . Déjà, en 1860 , les terres disponibles étaient, explique-t-il, rares en Nouvelle-Angleterre et, par contre, il y avait 181278 emplois dans les seules industries du coton, des laines et de la chaussure ${ }^{9}$. C'est donc pour remplir ces emplois en nombre toujours croissant qu'avant 1900, 348950 immigrants canadiens-français vinrent s'établir pour de bon en Nouvelle-Angleterre. De 1840 au début du siècle, la population d'origine française de la région augmenta de 8200 à $573000^{10}$. Il y a donc une grande incompatibilité entre l'estimation prudente des effectifs migratoires de Vicero et celle pratiquée par Paquet et Smith qui les situent, si on se limite à la Nouvelle-Angleterre, à environ 800 000. Il y a aussi un grand désaccord entre Paquet et Smith quant aux motifs de ces immigrants. En effet, Vicero savait qu'en général des cultivateurs prospères, des artisans bien établis, des journaliers et des jeunes gens avec un avenir assuré ne seraient pas tentés d'aller se constituer en sousprolétariat dans un pays voisin simplement parce que le ciel économique y serait plus ensoleillé. Non seulement Vicero note-t-il les incessantes hésitations de ces immigrants et leur désir souvent manifesté de retourner au Québec pour de bon (en fait $50 \%$ d'entre eux y retournèrent, selon lui), mais, dans un long chapitre d'introduction, il met le doigt sur les problèmes agricoles, le surpeuplement des terroirs seigneuriaux et les faiblesses du développement industriel au Québec.

Il est certain que toute cette question des causes de l'émigration est au cœur d'un sujet qui concerne aussi bien les migrations venant d'Europe, celles à l'intérieur du Québec et même celles vers l'Ontario. C'est pourquoi, en scrutant les motifs des émigrants canadiens-français vers les

${ }^{9}$ R.D. Vicero, op. cit., pp. 115, 119, 121, 304, 325, 345.

${ }^{10}$ Ibid., pp. 132, 152, 163, 192, 213, 275, 289, 340. 
États-Unis, François Weil, dans Les Franco-Américains ${ }^{11}$, distingue nettement les raisons de partir de "l'attraction qu'exerçait le voisin nord-américain ${ }^{12}$ ». D'un côté, il met dans la balance les répercussions des problèmes agricoles, voire de ceux qui résultaient d'une certaine modernisation de l'agriculture, et des pressions démographiques, auxquelles il ajoute l'attrait des régions périphériques du Québec en voie de colonisation et celui des villes québécoises toutes proches. Et, de l'autre, le puissant mirage américain, même si en fin de compte il s'agissait pour ces pauvres migrants, infériorisés dans la société nouvelle, d'avoir «des enfants pour les faire travailler, les faire travailler pour pouvoir vivre». Mais Weil était plus intéressé par le développement d'une communauté organisée incluant une large classe ouvrière identitaire francophone que par la cohérence des arrière-plans quantitatifs de Paquet et Lavoie sur le volume de cette émigration. Ainsi, pour concrétiser la fascination exercée par la Nouvelle-Angleterre stimulée par les agents recruteurs des firmes américaines, il se réfère au schéma de Faucher et aux chiffres de Lavoie, alors que, pour décrire la progression difficile de la société francoaméricaine, il fait état des travaux de Vicero.

Yves Roby, dans son livre sur les Franco-Américains de la Nouvelle-Angleterre, voulut, comme Weil, démontrer l'émergence parmi ces migrants d'une culture et d'une identité spécifiques ${ }^{13}$. Comme lui, il utilise, sans pour autant en faire la critique, le modèle de Faucher et les éléments de mesure mis au point par Lavoie, Paquet, Smith et Vicero. Ce qui ne l'empêche pas de s'interroger sur les «causes répulsives et attractives» du mouvement qui avait conduit un si grand nombre de Canadiens français à s'expatrier. $\mathrm{Au}$ sujet de ces migrants, il écrit:

\footnotetext{
${ }^{11}$ François Weil, Les Franco-Américains, 1860-1980, Paris, Belin, 1989, p. 251.

${ }^{12}$ Ibid., p. 18.

${ }^{13}$ Yves Roby, Les Franco-Américains de la Nouvelle-Angleterre, Sillery, Septentrion, 1990, 434 p.
} 
ce sont des paysans dynamiques et progressistes qui ont été ruinés par une succession de mauvaises récoltes ou une baisse prolongée des prix; des fermiers que le déclin de l'industrie du bois ou le ralentissement des grands travaux de voirie a jetés dans les griffes de l'usurier; des journaliers; des familles ouvrières réduites au chômage et criblées de dettes; des familles qui veulent maintenir leur intégrité; parfois des jeunes diplômés des collèges classiques que l'encombrement des professions libérales prive d'espoir ${ }^{14}$.

Pour mieux nuancer son propos, il ajoute que ce n'étaient pas des «êtres brisés» à tout jamais par un mauvais destin, puisqu'ils s'étaient lancés dans l'aventure, voyageant le plus souvent avec leur famille, allant rejoindre des parents ou des connaissances des mêmes paroisses ou des mêmes régions qu'eux. Ces migrations en chaîne aboutirent dans un premier temps, d'après lui, à la création de «Petits Canadas". À vrai dire, en Nouvelle-Angleterre, ce ne fut pas le Pérou puisque les Canadiens français «occup[ai]ent les emplois les plus modestes et les moins bien rémunérés ${ }^{15}$ " et ils ne parvinrent à améliorer leur sort qu'en amenant avec eux presque toute la famille à l'usine. Évidemment, la fréquentation scolaire en souffrit pendant des décennies. Avec le temps, cependant, leur identité originelle, refaçonnée au contact de la culture ouvrière ambiante et du milieu américain, prit une coloration nouvelle.

Avec la thèse d'Yves Frenette sur les Canadiens français de Lewiston (Maine), arrivés en ces lieux à la suite des Irlandais, le profil de l'émigrant rural en route vers la ville se précise davantage. Car son discours ${ }^{16}$ porte d'abord sur les raisons qu'avaient eues les émigrants de quitter la province et sur l'attrait qu'exerça sur eux la NouvelleAngleterre à l'époque. L'endettement provoqué par les

\footnotetext{
${ }^{14}$ Roby, ibid., p. 59.

${ }^{15}$ Ibid., p.67.

${ }^{16}$ Yves Frenette, "La Genèse d'une communauté canadienne-française en Nouvelle-Angleterre: Lewiston, Maine, 1800-1880», Thèse de Ph.D., Université Laval, 1988, 392 p.
} 
difficultés socio-économiques des campagnes, la rareté des terres sur l'aire seigneuriale qui forçait les jeunes à aller de plus en plus loin pour assurer la reproduction familiale, la qualité inférieure des terroirs disponibles en périphérie et, finalement, l'écart structurel entre l'économie américaine et l'économie québécoise constituaient la liste des facteurs répulsifs. "À mesure que croissait l'économie des ÉtatsUnis, plus particulièrement du Nord-Est, le Québec s'acheminait sur la voie du sous-développement ${ }^{17}{ }{ }$. De là, les départs vers Lewiston de 246 couples identifiés et appartenant en majorité à la première génération d'immigrants dans cette petite ville dont l'économie avait piétiné jusqu'en 1840 et qui était maintenant en pleine effervescence. Quatrevingt-sept pour cent de ces couples étaient originaires du Québec, plus spécifiquement de 102 paroisses recouvrant un vaste territoire qui s'étendait, à quelques exceptions près, sur la rive sud du fleuve, de Montréal et Longueuil jusqu'à la Rivière-au-Renard. Bien sûr, les principales régions de recrutement furent la Beauce et le centre du Québec avec 38 paroisses d'où provenaient $42 \%$ des ménages, soit 2,7 couples par localité. Les 142 autres couples tirés de 64 paroisses, soit 2,2 par localité, étaient issus d'un territoire encore plus vaste. Notons que seulement 11 couples venaient des villes de Québec et de Montréal. On peut se demander, étant donné le petit nombre de couples originaires de chaque endroit et leur dispersion sur un territoire aussi étendu, par quel mécanisme des couples ainsi répartis sur un tel territoire ont-ils pu tous se retrouver à un moment donné à Lewiston. La rumeur, l'errance, les liens familiaux, les connaissances! À cet égard, Frenette raconte que: "[i]nscrite dans le paysage socio-économique du Québec, la mobilité géographique continuait aux ÉtatsUnis. Suivant les rumeurs qu'on embauchait dans une ville, dans un État, les Canadiens français prenaient la route..." Il est vrai que le taux de persistance n'était que de

${ }^{17}$ Ibid., p. 130. 
$33 \%$, mais il est vrai aussi que, dans neuf cas sur dix, selon Frenette, il s'agissait de familles aux trois quarts nucléaires bien constituées qui recherchaient une certaine stabilité. En 1880, dans cette population canadienne-française établie à Lewiston, ajoute-t-il, 50\% des hommes et $56 \%$ des femmes savaient lire et écrire. Dans la cohorte des 50 ans et plus, ces pourcentages n'étaient que de 28 et $32 \%$ respectivement. Ces taux, excepté ceux pour les 50 ans et plus, étaient inférieurs, comme ceux de la fréquentation scolaire (41\%), à ceux du Québec à la même époque ${ }^{18}$. Néanmoins, bien des enfants allaient à l'école et les chances existaient qu'ils y aillent de plus en plus. À Lewiston, la pauvreté n'avait pas disparu de leurs rangs, mais ils avaient des emplois rémunérés et sans doute la promesse d'une amélioration de leur condition: 135 hommes sur 141, et 138 femmes sur 218 , étaient au travail en 1870 . Le fait est que, avec le temps, une communauté canadiennefrançaise avait pris forme en milieu hétérogène à Lewiston comme elle prendra forme à Hawkesbury et à Alfred.

Bruno Ramirez aborde le même problème mais avec l'idée de mieux faire comprendre le caractère à la fois international et régional du marché de la main-d'œuvre. Dans son livre Par monts et par vaux ${ }^{19}$ paru en 1991, il met en rapport deux courants migratoires, l'un parti du comté de Berthier vers la Nouvelle-Angleterre et l'autre de l'Apennin méridional vers l'Amérique du Nord. Ces expériences, explique-t-il, furent amorcées à la même époque dans des sociétés agraires et périphériques séparées par un océan et elles furent achevées dans «des centres de croissance capitaliste ${ }^{20}$ ".

Le comté de Berthier, en tant que microscome du Québec migrant, qui sert de test dans ce projet, était un de ces

${ }^{18} \mathrm{~F}$. Ouellet, «Fréquentation scolaire, alphabétisation et société au Québec et en Ontario jusqu'en 1911...», Cahiers Charlevoix 2, Études franco-ontariennes, pp. 271, 313.

${ }^{19}$ Bruno Ramirez, Par monts et par vaux. Migrants canadiens-français et italiens dans l'économie nord-atlantique, 1860-1914, Montréal, Boréal, 1991, 205 p.

${ }^{20}$ Ibid., p. 19. 


\section{FERnAND OUellet}

nombreux comtés situés au cœur de l'ancien territoire seigneurial, dont la population déclina après 1850 . Dans ce comté agricole, raconte Ramirez, la socio-économie était composée de trois segments: une agriculture en voie de commercialisation, une agriculture de subsistance stagnante et un segment en procès de prolétarisation. En 1871, moins de $10 \%$ des cultivateurs avaient des fermes de 200 acres et plus, un quart de 100 à 199 et un tiers de moins de 50 acres. Si Ramirez avait poussé son enquête un peu plus loin, il aurait vu que, de 1860 à 1911, la production de grains et racines par occupant avait le plus souvent diminué qu'augmenté. Ainsi l'agriculture commerciale aurait été plutôt le fait d'un groupe de plus en plus restreint, contrôlant une portion accrue de la terre. Selon Ramirez, l'immense majorité des émigrants se recrutait parmi les propriétaires de moins de 50 acres et parmi les journaliers qui constituaient entre 20 et $26 \%$ de la main-d'œuvre. «La prolétarisation devient un processus irréversible... transforme un nombre croissant de fils de cultivateurs en journaliers permanents ${ }^{21}$."

Ces émigrants, des ménages en majorité et de jeunes célibataires se dirigèrent surtout vers le Rhode-Island et le Massachusetts. On pourrait croire que, ainsi déclassés économiquement et socialement, ces migrants seraient partis sans espoir de retour. Ramirez trouve la première preuve du contraire dans le fait qu'avant de partir les propriétaires de lopins de terre les hypothéquaient au lieu de les vendre, ce qui leur permettait de financer leur voyage et leur établissement aux États-Unis. Peut-être étaient-ils simplement incapables de vendre! Toujours est-il que, de 1878 à 1900, 42\% des 1183 familles qui avaient quitté le comté vers les États-Unis, revinrent, fort souvent pour repartir plus tard vers d'autres lieux. Il est évident que cette expérience n'eut pas de retombées économiques et sociales aussi spectaculaires dans le comté natal qu'en eut ${ }^{21}$ Ibid., pp. 28, 31. 
dans l'Apennin le séjour des migrants italiens qui renvoyaient chaque année une partie de leurs gains dans leur région d'origine ${ }^{22}$. Quant aux francophones qui avaient persisté aux États-Unis, ils s'intégrèrent dans les communautés de même origine qu'ils avaient ralliées. Avec le temps, ces cultivateurs, ces journaliers et ces femmes transformés en ouvriers de manufactures améliorèrent leur condition, les enfants fréquentèrent davantage les écoles et un sens communautaire vit le jour. Mais les brassages démographiques au Québec ne se réduisirent pas à l'émigration vers les États-Unis, c'est-à-dire des campagnes vers une place dans le prolétariat urbain. La colonisation agricole des territoires situés en dehors de l'aire seigneuriale, amorcée en premier lieu à la fin du XVIII ${ }^{e}$ siècle par les anglophones, fut de plus en plus prise en charge par les Canadiens français à mesure que le terroir seigneurial devint saturé de population. En analysant ces déplacements d'une société rurale plus ancienne vers un univers en formation, les historiens ont récemment mis l'accent sur le thème de la reproduction familiale par les mariages, la transmission des biens à un des fils et leur établissement dans le voisinage. L'étude de Gérard Bouchard ${ }^{23}$ sur le SaguenayLac-Saint-Jean explique beaucoup de choses au sujet de ces chefs de famille, quatre sur cinq étant des cultivateurs, issus en immense majorité de Charlevoix et «en quête de terres pour leurs enfants", venus s'installer dans cette région jusque-là inculte. D'autant plus que, jouant en plus sur le thème de la pluriactivité, il démontre que la participation saisonnière aux travaux forestiers contribuait ellemême à la reproduction familiale et à la marche du peuplement. Cette façon assez juste de voir les choses risque cependant de sous-estimer le fait que, dans ces régions, il n'y avait pas seulement abondance de terres, mais aussi de

\footnotetext{
${ }^{22}$ Ibid., pp. 71-80.

${ }^{23}$ Gérard Bouchard, Quelques arpents d'Amérique. Population, économie, famille au Saguenay, 1838-1971, Montréal, Boréal, 1996, 635 p.
} 
richesses forestières, dont l'exploitation fut surtout prise en charge par des capitalistes. Ainsi, dans toutes les régions périphériques, la progression du peuplement accompagna celle de l'industrie forestière.

Suivant en cela la démarche de Bouchard, Martine Hamel s'est interrogée sur la situation et les motifs de ces migrants de Charlevoix qui allèrent ainsi coloniser le Saguenay et de ceux qui partirent en d'autres directions entre 1852 et $1861^{24}$. Elle mentionne, bien sûr, la rareté et le prix élevé des terres dans les environs, la nécessité d'établir les fils sur des terres, le besoin d'accroître le capital foncier, ainsi que l'urgence de trouver un emploi. Les émigrants, précise-t-elle, se recrutaient dans toutes les catégories d'âges, mais ceux qui allèrent vers le Saguenay étaient légèrement plus âgés que les «sédentaires» et un peu moins que ceux qui se dirigeaient vers ailleurs: vers le Saguenay, pour les hommes 40,7 ans en moyenne, pour les femmes 36,5 ans; vers ailleurs 41,8 ans et 38,4 ans respectivement. Même si les cultivateurs représentaient $69 \%$ de tous les migrants, les journaliers, surtout ceux qui préféraient aller ailleurs qu'au Saguenay, étaient ceux qui émigraient le plus volontiers. Cela se comprend puisqu'ils étaient plus vulnérables aux difficultés économiques que les cultivateurs. Quant à ceux qui appartenaient aux autres catégories sociales, ils avaient moins tendance à émigrer que les autres, mais ils empruntaient davantage une destination autre que celle du Saguenay. Enfin, les familles qui optaient pour le Saguenay étaient plus nombreuses et avaient plus de garçons que les sédentaires et que celles qui se déplaçaient plus au loin «au coût maximum de transport $\%$. Il semble bien que ces dernières étaient attirées soit par les villes, soit par les États-Unis, soit, sait-on jamais, par l'est de l'Ontario.

Contrairement au Saguenay où le recrutement des colons

\footnotetext{
${ }^{24}$ Martine Hamel, «De Charlevoix au Saguenay: caractéristiques des familles émigrantes au XIX ${ }^{\mathrm{e}}$ siècle", Revue d'histoire de l'Amérique française (RHAF), vol. 47, 1993, pp. 5-25.
} 
avait été pratiqué à une source presque unique des points de vue géographique et ethnique, la vallée de l'Outaouais, l'épicentre de l'exploitation forestière au $\mathrm{XIX}^{\mathrm{e}}$ siècle, s'était alimentée en personnel agricole et forestier dans les îles Britanniques et dans toutes les régions du Québec. Claude Baribeau, dans son étude sur la seigneurie de la PetiteNation $^{25}$, propriété des Papineau, dont le développement avait débuté vers 1805 , en même temps que l'exploitation en grand des forêts de pin et de chêne prenait forme aussi bien en dehors qu'à l'intérieur de la seigneurie, s'est intéressé à l'origine géographique des colons de l'endroit avant 1850. Comme à Lewiston, les Canadiens français y étaient originaires d'un grand nombre de paroisses (rurales dans une proportion de 91\%): cinquante-huit localités au total disséminées dans les trois districts avec forte prédominance de la région de Montréal. Des quarante-deux paroisses de cette région étaient sortis 106 colons sur 136. Les seize paroisses des districts de Trois-Rivières et Montréal avaient fourni trente chefs de famille. La même diversité se retrouvait parmi les conjoints canadiens-français choisis en dehors de la Petite-Nation. Seulement $17 \%$ étaient originaires de localités du Haut-Canada et 125 provenaient des trois districts du Bas-Canada avec forte suprématie de la région de Montréal. Quant aux anglophones, 37 de leurs conjoints étaient venus avec eux des îles Britanniques et des ÉtatsUnis, 22 habitaient le Haut-Canada et 11 le Bas-Canada, dont 10 la région de Montréal.

Pendant ce temps, une autre expérience migratoire également significative en ce qui concerne celle de l'Est de l'Ontario et décrite par John Little ${ }^{26}$, avait cours dans les cantons de l'Est du Québec juste au moment où se dessinait

\footnotetext{
${ }^{25}$ Claude Baribeau, La Seigneurie de la Petite-Nation, 1801-1854. Le rôle économique et social du seigneur, Hull, Éditions Asticou, 1983, pp. 41-44.

${ }^{26}$ J.I. Little, Crofters and Habitants. Settler Society, Economy, and Culture in a Quebec Township, 1848-1881, Montréal-Kingston, McGill-Queen's University Press, 1991, $368 \mathrm{p}$.
} 
ce qu'il avait appelé auparavant la reconquête pacifique de ces territoires par les Canadiens français. Il s'agissait de 35 familles écossaises protestantes et rurales, parties de Lewis Island en Écosse, et de 58 familles canadiennes-françaises catholiques originaires de la seigneurie de Lauzon qui, en 1852, se fixèrent dans le canton de Winslow, comté de Compton. Les unes et les autres étaient pauvres, avaient quitté leurs communautés respectives pour des raisons économiques et démographiques similaires et n'avaient pas été attirées à cet endroit par la promesse d'un brillant avenir: le sol était aride, le climat rigoureux et les circonstances difficiles. À l'intérieur de chaque groupe, les individus pouvaient être liés par des rapports de parenté, mais, sachant qu'ils venaient de 19 et 13 paroisses différentes respectivement, on pourrait peut-être en douter. En tout cas, il ne s'agissait pas, selon Little, d'un «volountary process in chain migration ${ }^{27} »$. D'autant moins, en ce qui concerne les Écosssais, que leur départ non seulement avait été occasionné par la crise de la pomme de terre, dont ils dépendaient pour les deux tiers de leur diète, mais il avait été décidé par le Lord de l'endroit qui avait placé 5000 d'entre eux sur sa liste d'émigrants.

C'est donc en ces lieux défavorables qu'ils reproduisirent deux sociétés ethniquement distinctes: 669 Écossais et 1107 Canadiens français, chacune occupant son côté de la rivière. Certes la famille constituait partout l'unité sociale de base, mais les Canadiens français se mariaient plus jeunes, avaient plus d'enfants et étaient moins alphabétisés, alors que les autres pratiquaient une certaine forme de contrôle des naissances. Leur mortalité, surtout la mortalité infantile, était aussi plus élevée. Little n'accorde pas beaucoup d'importance à ces différences: "We have uncovered no evidence of major distinctions between the two cultural communities ${ }^{28}$.) Pourtant, on doit en plus, à

${ }^{27}$ Ibid., p. 25.

${ }^{28}$ Ibid., pp. 80-93. 
d'autres niveaux, particulièrement au plan agricole, constater l'existence, en 1871 , de différences substantielles entre elles. En effet, en 1871, la ferme moyenne écossaise avait un profil relativement prospère en comparaison de celui de l'exploitation canadienne-française: superficie de la terre $129 \%$, portion améliorée $120 \%$, récolte de grains et de racines $146 \%$, nombre d'animaux de la ferme $167 \%$, foin $159 \%$, valeur de la ferme $119 \%$. Et cela, sans compter les écarts dans les rendements. À cette date, seulement $8 \%$ des Écossais possédaient moins de 50 acres de terre, alors que $41 \%$ des francophones se trouvaient dans cette catégorie. Quoi qu'il en ait dit, il est évident que l'inégalité régnait entre les deux communautés et à l'intérieur de chacune d'elles. Plus dépendants que leurs voisins de l'agriculture de subsistance, les Canadiens français l'étaient, cela va de soi, du travail forestier. Little en conclut: «The essentially household-oriented economy permitted survival of certain culturally related agricultural practices ${ }^{29}$."

Bien qu'il ne soit jamais question de classes à propos de Winslow, la société était cependant stratifiée. Avec le temps, les francophones devinrent sur-représentés parmi les travailleurs non qualifiés et sous-représentés dans la petite élite économique. Apparemment, à Winslow, les Écossais ne réussirent pas si mal. Leur croissance naturelle était vigoureuse, mais ils connaissaient néanmoins une grande instabilité démographique. En effet, leur progression fut minée à tel point par les départs qu'au tournant du siècle cette communauté avait disparu, alors que ses voisins francophones avaient assez bien survécu. À ce point dans son histoire, Little s'est demandé si les attentes vis-à-vis la modernité n'étaient pas en partie responsables du destin écossais. Cette expérience rurale est tellement pertinente qu'on se croirait dans l'Est ontarien. En tout cas, elle trouve son complément dans le livre de Donald Akenson qui met

${ }^{29}$ Ibid., pp. 136-152. 
en scène, dans les cantons ontariens qu'il étudie, des colons irlandais, écossais, anglais et canadiens-français.

Cette cuvre, The Irish in Ontario ${ }^{30}$, de Akenson est d'abord une remise en question du stéréotype selon lequel les Irlandais auraient été culturellement prédisposés à vivre dans les villes et, dans le cas des catholiques, à s'y constituer en prolétariat pauvre. Pour corriger cette fausse impression laissée par les historiens, il fait observer qu'en Ontario, en 1871, les Irlandais protestants étaient non seulement les plus ruraux de la province $(82,2 \%)$, qu'ils l'étaient plus que les catholiques de même origine $(66,3 \%)$, mais que ceux-ci l'étaient même un peu plus que les Anglais $(64,2 \%)$. Akenson oublie cependant de dire que le taux de ruralité des Canadiens français était alors de 76,1\% et celui de l'ensemble des Ontariens de $79 \%{ }^{31}$.

Comme le contexte de la situation qu'il décrit déborde l'Ontario, il faut rappeler ici que, sans compter les Loyalistes et les autres qui vinrent avant 1815, l'immigration totale en provenance des îles Britanniques vers l'Amérique britannique du Nord totalisa, de 1815 à 1871, 1290040 individus. De 1825 à 1871 , période pour laquelle des informations existent sur l'immigration irlandaise, la proportion de ces derniers parmi les immigrants venus de cette source britannique était de $74 \%$. Sachant que les minuscules villes des Canadas n'auraient pu absorber tous ces éléments et que seules les campagnes, avec leur grande abondance de terres disponibles et leur besoin de maind'œuvre saisonnière pour l'exploitation forestière, pouvaient attirer ces masses d'immigrants, l'option rurale et agricole allait de soi pour la grande majorité de ces familles d'origine rurale. Il est vrai qu'avant 1785, époque où l'im-

\footnotetext{
${ }^{30}$ Donald Harman Akenson, The Irish in Ontario. A Study in Rural History, Montréal-Kingston, McGill-Queen's University Press, 1984, pp. 37-45.

${ }^{31} \mathrm{~F}$. Ouellet, «Canadiens français et non-francophones dans les villes québécoises et ontariennes, 1851-1911...)", Cotnam, Frenette, Whitfield (dir.), La Francophonie ontarienne..., p. 159.
} 
migration avait été peu nombreuse et sélective, la plupart des anglophones avaient pu se concentrer dans les villes du Québec. Mais, par la suite, cette tendance se renversa, de sorte qu'en 1871 les habitants de langue anglaise, à la suite de leur occupation des cantons situés au nord et au sud des seigneuries du Bas-Canada, étaient rapidement devenus de plus en plus ruraux, bien que se tenant toujours derrière les Canadiens français à cet égard: soit un taux de ruralité de $70,4 \%$ pour eux contre $84,1 \%$ pour ces derniers. À plus forte raison, en fut-il ainsi en Ontario, terre par excellence de colonisation qui, à ce titre, attirait la très grande majorité des nouveaux venus, dont un grand nombre poursuivait néanmoins sa route vers les EtatsUnis. Étant donné l'origine rurale des immigrants et la structure économique du milieu ontarien, on ne saurait alors s'étonner de constater que seulement deux Ontariens sur dix aient alors résidé dans les villes et villages de 1000 habitants et plus.

Pour illustrer ses dires sur la constitution d'une ruralité irlandaise spontanée dans le Haut-Canada, Akenson s'était limité à deux cantons, ceux de Leeds et de Lansdowne, dans le comté de Leeds. Ces cantons, contrairement à d'autres colonies établies pour les Irlandais et les Écossais, n'avaient pas été créés spécifiquement pour recevoir des Irlandais.

Lansdowne was open to the Irish on the same basis as to everyone else. The timing of the filling up of Leeds and Landsdowne meant that not only the industrializing village of Gananoque but the rural areas as well were open both to the pre-Famine Irish migrants and to those who left Ireland because of the Famine ${ }^{32}$.

Ce discours sur l'accueil fait aux Irlandais ne va pas plus loin que de mettre en évidence le fait que l'accès à la terre était un atout essentiel pour le Haut-Canada et que les Irlandais en tirèrent profit comme les autres.

${ }^{32}$ Ibid., p. 337. 
Le livre de Bruce Elliott, Irish Migrants in the Canadas ${ }^{33}$, est, à sa façon, tout aussi riche en contexte que les études de Little et d'Akenson sur les migrants britanniques. Pour illustrer sa thèse sur les rapports entre migration et reproduction familiale, Elliott part des campagnes de TipperaryNord en Irlande avec ses émigrants protestants. Il les suit au-delà de l'Atlantique dans les nombreuses colonies qu'ils créèrent à partir de 1818 dans le Canada-Est à Montréal, dans quelques seigneuries de la région, dans le voisinage de Hull, ainsi que dans le comté de Pontiac. Il pénètre ensuite dans la cinquantaine de colonies qu'ils établirent dans toutes les régions du Canada-Ouest. Ces émigrants, comme les Écossais de Lewis Island dont parle John Little, étaient originaires d'une région agricole, Tipperary-Nord, où de nombreux changements se produisaient. Aussi les premières vagues de migrants protestants étaient-elles composées, pour l'essentiel, de:

small and middling farmers... quite literally caught in the middle of an increasingly polarizing society. Realizing that they faced an uncertain economic future in Ireland and that in the absence of alternative sources of employment their children would depend upon subdivision of parental land for livelihood, many seized the opportunity to sell out their interests and emigrate to Canada ${ }^{34}$.

Ces cultivateurs se sentaient donc, à travers leurs enfants, menacés non seulement par la rareté des terres et par les changements introduits dans l'agriculture par les grands propriétaires fonciers, mais aussi par la poussée démographique des catholiques et l'agressivité politique de ceux qui, parmi eux, étaient les plus heurtés par cette situation. Lorsqu'il s'agit des motifs de ces fermiers qui décidaient de quitter leur pays, Elliott reconnaît l'importance des circonstances économiques, démographiques et politiques en question, mais il tient quand même à les

\footnotetext{
${ }^{33}$ Bruce C. Elliott, Irish Migrants in the Canadas. A New Approach, MontréalKingston, McGill-Queen's University Press, 1988, 371 p.

${ }^{34}$ Ibid., p. 37.
} 
InÉGalités ethniques À HaWkesbury et À Alfred en 1871

présenter sous l'angle de la reproduction familiale et de l'émigration en chaîne:

migration was largely a family affair. People moved in families, moved with kin, and moved to join kin... The direction, destination, and to some extent the volume of movements were clearly determined by family considerations ${ }^{35}$.

Il est évident, cependant, que les craintes de ceux qui émigrèrent étaient à la fois personnelles et familiales et que la réalisation de leur projet dépendait en plus de leur capacité de financer leur transport d'un lieu à un autre. Ce fut d'ailleurs de plus en plus le cas de ceux qui, parmi ces fermiers moyens, furent forcés de rester en Irlande faute d'argent, et dont la condition se détériora, et des pauvres journaliers qui, un jour, furent en mesure de partir grâce à l'aide gouvernementale ou à celle des grands propriétaires fonciers. La famine, époque "of horror and misery" marqua un tournant à cet égard. De cette façon, ces ruraux furent capables de se rendre en des lieux où la terre était abondante, facile d'accès et les emplois étaient disponibles. Ailleurs, dans le texte, Elliott nuance à nouveau son discours:

While the destination to which emigrants proceeded was influenced most strongly by the presence of kin, the timing of the decison to leave Ireland related to domestic economic and social conditions ${ }^{36}$.

À vrai dire, où a-t-on vu, au XIX ${ }^{\mathrm{e}}$ siècle, un mouvement d'émigration massive se déclencher d'un continent à un autre afin d'assurer simplement la reproduction familiale et d'améliorer le sort de la famille si la possibilité de le faire sur place existe? Que le migrant, qu'il soit marié ou célibataire, une fois sa décision prise de quitter sa paroisse ou son pays pour différentes raisons, choisisse sa destination en fonction de renseignements obtenus dans les réseaux familiaux et parmi les connaissances, cela fait partie d'une

${ }^{35}$ Ibid., p. 195.

${ }^{36}$ Ibid., p. 115. 
gamme de motifs qui sans doute incluent mais débordent de beaucoup le besoin de se reproduire.

Quoi qu'il en soit, les migrants dont il est question dans cette historiographie sont avant tout, d'où qu'ils viennent, des ruraux. L'immense majorité d'entre eux est constituée de couples avec enfants qui, en général, se recrutent, dans un assez grand nombre de localités au Québec, en Irlande, en Écosse ou en Angleterre. Ce ne sont pas surtout des jeunes dans la vingtaine qui se déplacent ainsi, mais des familles à tous les stades de leur évolution. Les unes vont vers la prolétarisation dans les villes et les autres sont en quête de terres pour eux et leurs enfants. Qu'en est-il à Hawkesbury et à Alfred?

\section{LES ÉTAPES DE LA MIGRATION À HAWKESBURY eT À AlFRED PARMI LES DIFFÉRENTS GROUPES ETHNIQUES}

C'est en puisant inégalement à tous les courants migratoires venus des États-Unis, des îles Britanniques et du Québec depuis la Révolution américaine, qu'une société hétérogène s'était constituée à Hawkesbury et à Alfred. Ici, contrairement à ce qui s'est passé dans la plupart des régions de l'Ontario, où, le plus souvent, les Irlandais dominaient numériquement, ce furent les Canadiens français qui, en plus de former le groupe le plus nombreux, l'emportaient même sur tous les autres réunis: $51,4 \%$ des chefs de maisonnée. La chose se vérifie à Hawkesbury et à Alfred avec $55,5 \%$ et $75,9 \%$ respectivement des chefs de maisonnée. À Hawkesbury-Ouest, cependant, les Canadiens français ne représentaient qu'un peu plus du tiers des chefs de maisonnée, alors que, dans le village, ils l'emportaient numériquement dans la population mais ne regroupaient que $49 \%$ des chefs de maisonnée. 
Inégalités ethniques À HaWkesbury et À AlfRed en 1871

TABLEAU 1

Les chefs de maisonnée à Hawkesbury et à Alfred selon l'origine ethnique, le lieu d'origine, l'âge

et le nombre des années de résidence en Ontario en 1871

\begin{tabular}{lrrrrrrr}
\hline & & & & & & & \\
& Erossais & Anglais & Allemands & Irlandais Anglophones & C. frangais & Total \\
nombre & 258 & 108 & 21 & 366 & 753 & 798 & 1551 \\
âge moyen & 49,6 & 44,4 & 49,0 & 47,2 & 47,7 & 42,4 & 45,0 \\
& & & & & & & \\
origine ont. ( $n$ ) & 123 & 46 & 7 & 97 & 273 & 115 & 388 \\
(\%) & 47,7 & 42,6 & 33,3 & 26,5 & 36,2 & 14,4 & 25,0 \\
âge moyen & 40,2 & 38,0 & 37,7 & 34,6 & 37,8 & 31,9 & 36,0 \\
années de résidence & 40,2 & 38,0 & 37,7 & 34,6 & 37,8 & 31,9 & 36,0 \\
& & & & & & & \\
nés ailleurs ( $n$ ) & 135 & 62 & 14 & 269 & 480 & 683 & 1163 \\
(\%) & 52,3 & 57,4 & 66,7 & 73,5 & 63,8 & 85,6 & 75,0 \\
âge moyen & 53,7 & 49,2 & 54,6 & 51,8 & 52,1 & 44,2 & 47,4 \\
années de résidence & 17,4 & 12,6 & 16,3 & 14,8 & 15,3 & 8,6 & 11,4 \\
& & & & & & & \\
\hline
\end{tabular}

Sources: APC, Recensement nominatif de 1871, bobine 10010-10011.

Ainsi que l'atteste le tableau 1, des différences notables existaient d'un groupe anglophone à un autre. Mais, en cela, rien de comparable aux disparités qui apparaissaient entre eux tous et les Canadiens français, particulièrement en ce qui concerne leur lieu d'origine. En effet, seulement $14,4 \%$ des Canadiens français étaient originaires de l'Ontario, alors que le pourcentage des anglophones dans la même situation était de $36,2 \%$. À Alfred, cette polarisation était encore plus marquée puisque $8,5 \%$ des chefs de maisonnée francophones et $38 \%$ des anglophones s'étaient déclarés d'origine ontarienne. Curieusement, Chad Gaffield affirme qu'en se basant sur les recensements de 1851 à 1871 , «il est impossible de faire une telle évaluation de l'importance de la colonisation familiale chez les anglophones puisque, dès 1851 , les parents faisaient habituellement inscrire le nom de HautCanada comme lieu de naissance de leurs enfants ${ }^{37}$ ". Pourtant, il ne fait aucun doute, étant donné la diversité

${ }^{37}$ Chad Gaffield, Aux origines de l'identité franco-ontarienne..., p. 67. 
et la cohérence des déclarations faites aux recenseurs en 1871 par les chefs de maisonnée sur leur lieu d'origine (Ontario ou ailleurs), que les réponses étaient exactes. Sans compter le fait que la mention Ontario n'est pas si fréquente que cela. $\mathrm{Si}$, par exemple, dans le recensement de 1871 , la mention d'origine américaine est si rare ici et pas dans les cantons de Leeds et Lansdowne, c'est sans doute que les Loyalistes et les colons américains du début du siècle avaient eu peu d'impact sur la démographie de la population d'origine anglophone de la région. Par contre, si le Québec est si souvent mentionné par les anglophones comme lieu d'origine (de séjour ou de naissance) d'eux-mêmes et de leurs enfants, on ne saurait y voir autre chose que le désir d'être exact. D'ailleurs, sur cette question, Gaffield n'est pas tout à fait conséquent. En effet, discutant de la population de Prescott originaire des îles Britanniques, il prétend que la "plupart de ces gens étaient nés en Amérique du Nord britannique mais [qu']un nombre considérable venait des îles Britanniques (particulièrement d'Irlande) et des États-Unis (voir tableau 4$)^{38}$ ".

Nous n'avons décelé aucune anomalie à cet égard dans la cueillette des données par les recenseurs qui résidaient dans les communautés en question. Car les chiffres sont clairs et cohérents puisqu'ils disent que, parmi ceux qui étaient nés en Ontario, les plus âgés, c'est-à-dire ceux qui $y$ avaient résidé le plus longtemps, étaient ceux qui étaient arrivés les premiers dans la province: les Écossais, les Allemands et les Anglais. À leur suite, venaient les Irlandais et, plus tard, les Canadiens français. Ils disent aussi que, parmi ceux qui étaient venus en Ontario d'ailleurs, donc plus récemment, les Écossais, les Allemands, les Anglais et les Irlandais étaient les plus âgés, les Canadiens français venant au dernier rang. Encore là, pour le nombre d'années de résidence, les Écossais, les Allemands, les

${ }^{38}$ Ibid., p. 58. 
INÉGalités ETHNiques À HaWkESBury ET À ALFRED EN 1871

Irlandais et les Anglais étaient, dans l'ordre, les plus anciennement établis, les Canadiens français se trouvant à un niveau $44 \%$ plus bas que les autres. Tout cela semble parfaitement conforme au déroulement du processus migratoire décrit maintes fois par les historiens qui racontaient que, une fois l'immigration loyaliste révolue, les combattants de la guerre de 1812 s'installèrent, suivis des Irlandais et, plus tard, des francophones. C'est d'ailleurs le déclin de l'immigration britannique et irlandaise depuis le milieu des années 1850 qui avait laissé de plus en plus le champ libre aux Canadiens français dans la région. Cette hiérarchie des arrivages paraît encore plus évidente si on remonte dans le temps jusqu'à 1845 afin d'identifier les groupes qui dominaient numériquement avant cette date. Dans cette catégorie, $63 \%$ des chefs de maisonnée étaient écossais, allemands ou anglais, $41 \%$ irlandais et $13 \%$ canadiens-français.

Dans le village de Hawkesbury, où les principales industries étaient concentrées, le contraste entre anglophones et francophones était toujours présent mais considérablement réduit. La proportion des Canadiens français natifs de l'Ontario y était plus élevée. En fait, entre eux et les Irlandais, l'écart avait presque disparu à cet égard, alors qu'un nivellement partiel s'était aussi opéré au point de vue des âges. Il en était ainsi des années de résidence en terre ontarienne.

Pour se rapprocher ainsi de celui des anglophones, le profil villageois des Canadiens français n'avait pas eu besoin de se modifier radicalement puisque le changement majeur s'était fait du côté des anglophones. Il est vrai qu'entre eux et les Écossais les différences étaient considérables. Il n'en reste pas moins que, dans l'ensemble, les chefs de maisonnée anglophones du village avaient une physionomie plus jeune que celle de leurs compatriotes ruraux de même origine et qu'ils résidaient depuis moins longtemps qu'eux dans la province et sur place. On pourrait 
même avoir l'impression que bon nombre d'entre eux vivaient dans l'attente d'un départ vers l'extérieur. En cela, ils étaient forts différents des Canadiens français qui paraissaient beaucoup plus solidement établis dans le village.

TABLEAU 2

Les chefs de maisonnée dans le village de Hawkesbury-Ouest selon l'origine ethnique, le lieu d'origine, l'âge et le nombre d'années de résidence en

Ontario en 1871

\begin{tabular}{lrrrrrrr}
\hline & & & & & & & \\
& Écossais & Anģais & Allemands & Irlandais Anglophones & C. français & Total \\
nombre & 30 & 34 & 7 & 67 & 138 & 134 & 272 \\
âge moyen & 40,2 & 40,4 & 42,3 & 43,3 & 41,9 & 37,8 & 40,7 \\
& & & & & & & \\
origine ont. ( $n$ ) & 16 & 11 & 2 & 17 & 46 & 32 & 78 \\
(\%) & 53,3 & 32,3 & 28,6 & 25,4 & 33,3 & 23,9 & 28,7 \\
âge moyen & 33,9 & 38,4 & 36,0 & 35,9 & 35,9 & 28,7 & 32,6 \\
années de résidence & 35,9 & 38,4 & 36,0 & 35,9 & 35,9 & 28,7 & 32,6 \\
& & & & & & & \\
nés ailleurs (n) & 14 & 23 & 5 & 50 & 92 & 102 & 194 \\
(\%) & 46,7 & 67,7 & 71,4 & 74,6 & 66,7 & 76,1 & 71,3 \\
âge moyen & 47,3 & 41,3 & 44,0 & 45,9 & 44,8 & 40,6 & 42,9 \\
années de résidence & 14,8 & 6,2 & 9,2 & 10,1 & 9,8 & 8,2 & 9,0 \\
& & & & & & & \\
\hline
\end{tabular}

Sources: APC, Recensement nominatif de 1871, bobine 10010-10011.

Les chefs de maisonnée qui vinrent s'intégrer pour de bon ou pour un temps dans ces communautés étaient certainement issus d'un grand nombre de localités dans leurs régions et pays respectifs. Cependant, il faut dire qu'il est difficile d'être très précis à ce sujet, puisque les questions posées par les recenseurs ne concernaient que des pays et des provinces, non les paroisses, qui fournissaient des immigrants: d'une part, l'Angleterre, l'Écosse, l'Irlande et les États-Unis et, de l'autre, l'Ontario, le Québec, le NouveauBrunswick, la Nouvelle-Écosse et Terre-Neuve. Il faut dire que les Canadiens français qui venaient des États-Unis se comptaient sur les doigts de la main. Les francophones ontariens, cela va de soi, étaient nés soit au Québec, soit en Ontario. À propos des Canadiens français, Lucien Brault, 
dans son histoire de Prescott-Russell, affirme que les premiers colons francophones provenaient d'un grand nombre de paroisses de la région de Montréal situées dans les comtés de Vaudreuil, Soulanges, Deux-Montagnes, Argenteuil et Terrebonne ${ }^{39}$. En fait, si on se réfère aux études de Little sur Winslow, de Frenette sur Lewiston et de Baribeau sur la Petite-Nation, il faut certainement considérer que ces immigrants vers l'Est ontarien étaient tirés d'un territoire plus vaste que celui que décrit Brault. Quant aux anglophones, $46 \%$ d'entre eux étaient originaires de l'Ontario et du Québec et quelques-uns des Maritimes. Le reste, plus de $50 \%$, était venu essentiellement des îles Britanniques et un petit nombre des États-Unis.

Cette migration vers l'Ontario fut réalisée en grande partie par des couples, à savoir les parents de ceux qui étaient nés en Ontario et ceux qui, récemment, étaient venus d'ailleurs en une ou plusieurs étapes. En effet, le pourcentage de célibataires et de veufs parmi eux ne représentait, semble-t-il, pas plus de 10 à $15 \%$ des chefs de maisonnée. Sans doute pourrait-on en conclure qu'environ $85 \%$ des nouveaux venus dans ces cantons étaient des gens mariés. Les différences d'âge entre les maris et les épouses variaient de trois à neuf ans et elles étaient légèrement plus élevées chez les anglophones que chez les francophones. Ceux qui avaient le plus grand nombre d'enfants au moment de la migration étaient les Canadiens français $(4,5-3,2=1,3)$ contre $(4,0-3,6=0,4)$ pour les autres (tableau 3$)$. Enfin, c'est parmi les Canadiens français que les personnes étrangères à la famille nucléaire étaient les moins nombreuses dans les maisonnées.

\footnotetext{
${ }^{39}$ Lucien Brault, Histoire des comtés unis de Prescott et de Russell, L'Orignal, 1965, p. 27. Voir aussi Cyrus Thomas, History of the Counties of Argenteuil and Prescott from the Earliest Settlement to the Present, Montreal, 1896, 665 p.
} 
TABLEAU 3

Épouses des chefs de maisonnée selon l'ethnicité, l'âge, le nombre d'enfants, le nombre de nés en Ontario et la dimension des maisonnées à Hawkesbury et à Alfred en 1871

\begin{tabular}{|c|c|c|c|c|c|c|c|}
\hline \multirow{2}{*}{$\begin{array}{l}\text { Origine ont. } \\
\text { (\%) }\end{array}$} & \multirow{2}{*}{$\begin{array}{l}\text { Écossais } \\
46,7\end{array}$} & \multirow{2}{*}{$\begin{array}{l}\text { Anglais } \\
39,0\end{array}$} & \multirow{2}{*}{$\begin{array}{l}\text { Allemands } \\
39,1\end{array}$} & \multicolumn{2}{|c|}{ Irrandals Anglophones } & \multirow{2}{*}{$\begin{array}{r}\text { C. français } \\
22,5\end{array}$} & \multirow{2}{*}{$\begin{array}{r}\text { Total } \\
29,9\end{array}$} \\
\hline & & & & 33,4 & 38,8 & & \\
\hline $\begin{array}{l}\text { Origine ailleurs } \\
\text { (\%) }\end{array}$ & 53,3 & 61,0 & 60,9 & 66,5 & 61,1 & 77,5 & 70,1 \\
\hline âge moyen & 42,3 & 41,0 & 39,3 & 41,6 & 41,6 & 37,3 & 39,7 \\
\hline âge: $1^{\text {er }}$ enfant & 24,8 & 22,6 & 21,9 & 24,5 & 23,8 & 21,8 & 22,7 \\
\hline enfants (n) & 4,0 & 3,7 & 3,4 & 4,2 & 4,0 & 4,5 & 4,2 \\
\hline nés en Ontario & 3,7 & 3,2 & 3,3 & 3,7 & 3,6 & 3,2 & 3,3 \\
\hline maisonnée (n) & 6,7 & 6,1 & 5,4 & 6,7 & 6,5 & 6,6 & 6,5 \\
\hline
\end{tabular}

Sources: APC, Recensement nominatif de 1871, bobine 10010-10011.

Même si les femmes francophones étaient celles dont l'âge moyen était le plus bas à la naissance de leur premier enfant, elles étaient néanmoins celles qui en avaient le plus. Comme elles étaient venues récemment du Québec, le profil démographique de leur famille ressemblait davantage à celui des gens de leur milieu d'origine plutôt qu'à celui qui prévalait dans leur terre d'accueil: pour la natalité $38,4^{0 / 00}$ au Québec et $35,2^{0 / 00}$ en Ontario en $1871^{40}$. Les mêmes écarts existaient en ce qui concerne la mortalité générale et infantile entre les deux provinces: au Québec $17,5^{\circ / 00}$ et $164^{0 / 00}$ respectivement et en Ontario $11,1^{0 / 00}$ et $85^{\% 00}$.̀̀ Hawkesbury et à Alfred, les disparités qui existaient au Québec entre Canadiens français et anglophones y furent elles-mêmes reproduites.

\footnotetext{
${ }^{40} \mathrm{~F}$. Ouellet, «Aperçus comparatifs sur la démographie des communautés francophones dans l'Est du Canada avant 1911", Cahiers Charlevoix 3, Études franco-ontariennes, pp. 154s.
} 
TABLEAU 4

Natalité*, mortalité générale* et mortalité infantile**

à Hawkesbury et à Alfred en 1871

$\left({ }^{*} n\right.$. de naissances et $n$. de décès par 1000 habitants;

**n. de décès d'enfants de 12 mois et moins par 1000 naissances)

natalité

mortalité générale

croissance

mortalité infantile

\section{Anglophones}

26,0

10,4

15,6

46,3
Francophones

39,5

12,8

26,7

123,1
Ensemble

33,5

11,7

21,8

96,5

Sources: APC, Recensement nominatif de 1871, bobine 10010-10011.

Les Canadiens français étaient certainement désavantagés à plusieurs égards par le fait qu'ils étaient arrivés les derniers dans la région. Par contre, ils étaient bien servis, en dépit d'une mortalité relativement très élevée, par une croissance naturelle vigoureuse, surpassant par une marge de $40 \%$ celle des anglophones. Et cela, au moment où les immigrants britanniques, en plus de se raréfier, se sentaient davantage attirés par d'autres régions plus prometteuses que l'Est ontarien. Ajoutons à cela que les anglophones précédaient de plusieurs décennies les Canadiens français dans la pratique du contrôle des naissances ${ }^{41}$. Ainsi, en 1871, la société anglophone paraissait avoir atteint un état de maturité qui laissait peu d'espoir pour une croissance significative de ses effectifs.

Ce tournant, on ne peut malheureusement parvenir à le lire à travers le profil des hommes âgés de 15 à 35 ans inscrits au recensement, ayant déclaré des occupations qui étaient en général les mêmes que celles des chefs de maisonnée. En effet, il s'agit, dans l'immense majorité des cas, de jeunes hommes, vivant à l'intérieur des maisonnées, presque toujours non mariés et appartenant le plus souvent à la famille.

\footnotetext{
${ }^{41}$ Marvin McInnis, "Women and Childbearing: Ontario in the Second Half of the Nineteenth Century", Histoire sociale/Social History, vol. 24, 1991, pp. 237-262.
} 
TABLEAU 5

Membres de la maisonnée qui, sans être chefs de maisonnée, ont déclaré des occupations à Hawkesbury et à Alfred en 1871 selon l'âge et le lieu de résidence*

\begin{tabular}{lrrrrrr}
\hline & Écossais & Anglais & Allemands & Illandais & Anglophones & C. Fançajs \\
nombre & 179 & 66 & 14 & 286 & 545 & 450 \\
âge moyen & 24,2 & 23,7 & 24,2 & 24,2 & 24,5 & 23,6 \\
nés en Ont. $(n)$ & 162 & 53 & 14 & 198 & 427 & 175 \\
(\%) & 90,5 & 80,3 & 100 & 69,2 & 78,3 & 38,9 \\
âge moyen & 23,2 & 22,9 & 24,2 & 22,9 & 23,1 & 20,8 \\
nés ailleurs ( $n$ ) & 17 & 13 & 0 & 88 & 118 & 275 \\
(\%) & 9,5 & 19,7 & 0 & 30,8 & 21,7 & 61,1 \\
âge moyen & 33,8 & 27,2 & 0 & 29,0 & 29,5 & 25,4
\end{tabular}

Sources: APC, Recensement nominatif de 1871, bobine 10010-10011.

*non mariés dans l'immense majorité des cas.

Le pourcentage de ceux qui, parmi ces individus, étaient nés en Ontario, avait fait un bond gigantesque des pères aux fils chez les anglophones: de $36,2 \%$ à $78,3 \%$, alors que dans le village leur progression avait été beaucoup plus modeste. Chez les francophones, au contraire, le changement avait été énorme dans le village (de $23,9 \%$ à $73,5 \%$ ), mais relativement modéré dans les campagnes (de 14,4\% à $38,9 \%$ ). Les moyennes d'âge, à peu près uniformes dans tous les groupes, étaient cependant fort contrastées parmi ceux qui étaient nés à l'extérieur de la province: 34 ans chez les Écossais, environ 28 chez les autres anglophones et 25 chez les Canadiens français.

Ainsi, dans un premier et un second temps, une population anglophone, ethniquement diversifiée et à grande majorité protestante, s'était partout répandue dans la région. Elle en avait alors pris possession. Puis, dans un troisième temps, des immigrants canadiens-français s'y étaient installés en grand nombre, apparemment sans obstacles sérieux, et y avaient même acquis en moins de deux décennies la suprématie numérique. La chose est d'autant plus surprenante que cette immigration avait conféré une 
prépondérance encore plus décisive aux catholiques à un moment où les variables de la croissance démographique jouaient contre les protestants.

\section{Diversité des confessions Religieuses ET CONSTRASTES CULTURELS}

Vers 1825 , la grande majorité des habitants de la région étaient de langue anglaise et répartis entre la plupart des confessions religieuses protestantes. Ce qui ne veut pas dire que chaque groupe ethnique s'identifiait entièrement à une croyance religieuse particulière. Au contraire, chacun d'eux était rangé sous plusieurs bannières. Puis, vers 1830 , le paysage fut légèrement modifié lorsque les Irlandais catholiques eurent commencé à prendre place pour de bon dans les trois cantons. Mais leur progression fut si lente qu'en 1871 moins de la moitié des Irlandais étaient catholiques. Les catholiques de langue française, au contraire, se multiplièrent si rapidement au cours des années 1850-1860 qu'en $187160 \%$ des chefs de maisonnée dans les trois cantons se rattachaient à leur communauté. D'ailleurs eux-mêmes étaient tellement homogènes à cet égard que seulement $1,1 \%$ des chefs de maisonnée francophones étaient protestants. Même si les Anglais, les Allemands et les Irlandais avaient une grande prédilection pour l'Église d'Angleterre, un grand nombre d'entre eux échappaient à son emprise. On peut en dire autant des liens entre l'Église presbytérienne et les Écossais. Ainsi, une grande diversité religieuse régnait parmi les anglophones, alors que les Canadiens français se ralliaient derrière un seul drapeau. Et cela au point que, si on peut parler d'une communauté francophone catholique unie autour de la langue et de la religion, comment peut-on faire autre chose que de se référer, dans la mesure où cela est possible, à une communauté anglophone et protestante? Sans doute les Irlandais catholiques étaientils les seuls à pouvoir être considérés à cet égard comme un groupe séparé. 


\section{TABLEAU 6}

La religion des chefs de maisonnée par groupe ethnique et par confession religieuse (en pourcentage)

\begin{tabular}{|c|c|c|c|c|c|c|c|}
\hline & Écossais & Anghlais & Allemands & \multicolumn{2}{|c|}{ Irlandais Anglophones } & C. français & Total \\
\hline Égl. catholique & 7,8 & 7,5 & 28,0 & 44,2 & 25,6 & 98,9 & 68,3 \\
\hline Égl. d'Angleterre & 2,7 & 46,7 & 40,0 & 25,7 & 21,2 & & 8,8 \\
\hline Égl. d'Écosse & 23,3 & 1,9 & & 4,0 & 10,3 & & 4,3 \\
\hline Égl. presbytérienne & 51,4 & 13,1 & & 13,0 & 26,0 & 0,3 & 11,0 \\
\hline Egl. méthodiste & 0,8 & 17,7 & 20,0 & 10,1 & 8,3 & 0,3 & 3,6 \\
\hline Autres & 14,0 & 13,1 & 12,0 & 2,9 & 8,6 & 0,5 & 3,8 \\
\hline Total & 100 & 100 & 100 & 99,9 & 100 & 100 & 99,8 \\
\hline
\end{tabular}

Sources: APC, Recensement nominatif de 1871, bobine 10010-10011.

Cette diversité des effectifs religieux à l'intérieur de chaque ethnie n'est pas sans suggérer que les mariages entre époux d'origine et de religion différentes étaient partout nombreux chez les anglophones, même à Alfred où nous en avons relevé onze en 1871 parmi les chefs de maisonnée irlandais, écossais, anglais et allemands de l'endroit. Ce qui va à l'encontre de ce que Gaffield affirme à propos d'Alfred et de Caledonia: les recensements de 1851, 1861 et 1871, affirme$\mathrm{t}$-il, ne montrent pratiquement aucun mariage entre des époux d'origine et de religion différentes ${ }^{42}$. Le tableau suivant sur la religion des épouses des chefs de maisonnée comparé à celui des chefs de famille indique, au contraire, qu'il existait dans ces trois cantons un marché matrimonial fort actif entre tous les groupes ethniques d'origine britannique et allemande. À l'exception toutefois des Canadiens français, dont la concentration dans le même groupe ethnique et religieux semble presque totale.

${ }^{42}$ Gaffield, op.cit., p. 69. À la Petite-Nation, Baribeau a trouvé 9 mariages entre Irlandais catholiques et protestants, op.cit., pp. 39-41. 
TABLEAU 7

La religion des épouses des chefs de maisonnée par groupe ethnique et par confession religieuse en 1871

\begin{tabular}{lrrrrrrr}
\hline & Écossis & Anglais & Allemands & \multicolumn{1}{l}{ rllandads Anglophones } & C. fançalis & Total \\
Égl. catholique & 7,6 & 19,2 & 25,0 & 46,2 & 28,7 & 98,6 & 66,4 \\
Égl. d'Angleterre & 4,3 & 34,3 & 42,8 & 23,2 & 19,7 & 0,1 & 9,1 \\
Égl. d'Écosse & 22,4 & 4,0 & 3,6 & 3,5 & 9,7 & & 4,4 \\
Égl. presbytérienne & 50,9 & 8,1 & 3,6 & 11,8 & 23,5 & 0,3 & 10,9 \\
Égl. méthodiste & 0,9 & 18,2 & 14,3 & 12,4 & 9,7 & 0,3 & 4,8 \\
Autres & 13,8 & 16,2 & 10,7 & 2,9 & 8,7 & 0,4 & 4,2 \\
Total & 99,9 & 100 & 100 & 100 & 100 & 100 & 99,8 \\
& & & & & & &
\end{tabular}

Sources: APC, Recensement nominatif de 1871, bobine 10010-10011.

La fréquence des mariages interethniques et interconfessionnels reflétait moins les attitudes des hiérarchies laïques et ecclésiastiques, toujours attentives à maintenir et à accroître leurs clientèles, vis-à-vis de ces unions que celles des populations qui étaient avant tout sensibles au besoin de trouver des épouses. Aussi, parmi ces besoins, les taux de masculinité, la dimension, la géographie des groupes ethniques et religieux et même le statut social figuraient-ils en bonne place.

\section{TABLEAU 8}

Le nombre de mariages interethniques ou interconfessionnels des chefs de maisonnée par rapport au nombre de chefs de maisonnée dans chaque groupe ethnique

\begin{tabular}{lrrrrrrr}
\hline & Écossais & Anglais & Allemands & Irlandais Anglophones & C. français & Total \\
Alfred & 2 & 1 & 1 & 7 & 11 & 0 & 11 \\
Hawkesbury-Est & 22 & 15 & 7 & 18 & 62 & 12 & 74 \\
Hawkesbury-Ouest & 25 & 33 & 9 & 37 & 104 & 7 & 111 \\
total & 49 & 49 & 17 & 65 & 180 & 19 & 199 \\
$(\%)$ & 18,3 & 44,8 & 68,0 & 19,9 & 24,6 & 1,9 & 11,3 \\
\hline
\end{tabular}

Sources: APC, Recensement nominatif de 1871, bobine 10010-10011.

Comme le démontrent ces pourcentages, les chefs de maisonnée appartenant aux groupes les moins nombreux, en l'occurrence les Anglais et les Allemands, puis les Écossais et les Irlandais, ceux-ci à cause de leur forte division entre 
catholiques et entre protestants, avaient été les plus susceptibles de rechercher des épouses dans les ethnies et les confessions religieuses les mieux pourvues en candidates. À vrai dire, comment quinze familles catholiques, dont huit anglaises, et sept allemandes, auraient-elles pu se perpétuer sans aller chercher des conjoints en dehors de leur cercle ethnique restreint? On comprend pourquoi, pour cette raison et pour d'autres, les anglophones avaient été responsables de neuf de ces mariages interethniques sur dix, alors qu'ils ne constituaient que $42 \%$ des chefs de maisonnée. Dans cette démarche, la barrière ethnique avait été plus facilement franchie que celle de l'appartenance religieuse. Si les chefs de maisonnée francophones catholiques furent si peu actifs sur ce marché matrimonial interethnique et interconfessionel, c'est sans doute, à part la rigidité de leurs principes et des contrôles exercés par l'Église, que, étant les plus nombreux, ils pouvaient plus aisément trouver une épouse à l'intérieur de leur groupe. Ce qui n'empêcha pas les Irlandais, les Anglais, les Écossais et les Allemands catholiques de se trouver dix-sept Canadiennes françaises comme épouses, alors que les anglophones protestants attirèrent à eux sept francophones protestantes. Aussi ne doit-on pas s'étonner qu'il n'y ait eu que cinq unions entre des protestants et des femmes catholiques francophones.

Il va sans dire qu'un tel brassage eut des répercussions sur la répartition des jeunes anglophones, surtout les Écossais, les Anglais et les Allemands, de la génération suivante dans les différentes confessions religieuses. En effet, à la suite de ces unions, les méthodistes et, dans une certaine mesure, les presbytériens, avaient gagné du terrain sur les catholiques et les fidèles de l'Église d'Angleterre, alors que les francophones s'étaient trouvés encore plus confinés dans leur communauté. 
TABLEAU 9

Membres de maisonnée qui, sans être chefs de maisonnée, ont déclaré des occupations à Hawkesbury et à Alfred en 1871,

selon leur groupe ethnique et leur appartenance religieuse

Égl. catholique

Égl. d'Angleterre

Égl. d'Écosse

Égl. presbytérienne

Egl. méthodiste

Autres

Total

\begin{tabular}{|c|c|c|c|c|c|c|}
\hline Écossais & Anglais & Allemands & \multicolumn{2}{|c|}{ Irlandais Anglophones } & C. trangais & Total \\
\hline 14,7 & 6,0 & & 32,6 & 21,7 & 99,8 & 58,4 \\
\hline 8,8 & 38,8 & 57,1 & 30,2 & 23,8 & & 12,6 \\
\hline 21,6 & 6,0 & & 3,3 & 10,6 & & 5,6 \\
\hline 42,1 & 10,4 & & 18,8 & 26,2 & & 13,9 \\
\hline 2,9 & 25,4 & 28,6 & 12,2 & 10,7 & & 5,7 \\
\hline 9,8 & 13,4 & 14,3 & 2,4 & 7,0 & 0,2 & 3,8 \\
\hline 99,9 & 100 & 100 & 99,5 & 100 & 100 & 100 \\
\hline
\end{tabular}

Sources: APC, Recensement nominatif de 1871, bobine 10010-10011.

Les Canadiens français venus dans cette région étaient donc fort différents des autres habitants de l'endroit par leur arrivée tardive sur les lieux, par leur comportement démographique et par l'unique intensité de leur association avec le catholicisme. Ils l'étaient tout autant par leur analphabétisme. En effet, âgés en moyenne de 42 ans, ces immigrants mâles n'avaient pas été vraiment touchés par les changements majeurs engagés dans l'éducation au BasCanada vers 1830 et réanimés vigoureusement par l'intervention de l'État après $1840^{43}$. Aussi le contraste entre eux et les anglophones déjà enracinés à Hawkesbury et à Alfred était-il d'autant plus frappant qu'ils arrivaient dans une société, bien sûr, encore au stade de la formation mais largement alphabétisée. La chose est d'autant plus significative pour notre propos que les écarts en ce domaine, comme en matière de natalité et de mortalité, n'étaient pas seulement des signes de différences entre les groupes ethniques et religieux mais, plus encore, d'inégalités socio-économiques entre eux et à l'intérieur de chacun d'eux. Bien que présents dans toutes les catégories sociales, les Canadiens français ne l'étaient pas également dans toutes par rapport aux autres. Ce qui voudrait dire

${ }^{43}$ F. Ouellet, "Alphabétisation, fréquentation scolaire et société...", Cahiers Charlevoix 2, Études franco-ontariennes, pp. 265-349. 
qu'ils étaient fortement surreprésentés dans les groupes les plus susceptibles d'avoir de hauts taux de natalité, de mortalité générale et infantile, ainsi que de bas taux d'alphabétisation. À Hawkesbury et à Alfred, des taux d'analphabétisme de $14 \%$ pour les anglophones et de $74 \%$ pour les Canadiens français ne sont pas des différences qu'on peut aisément passer sous silence. Sur ce point, on s'étonnera que, dans le livre de Gaffield, où il est tellement question d'identité, d'éducation et de culture, il n'en soit pas même question.

\section{TABLEAU 10}

Niveaux d'analphabétisme des groupes ethniques

de Hawkesbury et d'Alfred en 1871.

Pourcentage de chefs de maisonnée

âgés de plus de vingt ans ne sachant ni lire ni écrire

\begin{tabular}{lrrrrrrr}
$\begin{array}{lrrrrr}\text { nés en Ontario } \\
\text { ne sait lire }\end{array}$ & 8,9 & 9,1 & 16,7 & 1,4 & 6,5 & 65,8 & 25,4 \\
ne sait écrire & 11,4 & 9,1 & 16,7 & 9,8 & 10,6 & 68,4 & 29,0 \\
$\begin{array}{l}\text { nés ailleurs } \\
\text { ne sait lire }\end{array}$ & 10,5 & 7,9 & 60,0 & 10,2 & 11,1 & 72,5 & 48,5 \\
ne sait écrire & 15,8 & 7,9 & 60,0 & 16,4 & 16,0 & 75,9 & 52,4 \\
$\begin{array}{l}\text { ensemble } \\
\text { ne sait lire }\end{array}$ & & & & & & & \\
ne sait écrire & 9,8 & 8,4 & 43,7 & 8,1 & 9,7 & 71,0 & 42,7 \\
& 13,7 & 8,4 & 43,7 & 14,8 & 14,0 & 74,4 & 46,6 \\
\hline
\end{tabular}

Sources: APC, Recensement nominatif de 1871, bobine 10010-10011.

Notons que les différences entre tous ceux qui étaient nés en Ontario et tous ceux qui étaient nés à l'extérieur de la province étaient probablement attribuables aux différences d'âges entre les uns et les autres (voir tableau 1) et à la plus grande accessibilité des écoles en Ontario que dans les pays et les provinces d'origine.

Les mêmes disparités entre anglophones et francophones se retrouvent, bien que moins considérables, parmi les épouses des chefs de maisonnée. À ce sujet, on ne saurait 
être surpris de constater que les femmes canadiennesfrançaises aient été plus alphabétisées que leurs conjoints. Car, contrairement à ce qui avait existé dans le passé, elles avaient été, plus rapidement que les hommes, les bénéficiaires de la multiplication des écoles dans les campagnes à la suite des législations scolaires québécoises des années 1830 et 1840 . En Ontario, où la participation scolaire des filles était encore moins intense que celle des garçons en 1871, on doit, au contraire, être surpris qu'à Hawkesbury et à Alfred les épouses anglophones aient été un peu plus alphabétisées que leurs maris ${ }^{44}$. Notons enfin que, chez les femmes aussi bien que chez leurs maris, des écarts substantiels existent d'un groupe anglophone à un autre.

\section{TABLEAU 11}

Niveaux d'analphabétisme des épouses des chefs de maisonnée à Hawkesbury et à Alfred en 1871 .

Pourcentage des épouses âgées de plus de vingt ans incapables de lire et d'écrire (en pourcentage des épouses)

\begin{tabular}{|c|c|c|c|c|c|c|c|}
\hline \multirow{3}{*}{$\begin{array}{l}\text { nées en Ontario } \\
\text { ne sait lire } \\
\text { ne sait écrire }\end{array}$} & Écossaises & Anglaises & Allemandes & \multicolumn{3}{|c|}{ Irlandaises Anglophones C. trançaises } & Total \\
\hline & 9,7 & 11,1 & 20,0 & 1,9 & 6,9 & 50,6 & 23,7 \\
\hline & 10,7 & 11,1 & 33,3 & 4,7 & 8,9 & 58,4 & 28,0 \\
\hline nées ailleurs & & & & & & & \\
\hline $\begin{array}{l}\text { ne sait lire } \\
\text { ne sait écrire }\end{array}$ & $\begin{array}{l}16,7 \\
22,7\end{array}$ & $\begin{array}{l}3,2 \\
3,2\end{array}$ & $\begin{array}{l}16,0 \\
24,0\end{array}$ & $\begin{array}{l}13,0 \\
16,8\end{array}$ & $\begin{array}{l}12,8 \\
17,0\end{array}$ & $\begin{array}{l}52,5 \\
63,0\end{array}$ & $\begin{array}{l}35,9 \\
43,7\end{array}$ \\
\hline $\begin{array}{l}\text { Ensemble } \\
\text { ne sait lire }\end{array}$ & 13,8 & 6,1 & 17,1 & 9,2 & 10,4 & 52,3 & 32 , \\
\hline ne sait écrire & 17,8 & 6,1 & 25,7 & 12,7 & 14,2 & 62,3 & 39,5 \\
\hline
\end{tabular}

Sources: APC, Recensement nominatif de 1871, bobine 10010-10011.

Ainsi, dans le cas des Canadiens français, les écarts qui avaient existé au Québec entre francophones et anglophones se trouvèrent reproduits en Ontario. Déjà, cependant, les

${ }^{44}$ F. Ouellet, "Fréquentation scolaire, alphabétisation....", Cahiers Charlevoix 2, Études franco-ontariennes, pp. 322s. 
effets de la révolution scolaire engagée par Meilleur au Canada-Est et Ryerson au Canada-Ouest avaient mis en lumière l'importance du contrôle de l'État par rapport à celle d'élites toutes-puissantes poursuivant leurs propres fins à travers la diffusion sélective des écoles et de l'alphabétisation. En 1871, ce mouvement auquel la population avait volontiers pris part, se poursuivait. Aussi, de la génération des pères à celle des fils dans la vingtaine, les progrès, sans pour autant réduire, voire éliminer, les disparités entre les groupes culturels, notamment celles entre les plus riches et les plus pauvres, furent remarquables non seulement chez les anglophones mais aussi parmi les francophones. En effet, l'incapacité de lire et d'écrire déclina radicalement chez les premiers, de $14 \%$ à $0,6 \%$, et substantiellement chez les seconds, de $74 \%$ à $57,7 \%$. Par contre, l'écart entre les deux resta ce qu'il était auparavant.

\section{TABLEAU 12}

Membres de maisonnée qui, sans être chefs de maisonnée, ont déclaré des occupations à Hawkesbury et Alfred en 1871. Pourcentage de ceux qui, âgés de vingt ans et plus, ne savent ni lire ni écrire.

\begin{tabular}{lrrrrrr}
\hline & Écossais & Anglais & Allemands & Irlandais & Anglophones & C. franģais \\
nés en Ontario & & & & & & \\
ne sait lire & 0 & 0 & 0 & 0 & 0 & 42,8 \\
ne sait écrire & 0 & 0 & 0 & 1,0 & 0,4 & 44,1 \\
nés ailleurs & & & & & & \\
ne sait lire & 9,1 & 0 & 0 & 0 & 1,0 & 50,6 \\
ne sait écrire & 9,1 & 0 & 0 & 0 & 1,0 & 64,0 \\
Ensemble & & & & & & \\
ne sait lire & 9,3 & 0 & 0 & 0 & 0,3 & 48,1 \\
ne sait écrire & 9,3 & 0 & 0 & 0,5 & 0,6 & 57,7 \\
\hline
\end{tabular}

Sources: APC, Recensement nominatif de 1871, bobine 10010-10011.

À ce sujet, tout en reconnaissant que les enfants passaient de plus en plus de temps à s'instruire, Gaffield prétend que, de 1840 à 1871 y compris, «les groupes linguistiques ne se démarquaient pas vraiment par leur 
appui à l'instruction ${ }^{45} »$. Et cela, en dépit du fait que les Canadiens français auraient même été défavorisés dans leur développement scolaire par la politique du ministre de l'Éducation sur la nécessité de construire les écoles sur des sites élevés et par ce qu'il appelle «les modèles culturels de colonisation ${ }^{46}$ » qui les confinaient aux basses terres. Plus loin, cependant, il raconte dans son commentaire sur le recensement de 1881, que cette situation avait changé au cours des ans:

Cependant il y avait une dimension culturelle importante dans la croissance générale de l'instruction. Même s'il y avait de plus en plus d'écoles françaises, les francophones s'inscrivaient moins souvent à l'école que les anglophones. Le recensement de 1881 pour le canton d'Alfred démontre nettement ce modèle de fréquentation scolaire d'autant plus étonnant que les recensements précédents ne dénotaient pas de différences culturelles quant à l'inscription scolaire ${ }^{47}$.

En vérité, les données du recensement de 1871 relatives à la fréquentation scolaire des 5 à 15 ans dans les familles avec enfants appartenant à cette catégorie d'âge confirment ce que les tableaux 10 à 12 disent clairement sur les niveaux différentiels d'alphabétisation, à savoir que les disparités entre francophones et anglophones en ces matières dataient de bien longtemps avant 1871. D'ailleurs, ces disparités, visibles dans les trois cantons, étaient d'autant plus considérables que les familles canadiennes-françaises étaient plus jeunes et plus nombreuses.

\footnotetext{
${ }^{45}$ Gaffield, op.cit., p. 148.

${ }^{46}$ Ibid., p. 134. Cette interprétation est d'autant plus douteuse que, comme nous le verrons plus loin, les Canadiens français, étant les plus nombreux, constituaient le groupe le mieux réparti dans tous les rangs. Voir le tableau 18. ${ }^{47}$ Ibid., p. 153.
} 
TABLEAU 13

La fréquentation scolaire des enfants âgés de 5 à 15 ans dans les familles ayant des enfants dans cette catégorie d'âges en 1871 (nombre d'élèves par famille)

\begin{tabular}{lrrrrrrr}
\hline & Écossais & Anglais & Allemands & \multicolumn{2}{r}{ Irlandais Anglophones } & C. frangais & Total \\
Hawkesbury-Est & 3,35 & 1,48 & 2,83 & 2,87 & $\mathbf{2 , 8 4}$ & 1,87 & 2,28 \\
Hawkesbury-Ouest & $\mathbf{1 , 9 7}$ & 1,29 & 0 & 2,45 & 2,18 & 0,76 & 1,59 \\
Alfred & 1,50 & 0 & 1,00 & 1,71 & 1,67 & 0,92 & 1,03 \\
Total & 2,62 & 1,80 & 2,57 & 2,52 & 2,43 & 1,30 & 1,77
\end{tabular}

Sources: APC, Recensement nominatif de 1871, bobine 10010-10011.

S'il était besoin d'une autre confirmation en ce sens, il suffirait de relever les noms des instituteurs figurant au recensement. Au total, 31 instituteurs, dont 5 Canadiens français, 5 hommes, 10 fidèles de l'Église d'Angleterre, 9 catholiques, 4 méthodistes, 1 baptiste et 1 fidèle de l'Église d'Écosse. Lâge moyen était le même dans les deux groupes: $23 \mathrm{chez}$ les anglophones et $24 \mathrm{chez}$ les francophones. Les écarts dans les effectifs entre ceux-ci et ceux-là sont énormes et s'expliquent en partie par l'arrivée plus récente et, par conséquent, par le degré de maturité des deux sociétés. Ce délai se reflète directement dans le fait que $69 \%$ des enseignants anglophones étaient nés en Ontario et que tous les francophones étaient venus du Québec depuis peu de temps.

Il est bien évident qu'arrivés récemment dans une région où une population anglophone à grande majorité protestante était établie depuis plus longtemps, les Canadiens français, massivement catholiques, plus prolifiques qu'eux et peu alphabétisés, faisaient contraste. Comme la grande majorité d'entre eux étaient nés au Québec et qu'ils s'y rattachaient essentiellement, leur identité était, au même titre que celle des Québécois, canadienne-française et catholique. Il est donc beaucoup trop tôt, à cette date, pour leur attribuer une quelconque identité franco-ontarienne. D'ailleurs, étant si près des Québécois par leur niveau d'instruction et par leur comportement démographique, 
comment supposer qu'ils auraient pu être si différents que cela des Québécois ruraux par leur profil socio-économique?

\section{LES STRUCTURES SOCIO-ÉCONOMIQUES}

Ainsi les Canadiens français étaient arrivés les derniers, s'étaient insérés dans cette société hétérogène et étaient rapidement devenus majoritaires sans susciter d'abord de fortes inquiétudes. On doit alors supposer que leur présence répondait à un besoin, non pas de francophones ou de catholiques, mais bien de bras pour faire fonctionner une économie axée sur l'exploitation forestière et le défrichement des terres. La démarche qui consiste, comme nous l'avons pratiquée, à tenir compte du moment de l'immigration, qu'elle soit centrée sur les groupes ethniques ou sur certaines catégories sociales, n'était pas un vain exercice, puisqu'elle a contribué à établir une distinction entre ceux qui eurent les premiers, les seconds et troisièmes choix à bien des points de vue, notamment dans l'appropriation du sol et l'exploitation des autres ressources. Même si on accepte ce déterminisme, on doit néanmoins se demander dans quelle mesure un tel facteur suffisait, à lui seul, à expliquer la mise en place qui eut lieu, selon l'expression utilisée par Rusty Bitterman, Robert Mackinnon et Graeme Wynn dans leur étude sur la Nouvelle-Écosse, d'une hiérarchie du sol avec ses séquelles et, ajoutons-le, d'une hégémonie dans l'univers commercial et industriel.

Wealth and poverty, comfort and suffering, plenty and want not only existed side by side, they were intimately interconnected. The prosperity of the well-to-do rested on the availability of labour to attend those tasks it was beyond the capacity of individual households to manage. The survival of the poor depended on the returns of off-farm work. Position and power were the privileges of wealth. Subservience and dependence were the implications of poverty ${ }^{48}$.

${ }^{48}$ Bitterman, Mackinnon and Wynn, «Of Inequality and Interdependence in the Nova Scotian Countryside, 1850-1870", Canadian Historical Review (CHR), vol. 74,1993 , p. 35. 
Il est évident que, pour ces auteurs comme pour Akenson, le moment de l'entrée sur le marché foncier constituait une source significative d'inégalité. C'est d'ailleurs pour rendre compte de la sur-représentation des Loyalistes dans Leeds et Lansdowne à cet égard que celui-ci déclare:

They had arrived earlier and had an easier time in acquiring Crown patents. They had also settled longer and were more apt to have the money and knowledge to permit them to acquire land on the open market ${ }^{49}$.

Cette façon de voir les choses, pourtant raisonnable, ne semble pas avoir convaincu Gordon Darroch qui, à la suite de son enquête sur le développement d'une classe moyenne agricole dans le Centre ontarien, endroit privilégié de plusieurs façons, conclut:

Surprisingly, there is little support for a notion that either late entry into the land market or entry from non-farm background constrained opportunities for farm acquisition or for the size and improvements of farms in the region. Most striking is the evidence that, despite rapid population turnover and many new entrants into the farm economy, central Ontario was characterized by a stable structure of «middling" farm families in the $1860 \mathrm{~s}^{50}$.

Ainsi, tout considéré, l'inégalité, selon Darroch, "was marked mainly by differences in the size of the farm occupied $^{51} »$. Les choses ne sont pas aussi claires, puisque, même dans toute société en formation ou non, l'entrée en scène tardive est non seulement susceptible de déterminer jusqu'à un certain point la dimension de la terre de l'immigrant, mais d'avoir des effets négatifs sur son statut. Sur ce point, Darroch et Ornstein sont plutôt rassurants, puisqu'en Ontario, disent-ils, seulement $16 \%$ des cultivateurs étaient des locataires de terres ${ }^{52}$.

\footnotetext{
${ }^{49}$ Akenson, op.cit., pp. $113 \mathrm{~s}$.

${ }^{50}$ Gordon Darroch, «Scanty Fortunes and Rural Middle-Class Formation in Nineteenth Century Central Ontario», $C H R$, vol. 79, p. 623.

${ }^{51}$ Ibid., p. 624.

${ }^{52}$ Gordon Darroch and Michael Ornstein, «Ethnicity and Class, Transitions over a Decade; Ontario, 1861-1871", Historical Papers, 1984, pp. 123s.
} 
À notre avis, le développement d'une «middling class» de fermiers, dont ils font grand état, et, par conséquent, la présence d'une volumineuse classe inférieure, dont ils font peu de cas, ne peuvent être compris sans une référence explicite à des chaînes d'événements qui concernent le commerce, l'industrie et les villes d'ici et d'ailleurs. En effet, depuis le début du XIX ${ }^{e}$ siècle, la grande abondance de terres cultivables avait constitué un atout majeur pour le Haut-Canada. À lui seul, cependant, cet avantage n'aurait pas suffi à orienter l'immigration dans sa propre direction. Ce fut tout autant l'accroissement de la demande pour le blé sur les marchés impériaux urbains, conjugué avec le déclin de l'économie bas-canadienne du blé et les changements dans les transports et les institutions financières, qui rendit cette portion de l'espace économique des Canadas toujours plus attrayante pour ceux, de plus en plus nombreux, qui se virent forcés de quitter leur pays ou leur province. Faisant le pont entre la bourgeoisie des îles Britanniques, d'une part, et, d'autre part, la bourgeoisie locale et les producteurs du Haut-Canada, il y avait, bien sûr, la bourgeoisie montréalaise qui se trouva très tôt intimement associée au développement du Haut-Canada par le biais de l'exportation des grains, de l'acheminement des importations vers l'Ouest et par l'intervention des banques qu'elle contrôlait. Comment peuton alors parler de l'émergence des industries rurales et d'une «middling-class" rurale agricole comme s'il s'agissait d'une création spontanée de la paysannerie tout à fait indépendante de ces articulations?

Grande coïncidence, c'est d'ailleurs à cette époque, grâce à la conjoncture militaire et aux tarifs différentiels sur les bois, que se produisit une croissance spectaculaire de l'exploitation forestière, dictée en Angleterre par les besoins de la marine de guerre et par ceux des marchés impériaux. Les grands intérêts portuaires dans les trois îles intervinrent très vite et vigoureusement dans les colonies britanniques nord-américaines en réponse aux 
menaces du Blocus continental. Même si le commerce du bois équarri domina la scène jusqu'en 1870, l'exploitation forestière ne fut jamais une activité monolithique. Dès les débuts, elle fut diversifiée. Le ravitaillement en bois des constructeurs de navires locaux qui écoulaient leurs vaisseaux sur les marchés impériaux, la production du bois de sciage axée à la fois sur les marchés intérieurs et extérieurs, la préparation des douves, des mâts, de dormants pour les voies ferrées, du bois de chauffage et de la potasse étaient toutes des activités qui, d'une façon ou d'une autre et à des degrés variables, impliquaient, en plus des entrepreneurs, des agriculteurs, des journaliers et des artisans. Pour se développer, l'exploitation forestière eut non seulement recours à une abondante maind'œuvre saisonnière et à longueur d'année, mais elle engendra une forte demande pour les produits agricoles ${ }^{53}$.

Ainsi, du début du siècle à 1870 , malgré les fluctuations, parfois très considérables, du marché, l'exploitation forestière ne cessa de prendre de l'ampleur et de se concentrer sur les deux rives de l'Outaouais jusqu'à sa source ${ }^{54}$. Parmi le grand nombre de concessionnaires de forêts publiques, il y eut un noyau d'individus qui, à cause de leurs solides antécédents en affaires, de leurs relations en GrandeBretagne et à Québec, de leurs capitaux ou de leur capacité d'en générer, prirent le contrôle de cette industrie. L'histoire de William Price, d'abord agent d'une compagnie anglaise et, une fois à son propre compte, devenu un des magnats du bois sur l'Outaouais et au Saguenay, racontée

\footnotetext{
${ }^{53} \mathrm{~F}$. Ouellet, Histoire économique et sociale du Québec, 1760-1850. Structures et conjoncture, Montréal, Fides, 1966. Ces questions sont traitées dans les seize chapitres du livre; Douglass McCalla, Planting a New Province. The Economic History of Upper Canada, 1784-1870, Toronto, OHSS, 1993, pp. 45-66.

${ }^{54}$ Guy Gaudreau, "Le Développement des activités forestières en Ontario (1855-1900): une prise de vue quantitative ", Revue du Nouvel-Ontario, $\mathrm{n}^{\circ} 12$, 1990, pp. 65-90; «L'Exploitation des forêts publiques au Québec (1874-1905): transition et nouvel essor", RHAF, vol. 42, 1988, pp. 3-24.
} 
en partie par Louise Dechêne, en témoigne abondamment ${ }^{55}$. Le parcours des Gilmour, étroitement liés à la firme-mère de Glasgow, arrivés à la même époque et très engagés dans la construction navale à Québec, est tout aussi significatif, puisqu'en 1855 ils étaient parvenus à dominer le commerce de l'Outaouais. Et cela, sans compter les Hall, les Egan, les Wright ${ }^{56}$ et bien d'autres, tout aussi polyvalents.

Il ne fait pas de doute que, dans l'Outaouais comme ailleurs, il y avait une hiérarchie changeante mais non moins réelle. Les frères Hamilton, qui, à cause de leur identification avec Hawkesbury, méritent une attention spéciale, étaient fort bien situés à cet égard. Ils étaient d'origine écossaise, avaient acquis des terres en Irlande et avaient d'abord pratiqué le commerce du bois avec la Baltique. Le Blocus continental les força à transférer leurs activités de la Baltique vers Québec. Dès lors ils s'occupèrent d'assurances maritimes, firent l'acquisition d'un quai du seigneur de Lauzon, créèrent un chantier naval près de Québec, se livrèrent à l'exportation des douves, puis se lancèrent dans le commerce du bois équarri et de sciage sur l'Outaouais ${ }^{57}$. En 1870 , ils se classaient au cinquième rang parmi les concessionnaires de forêts publiques au Québec ${ }^{58}$. À Hawkesbury, ils possédaient une scierie qui, en 1871, traitait 200000 billes et donnait du travail à 168 personnes. Ils y possédaient en plus un moulin à farine, une forge, un atelier pour fabriquer et réparer des wagons et des harnais, de même qu'une boulangerie. À cette date, le nombre total de leurs employés à Hawkesbury se chiffrait à 287, dont 22 femmes et 2 filles. La valeur totale de leur production à cet endroit

\footnotetext{
${ }^{55}$ «William Price», DBC, vol. IX, pp. 704-708.

${ }^{56} \mathrm{~F}$. Ouellet et Benoît Thériault, «Philemon Wright», Dictionnaire biographique du Canada (DBC), vol. VII, pp. 1003-1006.

${ }^{57}$ Kenneth G. Pryke, "George Benson Hall», DBC, vol. VI, pp. 339-341; Andrée Désilets, "George Benson Hall», DBC, vol. X, pp. 359s.

${ }^{58}$ Guy Gaudreau, "Les Concessionnaires forestiers québécois de la seconde moitié du XIX ${ }^{e}$ siècle: essai de typologie ", Histoire sociale/Social History, vol. 21, 1988, pp. 97-112.
} 
s'établissait à $571000 \$$. Ces chiffres ne représentent pas tout le volume de leur main-d'œuvre et la valeur totale de leur production, puisqu'ils embauchaient en plus des hommes à l'échelle de la région et de l'Outaouais pour la coupe du bois et son acheminement vers Hawkesbury, Montréal et, surtout, le port de Québec.

Comme les entrepreneurs forestiers avaient besoin de produits agricoles et de main-d'œuvre pour faire fonctionner leurs entreprises, ils ne pouvaient être hostiles à l'établissement des immigrants sur des terres. Il est d'ailleurs remarquable qu'eux-mêmes figurent en bonne place parmi les initiateurs de l'agriculture capitaliste. Ce fut le cas, entre autres, de Philemon Wright à Hull, de William Price au Saguenay, des Cook à la Petite-Nation et, bien entendu, des Hamilton à Hawkesbury. À propos des Hamilton, Gaffield affirme qu'ils avaient plusieurs fermes sur la rive nord de l'Outaouais. En 1867, celles-ci contribuaient, écrit-il, à une partie des produits consommés dans leurs chantiers de l'Outaouais québécois, soit 750 tonnes de foin, 2500 boisseaux d'avoine, 11000 boisseaux de racines, 1000 barils de porc, 9000 barils de farine et 2000 boisseaux de flocons d'avoine ${ }^{59}$. Sur leur terre de 800 acres, dont 300 améliorées, qu'ils possédaient à Hawkesbury, ils récoltaient, selon le recensement de 1871, 3000 boisseaux d'avoine, 8600 boisseaux de racines et 90 tonnes de foin. Leur troupeau comptait 282 bêtes et ils en tiraient, entre autres, 3000 livres de beurre et 350 de laine. Enfin, comme la plupart des entrepreneurs forestiers, les Hamilton pratiquaient la traite des fourrures et, de cette manière, ils recueillaient 1263 peaux de pelleteries. Qui oserait dire que les 74 bœufs de la ferme d'Hawkesbury étaient seulement utilisés pour les labours?

Tous ces personnages éminents, arrivés au début du siècle, avaient tenu le coup et ils s'étaient hissés au sommet. Mais cette histoire de réussite ne dit rien quant à la variété des ${ }^{59}$ Gaffield, op.cit., p. 107. 
destins de tous ceux qui les accompagnèrent, vinrent par la suite et empruntèrent le même sentier, souvent sans aller jusqu'au bout. On peut en dire autant de la masse des immigrants ordinaires issus des milieux ruraux qui vinrent avec l'idée de s'installer sur une terre bien à eux. Pour y parvenir, ils eurent à composer, selon leurs disponibilités financières, avec les aléas des politiques agraires, alors que ceux qui avaient de l'argent comme l'Américain Nathaniel Treadwell, qui acheta la seigneurie de Longueuil pour en convertir ensuite la tenure en franc et commun soccage, furent en mesure de s'installer rapidement et de s'étendre par la suite dans plusieurs cantons, y compris celui d'Alfred. Il en fut de même des gens de pouvoir et d'influence qui, tout comme les officiers militaires par rapport aux simples soldats, furent favorisés. Les Loyalistes et les combattants de la Guerre de 1812 eurent aussi un accès facile et à bon compte à la terre. Mais, dans l'ensemble, il y eut toujours, malgré le bas prix des terres et le taux peu élevé des rentes, une différence entre l'immigrant dépourvu qui payait un loyer aux gens de la région et celui qui avait un capital, même minime ${ }^{60}$. Cette différence se manifestait par des termes qui définissaient bien le statut de l'immigrant: ceux de propriétaire et de locataire. À ce sujet, Akenson affirme: «For many new arrivals, the choice was not between leasing and buying but between leasing and becoming a wage labourer $^{61}$." À vrai dire, le pauvre journalier n'avait-il pas plus de chances d'être locataire que le cultivateur?

Entre 1810 et 1835 , c'est-à-dire avant l'arrivée des Canadiens français en grand nombre, $36 \%$ des terres de Hawkesbury et $62 \%$ de celles d'Alfred avaient été vendues ou louées ${ }^{62}$. L'étendue moyenne de ces concessions était de 165 acres à Alfred et de 434 à Hawkesbury. En 1871,

${ }^{60}$ Leo Johnson, «Land Policy, Population Growth and Social Structure in the Home District, 1793-1851», J.K. Johnson (dir.), Historical Essays on Upper Canada, Toronto, Carleton Library, $\mathrm{n}^{\circ}$ 82, pp. 32-57.

${ }^{61}$ Akenson, op.cit., p. 160.

${ }^{62}$ Lucien Brault, op.cit., pp. 341-348. 
ces étendues moyennes avaient été réduites à 67 acres dans le premier cas et à 117 dans le second. Il faut en conclure que cette subdivision fut réalisée partiellement en réponse à l'immigration des Irlandais catholiques et des francophones. À propos des Canadiens français qui auraient pu être disposés à émigrer, le curé des Cèdres disait en 1821 : «la pauvreté et la difficulté de pratiquer leur religion les en excluent ${ }^{63} \%$. Ainsi la pauvreté et les considérations religieuses auraient pu retarder la migration, comme cela s'était produit en Irlande et en Écosse pour un grand nombre de migrants, et tout cela ensemble aurait, entre autres, influé sur leur date d'entrée sur le marché foncier et sur leur statut en Ontario.

TABLEAU 14

Pourcentage des chefs de maisonnée locataires et propriétaires dans chaque groupe ethnique à Hawkesbury et à Alfred en 1871

Hawkesbury-Est

Écossais Anglais Allemands Iriandais Anglophones C. français Total

propriétaires

locataires

ensemble

$\begin{array}{rrrrrrr}88,3 & 75,0 & 92,3 & 81,1 & 83,6 & 55,7 & 68,1 \\ 11,7 & 25,0 & 7,7 & 18,9 & 16,4 & 44,3 & 31,9 \\ 100,0 & 100,0 & 100,0 & 100,0 & 100,0 & 100,0 & 100,0\end{array}$

Hawkesbury-Ouest

propriétaires

locataires

ensemble

$\begin{array}{rrrrrrr}73,2 & 46,6 & 36,4 & 59,2 & 61,1 & 18,3 & 44,8 \\ 26,8 & 53,4 & 63,6 & 40,8 & 38,9 & 81,7 & 55,2 \\ 100,0 & 100,0 & 100,0 & 100,0 & 100,0 & 100,0 & 100,0\end{array}$

Alfred

propriétaires

locataires

ensemble

$\begin{array}{rrrrrrr}80,0 & 100,0 & 100,0 & 94,3 & 93,5 & 84,1 & 83,6 \\ 20,0 & & & 5,7 & 6,5 & 15,9 & 16,4 \\ 100,0 & 100,0 & 100,0 & 100,0 & 100,0 & 100,0 & 100,0\end{array}$

Total

propriétaires

locataires

$\begin{array}{lllllll}79,6 & 57,1 & 68,0 & 72,7 & 72,8 & 50,7 & 61,4\end{array}$

ensemble

$\begin{array}{lllllll}20,4 & 42,9 & 32,0 & 27,3 & 27,2 & 49,1 & 38,6\end{array}$

$\begin{array}{lllllll}100,0 & 100,0 & 100,0 & 100,0 & 100,0 & 100,0 & 100.0\end{array}$

Sources: APC, Recensement nominatif de 1871, bobine 10010-10011.

${ }^{63}$ Brault, ibid., p. 27. 
Les Canadiens français avaient pu s'assurer, comme l'avait désiré le haut clergé, la domination numérique des lieux mais, ce qui n'inquiétait pas outre mesure les clercs, ils ne jouissaient aucunement d'une position d'égalité dans la société. En effet, dans les trois cantons, trois anglophones sur quatre étaient propriétaires, alors que seulement un Canadien français sur deux jouissait de ce statut. À Hawkesbury-Ouest où les industries étaient davantage concentrées, les proportions étaient de six sur dix pour les premiers et de deux sur dix pour les seconds. Ces chiffres, en plus de mettre l'accent sur les différences de statut et sur les disparités économiques entre les deux groupes, démontrent que celui qui voulait s'établir et avait le moindre capital pouvait devenir propriétaire, cultivateur ou autre chose. Mais, comme l'immense majorité de ceux qui se disaient cultivateurs étaient propriétaires $(89,5 \% \mathrm{chez}$ les anglophones et $95,8 \%$ chez les francophones), les éléments les plus pauvres, c'est-à-dire ceux qui étaient déjà prolétarisés avant leur arrivée en Ontario, n'avaient d'autre choix que de devenir locataires et journaliers. La seule différence avec le Québec était que, dans l'Outaouais québécois et ontarien, ils pouvaient compter sur un emploi. Le statut de locataire était presque synonyme de prolétaire. Aussi les deux tiers des locataires et $80 \%$ des journaliers de ces cantons étaientils des Canadiens français. Ne pourrait-on pas en conclure que "l'invasion" de l'Ontario par les Canadiens français ne créa pas sur le coup de sérieux remous parce qu'ils vinrent occuper un espace social devenu vacant par le déclin de l'immigration anglophone et par le besoin qu'on éprouvait d'une main-d'œuvre à bon marché constituée de journaliers forestiers et agricoles et de petits producteurs agricoles dépendant du travail saisonnier en forêt. Et cela, en dépit des célèbres affrontements entre les «hommes de chantiers" canadiens-français et irlandais catholiques dans l'Outaouais devenus objets de littérature et de folklore ${ }^{64}$.

${ }^{64}$ Michael Cross, «The Shiners' War: Social Violence in the Ottawa Valley in 
Notons que $74 \%$ des locataires anglophones étaient concentrés dans Hawkesbury-Ouest et $53 \%$ des locataires francophones dans les deux autres cantons. Cependant, dans leur étude sur la structure socio-ethnique en Ontario central, 1861-1871, Darroch et Ornstein affirment que, pour parler d'une polarisation ethnique, il fallait qu'un groupe ethnique monopolise, ou presque, une seule catégorie sociale. Ce qui voudrait dire que l'ethnicité et la culture ne sont pas, comme le sont la religion et les classes, le produit d'une histoire complexe faite de changements incessants, mais de variables tout à fait à part.

No ethnic group [in Central Ontario] dominates the class structure; no group is unequivocally proletarized. This is a reasonable conclusion, despite the evidence of systematic occupational differences between ethnic groups-differences that might be termed horizontal, not vertical, especially with respect to great variation in the proportion of farmers in the various ethno-religious groups ${ }^{65}$.

Néanmoins, à Hawkesbury et à Alfred, même si tous les groupes ethniques étaient présents dans toutes les catégories sociales, les polarisations horizontales et verticales étaient énormes. Car les Canadiens français qui y représentaient $51 \%$ des chefs de maisonnée, regroupaient $29,4 \%$ des membres des professions libérales et des gens d'affaires, $48,7 \%$ des artisans, $80 \%$ des travailleurs non qualifiés et $43 \%$ des cultivateurs. Rien, cependant, de comparable à ce que Akenson a observé dans Leeds et Lansdowne, à Gananoque où la minorité francophone était minime dans ce village et plus encore dans la zone rurale: $11,7 \%$ de la population dans le village et $3,3 \%$ dans le comté. À leur sujet, ce dernier écrit:

the native-born profile was brought down by the camouflaged presence of the least-advantaged group in the society, the individuals of French-Canadian ethnicity who had been born in Quebec. This group had no person whatsoever above the level of

the 1830 s», CHR, vol. 54,1973 , pp. 1-26.

${ }^{65}$ Darroch and Ornstein, "Ethnicity and Occupational Structure in Canada in $1871 \ldots$, CHR, vol. 61, 1980, p. 315. 
labourer... formed an isolated, almost hermetic, disadvantaged minority ${ }^{66}$.

Ce qui n'était pas tout à fait vrai des francophones de l'Est ontarien qui étaient majoritaires, énormément sur-représentés parmi les ouvriers non qualifiés, mais dont la structure sociale était déjà complexe. Loin de créer de l'ambiguité sur le statut des Canadiens français comme groupe ethnique, cette complexité ne fait que confirmer leur situation marginale dans la société.

\section{TABLEAU 15}

Répartition des chefs de maisonnée selon les groupes ethniques dans les diverses catégories occupationnelles, en 1871

\section{C. français}

nombre

(\%)

Irlandais

nombre

(\%)

Écossais

nombre

(\%)

$\begin{array}{rr}19 & 37 \\ 7,3 & 14,2\end{array}$

Anglais

nombre

(\%)

Allemands

nombre

(\%)

Anglophones

nombre

(\%)

Total

nombre

(\%)

$\begin{array}{rr}21 & 48 \\ 5,7 & 13,0\end{array}$

$25 \quad 96$

Non qualifiés

Cultivateurs

Autres

Total

$$
290
$$

384

15

810

$3,1 \quad 11,8 \quad 35,8$

47,4

1,8

99,9 
Dans les recensements de 1851 et de 1861, les fils de cultivateurs, non mariés et appartenant à la maisonnée, qui s'étaient déclarés cultivateurs sans posséder eux-mêmes de terres, avaient été classés comme journaliers. Cette décision des recenseurs, injustifiable parce qu'elle avait contribué à grossir indûment cette catégorie occupationnelle, ne l'était pas à cent pour cent puisqu'elle tenait compte du fait qu'une certaine proportion de ces individus, impossible à déterminer, se livrait en plus, au gré des circonstances, au travail saisonnier en forêt. N'oublions pas non plus que, dans chaque famille, il y avait un des fils qui était l'héritier éventuel de la ferme, les autres étant appelés à la quitter au moment de leur mariage. C'est afin de voir les implications d'une telle décision des recenseurs que nous avons construit le tableau suivant. Il est évident que le fait d'ajouter simplement les fils de cultivateurs dans la catégorie d'occupations qu'ils ont déclarée, modifie les nombres mais très peu les pourcentages. Par contre, l'opération qui consiste à ajouter les fils de cultivateurs aux journaliers, comme cela fut fait en 1851 et 1871 , gonfle ce dernier groupe et réduit artificiellement le groupe des cultivateurs. C'est pour éviter ces difficultés que nous avons systématiquement compté séparément les chefs de maisonnée et les hommes non mariés affichant des occupations de journaliers, d'artisans ou de cultivateurs. 
INÉGALITÉS ETHNIQUES À HAWKESBURY ET À AlfRED EN 1871

TABLEAU 16

Occupations des chefs de maisonnée

et des fils ayant déclaré une occupation en 1871

\begin{tabular}{|c|c|c|c|c|c|c|}
\hline \multicolumn{2}{|c|}{ Prof + Aff. } & \multicolumn{2}{|c|}{ Artisans Tr. non qualifiés } & Cultivateurs & Autres & Total \\
\hline \multicolumn{7}{|c|}{$\begin{array}{l}\text { Chefs de maisonnée + fils ayant déclaré une occupation } \\
\text { C. français }\end{array}$} \\
\hline nombre & 34 & 169 & 482 & 591 & 15 & 1291 \\
\hline$(\%)$ & 2,6 & 13,1 & 37,3 & 45,8 & 1,2 & 100 \\
\hline \multicolumn{7}{|c|}{ Anglophones } \\
\hline nombre & 104 & 275 & 150 & 910 & 34 & 1473 \\
\hline$(\%)$ & 7,1 & 18,7 & 10,2 & 61,8 & 1,5 & 99,3 \\
\hline Total & 138 & 444 & 632 & 1501 & 49 & 2764 \\
\hline$(\%)$ & 5,0 & 16,1 & 22,9 & 54,3 & 1,7 & 100 \\
\hline \multicolumn{7}{|c|}{$\begin{array}{l}\text { Tableau modifié en assumant que les fils de cultivateurs étaient des journaliers } \\
\text { C. français }\end{array}$} \\
\hline nombre & 34 & 169 & 681 & 392 & 15 & 1291 \\
\hline$(\%)$ & 2,6 & 13,1 & 52,7 & 30,4 & 1,2 & 100 \\
\hline \multicolumn{7}{|c|}{ Anglophones } \\
\hline nombre & 104 & 275 & 474 & 586 & 34 & 1473 \\
\hline$(\%)$ & 7,1 & 18,7 & 32,2 & 39,8 & 1,5 & 99,3 \\
\hline \multicolumn{7}{|l|}{ Total } \\
\hline nombre & 138 & 444 & 1155 & 978 & 49 & 2764 \\
\hline$(\%)$ & 5,0 & 16,1 & 41,8 & 35,4 & 1,7 & 100 \\
\hline
\end{tabular}

Sources: APC, Recensement nominatif de 1871, bobine 10010-10011.

Ainsi il y avait à Hawkesbury et à Alfred des groupes ethniques socialement stratifiés et, si on compare les Canadiens français et les anglophones, ethniquement hiérarchisés. Ils pouvaient être différents et isolés les uns des autres à bien des égards, mais ils se rejoignaient, sans toutefois se confondre, dans les activités économiques quotidiennes. Ainsi le recrutement des classes dirigeantes anglophones s'était fait en Ontario dans une proportion de $47 \%$ et l'âge moyen de ces individus était de 33 . Ceux qui étaient originaires des îles Britanniques ou du Québec avaient immigré à l'âge de 27 ans et ils habitaient l'Ontario depuis 22 ans. Le profil des artisans anglophones nés en 
Ontario, hors le fait que seulement $36 \%$ d'entre eux étaient nés dans la province, n'était pas tellement différent de celui des professionnels et des gens d'affaires. Ceux qui avaient immigré, l'avaient aussi fait à l'âge de 26 ans et ils résidaient dans la province depuis vingt ans.

Par contre, seulement $14 \%$ des membres des professions libérales et des gens d'affaires canadiens-français étaient nés en Ontario et ils étaient âgés de 53 ans en moyenne. L'immense majorité d'entre eux venait du Québec et avait immigré à l'âge de 27 ans et résidait en Ontario depuis seulement 11 ans. Quant aux artisans canadiens-français nés en Ontario, ils étaient beaucoup plus jeunes que les bourgeois de même origine, soit 38 ans en moyenne. Ce qui n'était pas vrai des artisans venus du Québec qui étaient à parité à cet égard avec les bourgeois de même origine géographique. Dans l'ensemble, les Canadiens français composaient moins d'un tiers des effectifs des classes dirigeantes et, si on inclut les fils qui avaient déclaré des occupations de même nature, seulement $24,6 \%$. Ils étaient également sousreprésentés parmi les artisans et leurs fils comptés ensemble, soit $48,7 \%$ pour les chefs de maisonnée et $38,1 \%$ pour eux et leurs fils combinés.

Comme nous l'avons déjà montré, la structure économique reposait sur le bois et sur l'agriculture, deux activités interdépendantes aux plans des marchés et de la main-d'œuvre. Celles-ci étaient à tel point liées qu'il est difficile d'identifier un homme d'affaires important qui n'ait pas été impliqué dans les deux activités de plusieurs façons. C'est à Hawkesbury-Ouest, le centre de cette économie, où dominaient les frères Hamilton, que cette rencontre était la plus intense. Mais, à part ceux-ci, il y avait William Hersig et Alexander McBean, gros cultivateurs, qui, l'un à Hawkesbury-Ouest et l'autre à Hawkesbury-Est, étaient, chacun pour soi, à la fois propriétaires d'un moulin à 
farine, d'une scierie et d'une tannerie. Sans compter certains autres comme John Higginson à Hawkesbury-Ouest qui, dans un de ses deux moulins, transformait de grandes quantités de bois et, dans l'autre, traitait 8000 livres de laine et de coton. Parmi les francophones, deux noms émergent d'une liste qui inclut 152 noms, dont 60 francophones et 92 anglophones: ceux de A. Saint-Denis qui possédait une scierie de bonne dimension à HawkesburyEst et de Félix Routhier qui possédait une fonderie à Hawkesbury-Ouest. Cette inégalité entre entrepreneurs anglophones et francophones reflétait une inégalité entre ces trois cantons. En effet, $46 \%$ des activités de type industriel, employant $52 \%$ de la main-d'œuvre et représentant $91 \%$ de la valeur des produits fabriqués dans la région, étaient concentrées à Hawkesbury-Ouest. C'était d'ailleurs là que se démarquait avec plus de force la prépondérance des Britanniques dans toute la région puisqu'ils étaient responsables de $96 \%$ de la valeur de cette production. Lactivité des francophones en ce domaine, bien que mineure, était concentrée à Hawkesbury-Est dans une proportion de $54 \%$. Aucun doute à cet égard et à d'autres, la part d'Alfred, où l'agriculture était plutôt médiocre, était marginale avec une participartion de moins de $9 \%$. 
TABLEAU 17

Les propriétaires d'industries, la main-d'œuvre et la valeur des produits énumérés au recensement de 1871

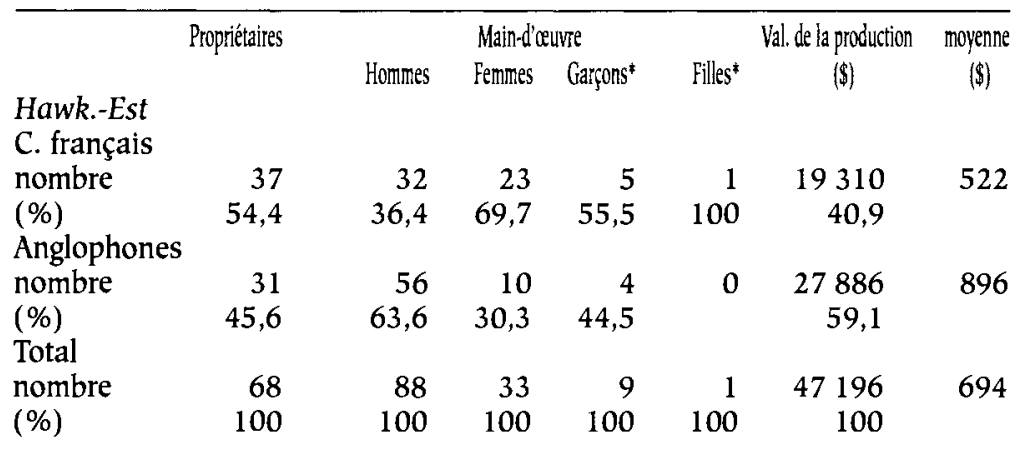

Hawk.-Ouest

C. français nombre

(\%)

Anglophones nombre

(\%)

Total

nombre

(\%)

19
6,2

$\begin{array}{llll}1 & 1 & 0 & 13410\end{array}$

112

17,1

$\begin{array}{rrrrrrr}58 & 286 & 24 & 44 & 2 & 784592 & 13527 \\ 82,9 & 93,8 & 96,0 & 97,8 & 100 & 98,3 & \end{array}$

Alfred

C. français

nombre

(\%)

Anglophones

nombre

(\%)

Total

(\%)

$\begin{array}{rrrrrrr}70 & 305 & 25 & 45 & 2 & 798002 & 11400 \\ 100 & 100 & 100 & 100 & 100 & 100 & \end{array}$

Ensemble

C. français

nombre

(\%)

Anglophones

nombre

(\%)

Total

(\%)

$\begin{array}{rrrrrrr}11 & 3 & 9 & 0 & 0 & 3131 & 285 \\ 78,6 & 13,0 & 100 & & & 10,7 & \\ 3 & 23 & 0 & 10 & 0 & 26112 & 8704 \\ 21,4 & 87,0 & 100 & & & 89,3 & \\ 14 & 26 & 9 & 10 & 0 & 29243 & 2089 \\ 100 & 100 & 100 & 100 & 100 & 100 & \end{array}$

Sources: APC, Recensement nominatif de 1871, bobine 10010-10011.

* garçons et filles de moins de 16 ans. 
Les productions de cette nature faites par des Canadiens français se faisaient dans quelques petites entreprises et, le plus souvent, dans des boutiques d'artisans. Aussi le nombre moyen d'employés par unité y était-il plus faible que chez les anglophones: 1,6 personnes contre 5,0. Même en éliminant les emplois générés par les frères Hamilton, la moyenne d'employés par unité des anglophones se chiffrait encore à 2,8 , soit $75 \%$ de plus que chez les francophones. Les femmes étaient relativement plus présentes dans les entreprises francophones, y occupant $36 \%$ de la main-d'œuvre, alors que chez les anglophones ce pourcentage n'était que de $8 \%$. Ces femmes francophones étaient des tisserandes, pas seulement des veuves, mais des femmes mariées qui avaient déclaré un métier. Les 36 femmes anglophones étaient aussi des tisserandes et des couturières. Chez les anglophones, la gamme des entreprises et des métiers était plus variée. Non seulement les petites boutiques d'artisans étaient-elles fort répandues, mais le nombre de ces entreprises dont la valeur des produits dépassait les $3000 \$$, s'élevait à 10 , dont 3 francophones. Chez les premiers, si on exclut les frères Hamilton, la valeur de leurs produits s'élevait à 134460 \$ et, chez les seconds, à $11500 \$$. Ces disparités étaient d'autant plus considérables que la valeur moyenne de toutes les entreprises des Britanniques était quinze fois plus élevée que celle des entreprises des Canadiens français.

Aucun doute n'est possible, une hiérarchie régnait dans l'entrepreneurship à Hawkesbury et à Alfred comme partout ailleurs. Ici, comme ailleurs au Canada, les Canadiens français ne logeaient pas à son sommet. Évidemment, pour rendre compte de cet état de choses, il faut invoquer, et à bon droit, le fait de leur arrivée tardive dans la région, l'absence de maturité de leur structure sociale, et la faiblesse de leurs appuis dans les milieux d'affaires francophones de Québec et de Montréal.

Parmi ceux qui dépendaient en grande partie de cette 
bourgeoisie locale pour un emploi sur place et dans l'ensemble de l'Outaouais, il y avait les journaliers. Les chefs de maisonnée anglophones, titulaires de cette occupation, représentaient $20 \%$ seulement des journaliers, un pourcentage réparti inégalement entre quatre groupes ethniques. Si on ajoute à leur nombre les fils qui avaient déclaré des occupations de journaliers, cette proportion augmente à $24 \%$. Cependant, ces journaliers ne comptaient que pour $9,4 \%$ des chefs de maisonnée anglophones, alors que les journaliers canadiens-français représentaient $35,8 \%$ des chefs de maisonnée francophones. Si on inclut dans ces chiffres leurs fils, cette proportion s'élève à $10,2 \% \mathrm{chez}$ les anglophones et à $37,3 \%$ chez les francophones. Si on regarde les occupations des pères et des fils canadiensfrançais, on peut déceler une tendance à la prolétarisation. Parmi les Canadiens français, les journaliers étaient ceux qui regroupaient, par une marge considérable, presque le double de celle des artisans, la plus forte proportion des chefs de maisonnée nés en Ontario. Leur âge moyen était de 30 ans et, en général, ils étaient mariés et avaient des enfants. Ceux qui étaient originaires du Québec, aussi mariés avec enfants en grande majorité, étaient âgés de 44 ans, avaient résidé en Ontario pendant 13 ans en moyenne et, par conséquent, avaient immigré à l'âge de 31 ans. S'ils étaient moins alphabétisés que les cultivateurs, leurs épouses l'étaient plus qu'eux.

Dans leur étude sur le Centre ontarien, Darroch et Ornstein ont observé, sans faire de commentaires sur l'écart considérable entre les francophones et les Irlandais, qu'à la même date les Irlandais catholiques étaient, comme les Canadiens français de Hawkesbury et d'Alfred, journaliers dans une proportion de $35,8 \%$, les Canadiens français de $25,5 \%$ et les Irlandais protestants de $14,8 \%$. La différence étant qu'à Hawkesbury et Alfred, le seul vrai prolétariat était canadien-français. Parmi tous les autres titulaires d'occupations de la région qui font l'objet de leur étude, 
seuls, disent Darroch et Ornstein, «the Irish Catholics were much overrepresented in one kind of work, labouring, and they experienced greater difficulty than other ethnic groups in moving into other occupations ${ }^{67}$ ". Ils ajoutent cependant que ces Irlandais catholiques avaient quand même eu tendance à se faire agriculteurs. En vérité, leurs succès à cet égard avaient été mitigés comparativement à ceux de leurs compatriotes de même origine ethnique de Hawkesbury et d'Alfred où seulement $8 \%$ des Irlandais catholiques et protestants étaient rassemblés parmi les journaliers et $69 \%$ parmi les cultivateurs. On peut alors se demander pourquoi, ici dans l'Est ontarien, les Irlandais catholiques avaient pu passer si aisément de la condition de journalier, si tel est le cas, à celle de cultivateur propriétaire, alors qu'ailleurs ils avaient, en réalité, rencontré autant d'obstacles à le faire que les Canadiens français en avaient éprouvé à Hawkesbury et Alfred. En tout cas, dans Lansdowne et Leeds, bien que sur-représentés parmi les travailleurs non qualifiés du village, les Irlandais catholiques s'étaient, affirme Akenson, solidement installés dans les campagnes comme agriculteurs.

On peut aussi se demander pourquoi les Canadiens français du Centre ontarien auraient-ils eu moins de problèmes à accomplir cette transition que les Irlandais catholiques de la même région et que les Canadiens français de Hawkesbury et d'Alfred qui sont le sujet de notre étude. Ne serait-ce pas une question d'âge comme semblent le suggérer Darroch et Ornstein, qui racontent que les journaliers sont les plus mobiles avant l'âge de 25 ans?

The ability to escape from labouring rapidly declined with age: only $21 \%$ of labourers under 25 in 1861 were still in labouring in $1871,43 \%$ of labourers between 24 and 34 remained in labouring and the percentage raised to about $50 \%$ after age $35^{68}$.

${ }^{67}$ Darroch and Ornstein, "Occupational Structure in Canada in $1871 \ldots$, Historical Papers, 1984, p. 137.

${ }^{68}$ Ibid., p. 133. 
Ce qui voudrait dire que les anglophones de Hawkesbury et d'Alfred auraient réussi cette mutation parce qu'ils étaient âgés de seulement 24 ans à l'époque de la migration et que les Canadiens français auraient échoué parce qu'ils avaient alors atteint l'âge de 31 ans. Tout cela peut sembler raisonnable, mais n'est pas tout à fait convaincant.

Le fait est que les immigrants anglophones ordinaires étaient arrivés les premiers, animés du désir de s'approprier la terre et, étant donné les circonstances plus favorables du moment, ils avaient réussi dans leur dessein. Les Canadiens français ordinaires les avaient suivis. Ceux qui avaient voulu s'établir sur des terres en avaient obtenu dans la mesure où ils avaient les moyens de les acquérir. Le grand nombre de ceux qui n'avaient pas ce capital dans l'immédiat, ou qui avaient été attirés en premier lieu par la nécessité d'avoir un emploi, se sont établis comme journaliers à cet endroit parce qu'il y avait une forte demande de travailleurs. C'est pourquoi ils se sont principalement concentrés dans le village de Hawkesbury et dans les campagnes des deux Hawkesbury beaucoup plus qu'à Alfred où il y avait moins de perspectives pour ce genre de travailleurs. S'ils avaient été trop frustrés dans leur besoin d'avoir accès à la terre, ils auraient poursuivi, comme bien d'autres, leur route vers d'autres terroirs. En 1871, la tendance n'était donc pas vers l'atomisation d'une classe de journaliers qui collait si bien à la géographie économique des lieux et qui, d'ailleurs, avait déjà fait l'expérience de la prolétarisation au Québec.

Les journaliers étaient des gens polyvalents, tantôt travailleurs agricoles, tantôt hommes de chantiers, tantôt faisant autre chose. La mobilité saisonnière géographique constituait aussi leur pain quotidien. On les décrit fort souvent, dans le recensement, comme des personnes sans parcelles de terre et sans production agricole. On sait néanmoins qu'ils avaient un lieu où ils habitaient, quoique mal indiqué dans le recensement, d'autant plus qu'ils y payaient un loyer. Ceux qui, nommément, avaient des parcelles de 
terre d'un quart, d'une demie, d'une ou de deux acres, menaient le plus souvent une activité agricole minimale: un jardin potager, un nombre variable de boisseaux de pommes de terre, une vache, un ou deux moutons, un ou deux porcs. Ils avaient ainsi trouvé leur place dans la région, leurs fils dans la vingtaine étaient plus instruits qu'eux et leurs enfants allaient à l'école en plus grand nombre. Néanmoins, plus que tous les autres, ils dépendaient de l'économie forestière. Aussi étaient-ils plus vulnérables à une crise profonde et prolongée dans ce secteur. Il serait intéressant de savoir comment ils ont réagi à la dépression des années 1873 à 1878 et au déplacement du centre de cette industrie vers d'autres régions situées plus à l'ouest et au nord.

\section{LA HIÉRARCHIE DE LA TERRE: CULTIVATEURS MARGINAUX ET "MIDDLING-CLASS" AGRICOLE}

Les chefs de maisonnée cultivateurs constituaient les éléments les plus nombreux de la société dans chacun des groupes ethniques. Presqu'un sur deux des francophones et deux sur trois des anglophones étaient cultivateurs. Un quart d'entre eux était né en Ontario mais ce pourcentage variait beaucoup d'un groupe ethnique à l'autre selon le moment de leur arrivée dans la province. Les Écossais, les Anglais et les Allemands étant les plus anciens, leur proportion à cet égard s'élevait à $45 \%$, alors que, chez les Irlandais et les Canadiens français venus dans l'ordre à leur suite, elle se chiffrait à $25 \%$ et $11 \%$ respectivement. Lâge moyen des anglophones se situait à 50 ans et celui des Canadiens français à 44 ans. Lâge moyen des cultivateurs nés en Ontario était également fort variable: un peu plus de 40 ans pour les trois groupes arrivés les premiers dans la province, 32 ans pour les Irlandais et 30 ans pour les Canadiens français. Quant à ceux qui étaient nés ailleurs, leur âge moyen oscillait entre 50 et 60 ans chez les anglophones et se situait à 45 ans chez les Canadiens français. 
Parmi les nés ailleurs, les trois premiers groupes de langue anglaise résidaient en Ontario depuis trois décennies, les Irlandais depuis deux et les cultivateurs canadiens-français depuis 11 ans.

Le profil de leurs épouses n'était pas tellement différent, si ce n'est qu'elles étaient un peu plus souvent nées en Ontario que leurs maris. Les différences d'âges entre elles et leurs époux étaient d'environ cinq ans. Leur âge au premier enfant était de 24 ans chez les anglophones et de 20 ans chez les francophones. Même si celles-ci étaient plus jeunes que leurs voisines d'une autre appartenance ethnique, elles avaient plus d'enfants qu'elles. Il en était de même de la dimension de leur maisonnée qui était plus considérable que celle de ces dernières. Enfin, comme les femmes anglophones, elles étaient plus alphabétisées que leurs maris, mais elles étaient loin derrière leurs compatriotes anglophones du même sexe sur ce plan.

Le délai qui existait d'un groupe ethnique à l'autre quant au moment de leur entrée dans la région était significatif non seulement pour les commerçants et pour les membres de chacune de ces communautés qui voulaient avoir accès à la propriété foncière, mais surtout pour ceux dont le métier était de cultiver le sol. Ce qui veut dire que le temps était un facteur crucial pour la maturation de la structure sociale et, il va de soi, de l'entreprise agricole. L'arrivée plus tardive dans la région ne pouvait que comporter des conséquences quant à l'accès à la terre, sa qualité, sa dimension et son degré de développement. Selon les historiens, le facteur culturel faisait même partie de cette équation.

Le géographe Cartwright ${ }^{69}$ qui, comme plusieurs autres, semble avoir considéré comme la même chose immigrant et cultivateur, a accrédité certaines idées plus anciennes relatives aux préférences culturelles des Canadiens fran-

${ }^{69}$ D.G. Cartwright, «Institutions of the Frontier: French Canadian Settlement in Eastern Ontario in the Nineteenth Century», The Canadian Geographer, vol. 21,1977, p. 9. 
çais et des anglophones en ce qui concerne la qualité des sols. Selon lui, les anglophones, les premiers colonisateurs de la région, auraient manifesté une grande prédilection pour les habitats plus élevés et pour les sols plus légers, plus malléables et sablonneux, alors que les Canadiens français, autant les paysans que leurs élites, auraient, par tradition, privilégié les sols plus humides, lourds, difficiles à travailler et argileux. Plus récemment, Chad Gaffield a parlé à ce sujet de modèle culturel appliqué grâce à ce déterminisme culturel. "Cette distinction, affirme-t-il, semble venir, d'une part, d'un concept culturel et, d'autre part, de la nécessité. (Cette réalité a aussi son importance pour les colons irlandais arrivés au cours des années 1840 car ils devaient eux aussi se contenter des terres humides) ${ }^{70}$."

Ce semblant de théorie, que Nicole Casterna ${ }^{71}$ mentionne aussi, est douteux. Il est vrai que les Canadiens français ont toujours préféré les sols les plus riches aux moins fertiles et cherché à s'établir près du Saint-Laurent, la grande voie de communication, plutôt qu'à l'intérieur des terres. Mais, une fois le premier rang concédé, les nouveaux concessionnaires ont dû s'adapter au fait que, le plus souvent, les circonstances devenaient de moins en moins avantageuses à mesure qu'on s'éloignait du front des seigneuries. L'analyse que Claude Baribeau ${ }^{72}$ fait de cette démarche dans sa monographie consacrée à la seigneurie de la Petite-Nation, démontre ce qui a été abondamment illustré dans d'autres études sur le Québec. En fait, les cultivateurs anglophones n'étaient pas différents des francophones à ces points de vue. À propos des préférences des fermiers anglais, écossais et irlandais de Leeds et de Lansdowne, Akenson conclut: «Nevertheless, rock is rock and workable clay or loam was the most desirable

\footnotetext{
${ }^{70}$ Gaffield, op.cit., pp. 93-95.

${ }^{71}$ Nicole Casterna, «Écologie et agriculture pré-industrielle dans l'Est ontarien", Thèse de Maîtrise, Université d'Ottawa, 1985, p. 39.

${ }^{72}$ Op. cit., pp. 68-80.
} 
land then as now ${ }^{73} . "$ Plus tard, revenant sur le même thème, il ajoute:

the land first patented (1796-1805) was chosen because of locational factors (proximity to the St. Lawrence River and, in the rear of Lansdowne to the alleged iron sites). Thereafter, the sequence of patenting followed, albeit crudely, one determined chiefly by the agricultural desirability of the land ${ }^{74}$.

Il ne semble pas que les anglophones des trois cantons, les initiateurs de la colonisation agricole, aient procédé d'une façon si différente que cela des anglophones du comté de Leeds, autrement le territoire aurait été rigidement structuré sur une base ethnique en fonction de ce critère: les francophones sur les basses terres et les anglophones sur les terrasses sablonneuses. Afin de vérifier l'existence de ce genre de différenciation en ce qui concerne la prise de possession du terroir par les cultivateurs et les non-cultivateurs des deux groupes, nous les avons regroupés et répartis rang par rang.

TABLEAU 18

Répartition des terres par rangs à Hawkesbury et à Alfred entre francophones et anglophones en 1871 (en pourcentages)

\begin{tabular}{|c|c|c|c|c|c|c|c|c|c|}
\hline & \multicolumn{3}{|c|}{ Pionniers" } & \multicolumn{3}{|c|}{ Irlandais } & \multicolumn{3}{|c|}{ Canadiens trançais } \\
\hline & Cullivateus & Authes & Total & Culthyaturs & Alltoss & Total & Culliratelus & Alutes & \\
\hline rangs $1-3$ & 25,1 & 62,3 & 43,7 & 50,9 & 29,4 & 47,5 & 27,4 & 62,4 & \\
\hline rangs 4-6 & 37,7 & 33,2 & 35,4 & 40,0 & 66,7 & 44,2 & 41,8 & 34,7 & \\
\hline rangs $7-9$ & 35,7 & 4,0 & 19,8 & 8,0 & 3,9 & 7,4 & 24,4 & 1,7 & \\
\hline rangs $10-14$ & 1,5 & 0,5 & 1,0 & 1,1 & 0 & 0,9 & 6,3 & 1,2 & \\
\hline ensemble & 100 & 100 & 99,9 & 100 & 100 & 100 & 99,9 & 100 & \\
\hline
\end{tabular}

Sources: APC, Recensement nominatif de 1871, bobine 10010-10011. *Écossais, Anglais et Allemands.

Il semble bien que la prise de possession du terroir se soit déroulée d'une façon ordonnée à partir du front de ces cantons vers l'intérieur, les non-cultivateurs, excepté les

\footnotetext{
${ }^{73}$ Akenson, op.cit., p. 143.

${ }^{74}$ Ibid., p. 164.
} 
Irlandais, étant davantage concentrés dans les rangs les plus près de la façade des cantons que les cultivateurs. C'est d'ailleurs dans les premiers rangs qu'étaient surtout rassemblés les locataires et les journaliers. Il existe cependant des différences entre, d'une part, les cultivateurs pionniers solidement enracinés dans les neuf premiers rangs et, d'autre part, les Irlandais et les Canadiens français plus fortement concentrés avec des nuances dans les six premiers. Ce qui frappe le plus à propos des Canadiens français, c'est, à cause de leur nombre supérieur, leur progression rapide vers les rangs sept à quatorze. Au total, il semble que les possessions des Irlandais et des Canadiens français ont été constituées, pour une bonne part, par acte d'achat ou de location, à même les lots de grande dimension déjà concédés aux pionniers. Si les anglophones furent plus souvent que les francophones en possession de terres sablonneuses, il faudrait l'attribuer moins à leur amour déréglé de ce genre de sols qu'à leur intérêt pour la culture de la pomme de terre. En effet, dans les récoltes des cultivateurs anglophones, cette denrée représentait $56 \%$ des grains et des racines alors que, chez les francophones, elle n'en occupait que $32 \%$.

L'échantillon recueilli par Casterna dans la profondeur de Plantagenet ${ }^{75}$ fait état d'une population de 68 cultivateurs composée de 24 francophones, dont 15 (62\%) établis sur des terres argileuses, et de 44 anglophones, dont $19(43 \%)$ établis sur le même type de sol. Cette sélection, dont nous ignorons le degré de représentativité, indique une différence significative entre les uns et les autres, mais aucunement une séparation aussi tranchée que celle proclamée dans l'historiographie. D'ailleurs, les Canadiens n'étaient pas défavorisés par cette situation puisque les sols argileux étaient généralement plus riches et plus propices que tout autre sol à la culture des céréales.

${ }^{75}$ Casterna, «Les Stratégies agricoles du paysan canadien-français de l'Est ontarien (1870)", RHAF, vol. 41, 1987, p. 30. 


\section{FERNAND OUELLET}

Il semble bien que le moment de l'arrivée dans la région, certaines habitudes acquises ou en voie de disparaître relatives à la hiérarchie des productions, ainsi que le degré de pauvreté des immigrants et le coût des terres aient eu des répercussions sur l'accès aux parcelles, sur leur dimension et, plus généralement, sur le statut des groupes ethniques et des individus qui les composaient. Dans sa tentative pour établir une hiérarchie des cultivateurs dans le Centre de l'Ontario à partir de l'idée de "middlingclass" agricole exprimée par la dimension des fermes, Gordon Darroch s'est heurté au problème du grand nombre de ceux qu'il nomme les cultivateurs sans fermes:

Even in 1871 the proportion of farmers without farms is large enough to underscore rural class divisions in a historically prosperous region. Some of those who called themselves farmers must have been farm labourers, working for more established farmers. Others, both owners and tenants, may have been just beginning as farmers and simply had no land crop ${ }^{76}$.

Il est certain que, parmi l'ensemble des chefs de maisonnée, il y eut un grand nombre d'individus dont la dimension de la terre ou de l'emplacement et, le plus souvent, le volume de la production n'étaient pas mentionnés dans le recensement. Mais, à Hawkesbury et à Alfred, ce furent les chefs de maisonnée autres que les cultivateurs qui furent sujets à ce genre d'omission. Dans leur cas, celle-ci se produisit pour au moins $50 \%$ d'entre eux, alors que les cultivateurs en furent exempts dans $94 \%$ des cas.

${ }^{76}$ Darroch, "Scanty Fortunes and Rural Middle-Class Formation...", CHR, vol. 79, p. 633. 


\section{INÉgalités ETHNiqueS À HaWkesbury eT À Alfred eN 1871}

\section{TABLEAU 19}

Répartition de la superficie de terre occupée et améliorée par les cultivateurs selon les ethnies et les catégories d'individus qui les composent à Hawkesbury et à Alfred en 1871

\begin{tabular}{|c|c|c|c|c|c|c|}
\hline \multirow[b]{2}{*}{ acres } & \multicolumn{2}{|c|}{ cultivateurs } & \multicolumn{2}{|c|}{ superficie occupée } & \multicolumn{2}{|c|}{ améliớée } \\
\hline & nombre & pourcentage & actes & pourcentage & actes & pourcentage \\
\hline \multicolumn{7}{|l|}{ Écossais } \\
\hline-2 & 2 & 1,2 & & & & \\
\hline $2-49$ & 8 & 5,0 & 194 & 0,9 & 1804 & 17,9 \\
\hline $50-99$ & 28 & 17,4 & 2597 & 11,7 & 5374 & 53,4 \\
\hline $100-149$ & 73 & 45,3 & 7732 & 34,7 & 1875 & 18,6 \\
\hline 150 et + & 50 & 31,0 & 11732 & 52,7 & 1015 & 10,1 \\
\hline total & 161 & 99,9 & 22255 & 100 & 10068 & 100 \\
\hline \multicolumn{7}{|l|}{ Anglais } \\
\hline-2 & 1 & 2,0 & & & & \\
\hline $2-49$ & 2 & 4,0 & 56 & 0,8 & 372 & 8,5 \\
\hline $50-99$ & 9 & 18,0 & 573 & 7,8 & 1515 & 34,5 \\
\hline $100-149$ & 23 & 46,0 & 2542 & 34,6 & 1245 & 28,3 \\
\hline 150 et + & 15 & 30,0 & 4174 & 56,8 & 1260 & 28,7 \\
\hline total & 50 & 100 & 7345 & 100 & 4392 & 100 \\
\hline \multirow{2}{*}{\multicolumn{7}{|c|}{$\begin{array}{l}\text { Allemands } \\
-2\end{array}$}} \\
\hline & & & & & & \\
\hline $2-49$ & 1 & 7,1 & 44 & 2,1 & 159 & 12,0 \\
\hline $50-99$ & 2 & 14,3 & 110 & 5,4 & 290 & 21,8 \\
\hline $100-149$ & 3 & 21,4 & 300 & 14,7 & 215 & 16,2 \\
\hline 150 et + & 8 & 57,1 & 1586 & 77,7 & 664 & 50,0 \\
\hline total & 14 & 99,9 & 2040 & 99,9 & 1328 & 100 \\
\hline \multicolumn{7}{|l|}{ Irlandais } \\
\hline-2 & 3 & 1,2 & 2 & 2 & & \\
\hline $2-49$ & 24 & 9,7 & 657 & 2,6 & 3594 & 29,5 \\
\hline $50-99$ & 77 & 31,3 & 4771 & 18,8 & 4672 & 38,4 \\
\hline $100-149$ & 87 & 35,4 & 8659 & 34,1 & 2430 & 20,0 \\
\hline 150 et + & 55 & 22,3 & 11270 & 44,4 & 1474 & 12,1 \\
\hline total & 246 & 99,9 & 25357 & 99,9 & 12172 & 100 \\
\hline \multicolumn{7}{|c|}{ C. français } \\
\hline-2 & 31 & 7,9 & 15 & & 17 & 0,1 \\
\hline $2-49$ & 74 & 18,9 & 2226 & 8,9 & 6143 & 53,0 \\
\hline $50-99$ & 184 & 46,9 & 11146 & 44,4 & 4450 & 38,5 \\
\hline $100-149$ & 90 & 22,9 & 9111 & 36,3 & 640 & 5,5 \\
\hline 150 et + & 13 & 3,3 & 2581 & 10,3 & 330 & 2,8 \\
\hline total & 392 & 99,9 & 25079 & 99,9 & 11587 & 99,9 \\
\hline \multicolumn{7}{|c|}{ Anglophones } \\
\hline-2 & 7 & 1,4 & 4 & & 4 & \\
\hline $2-49$ & 35 & 7,3 & 951 & 1,7 & 5964 & 21,6 \\
\hline $50-99$ & 126 & 26,1 & 8051 & 14,1 & 11853 & 42,9 \\
\hline $100-149$ & 186 & 38,6 & 19233 & 33,7 & 6100 & 22,1 \\
\hline 150 et + & 128 & 26,5 & 28762 & 50,4 & 3719 & 13,4 \\
\hline total & 482 & 99,9 & 57001 & 99,9 & 27640 & 100 \\
\hline
\end{tabular}

Sources: APC, Recensement nominatif de 1871, bobine 10010-10011. 
Ces chiffres suffisent à démontrer, contrairement à ce que Darroch affirme, que le moment de l'arrivée de l'immigrant dans la concurrence pour l'acquisition d'une terre était un facteur peut-être aussi important pour sa réussite que pouvait l'être le degré de pauvreté. En effet, la hiérarchie qui existait quant à la dimension des terres et de l'espace amélioré entre, d'une part, les Écossais, les Anglais et les Allemands et, d'autre part, les Irlandais, les Canadiens français venant au dernier rang, reflétait de près, tant pour l'espace occupé qu'amélioré, la chronologie de l'immigration dans la région. La grandeur moyenne de la ferme était de 141 acres pour les groupes pionniers, de 103 pour les Irlandais et de 64 pour les Canadiens français. La superficie améliorée était de 68 acres pour les premiers, de 48 pour les Irlandais et de 30 pour les Canadiens français.

Darroch affirme aussi que, dans le Centre ontarien, plus de la moitié des fermes se situaient dans la catégorie des 70-169 acres. À Hawkesbury et à Alfred, les performances étaient encore meilleures. Car $76 \%$ des cultivateurs écossais, anglais et allemands, $60 \%$ des Irlandais mais seulement $26 \%$ des Canadiens français possédaient des terres de 100 acres et plus. Les premiers y contrôlaient ainsi $89 \%$ de la superficie occupée dans leur groupe, les seconds $79 \%$ et les troisièmes $47 \%$. Il y avait donc une substantielle inégalité entre les groupes ethniques et à l'intérieur de chacun d'eux quant à la date d'arrivée et à l'étendue de leurs possessions foncières. Il est néanmoins évident que les Irlandais étaient, par une marge substantielle, plus près des autres anglophones que des Canadiens français non seulement en ce qui concerne la superficie occupée mais, en plus, quant à la superficie améliorée. En effet, $36 \%$ des fermiers écossais, anglais et écossais, 53\% des Irlandais et $78 \%$ des Canadiens français se classaient dans la catégorie de ceux dont la partie améliorée des terres était inférieure à 50 acres. Il y avait donc à Hawkesbury et 
à Alfred une hiérarchie de la terre qui s'étendait aux groupes ethniques et aux individus qui les composaient. La «middling-class» agricole, dont parle Darroch, était sans doute un aspect fort significatif du dynamisme du monde rural anglophone parce qu'elle était greffée sur les marchés urbains, ruraux et internationaux, mais il n'en était pas tout à fait ainsi de la moitié inférieure de son échantillon. Non seulement les Canadiens français de Hawkesbury et d'Alfred se trouvaient-ils dans une situation d'infériorité par rapport aux autres, mais c'étaient eux qui étaient les plus sérieusement touchés par l'inégalité sociale à l'intérieur de leur propre communauté. Ce qui permet de mieux comprendre pourquoi les familles agricoles canadiennesfrançaises, plus que celles de toutes les autres ethnies, constituaient, en plus des familles de journaliers, un réservoir tellement substantiel de main-d'œuvre saisonnière pour l'exploitation forestière. Cette dépendance avait sans doute en partie sa source dans la modeste dimension des terres mais, au moins autant, dans les autres causes des insuffisances de la production agricole, dont la pauvreté et les hauts taux d'analphabétisme.

Bien que la superficie de terre occupée et améliorée soit un bon révélateur des conditions inégales, elle ne constitue pourtant qu'un des regards possibles dans cette direction. Car, ultimement, il s'agit de savoir ce que le producteur fait de son exploitation et ce qu'il en retire en fonction de ses besoins de subsistance et des revenus nécessaires au développement de sa ferme. 
TABLEAU 20

Production de grains et de racines à Hawkesbury et à Alfred en 1871 par les cultivateurs récoltant 100 boisseaux et plus selon les groupes ethniques

\begin{tabular}{lrrrrrr}
\hline & Écossis & Anglais & Allemands & lilandais & Anglophones & C. français \\
blé (boisseaux) & 7398 & 2349 & 725 & 9273 & 19655 & 8948 \\
par cultivateur & 45,1 & 44,3 & 55,8 & 39,1 & 42,3 & 29,8 \\
& & & & & & \\
avoine (boisseaux) & 35547 & 10566 & 3245 & 45305 & 94672 & 37195 \\
par cultivateur & 219,4 & 199,3 & 249,6 & 191,2 & 203,6 & 123,9 \\
& & & & & & \\
pois (boisseaux) & 3875 & 1046 & 460 & 3684 & 9065 & 9608 \\
par cultivateur & 23,9 & 19,7 & 35,4 & 15,5 & 19,5 & 32,0 \\
& & & & & & \\
pomme de terre & 62647 & 24186 & 3590 & 103339 & 193762 & 29258 \\
(boisseaux) & 386,7 & 456,3 & 276,1 & 436,0 & 416,7 & 97,2 \\
par cultivateur & & & & & & \\
& 10777 & 3311 & 467 & 15644 & 30199 & 4756 \\
autres (boisseaux) & 66,5 & 62,5 & 35,9 & 66,0 & 64,9 & 15,8 \\
par cultivateur & & & & & & \\
& 120154 & 41458 & 8487 & 177245 & 347344 & 89665 \\
total & 741,7 & 782,2 & 652,8 & 747,9 & 747,0 & 298,9 \\
par cultivateur & & & & & & \\
foin (tonnes) & 2082 & 1259 & 195 & 2820 & 6356 & 1334 \\
par cultivateur & 12,8 & 23,7 & 15,0 & 11,9 & 13,7 & 4,4 \\
\hline
\end{tabular}

Sources: APC, Recensement nominatif de 1871, bobine 10010-10011.

Comme ces chiffres le démontrent, il existait à Hawkesbury et, à un bien moindre degré, à Alfred une agriculture articulée sur le marché à laquelle les groupes ethniques participaient très inégalement par le biais de l'avoine, de la pomme de terre et du foin. Il est certain que, toutes choses étant égales par ailleurs, les Canadiens français se trouvaient dans une situation défavorisée par rapport au bloc anglophone. Non seulement la hiérarchie des cultures n'était pas exactement la même dans les deux blocs mais les quantités de grains et de racines qu'ils récoltaient alors par unité de production étaient deux fois et demie inférieures à celles de leurs compatriotes d'une autre origine. Il en était ainsi de la moisson de foin qui était trois fois plus petite que celle des producteurs anglophones. Il est vrai qu'il y avait parfois des 
variations importantes à l'intérieur du groupe anglophone. Par exemple, la pomme de terre représentait $58 \%$ de la récolte chez les Anglais et les Irlandais, et seulement 52\% dans le groupe écossais. Mais, dans l'ensemble de ces éléments, les performances étaient plutôt uniformes.

Tout cela dénote la présence d'une économie de marché, à laquelle les différents groupes ethniques réagissaient inégalement et qui trouve aussi son prolongement dans les activités liées à l'élevage des animaux.

TABLEAU 21

Les troupeaux et les produits des animaux à Hawkesbury et à Alfred parmi les cultivateurs récoltant 100 boisseaux et plus de grains et de racines selon les groupes ethniques en 1871

\begin{tabular}{|c|c|c|c|c|c|c|}
\hline & Écossais & Anglais & Allemands & Irlandais & Anglophones & C. français \\
\hline chevaux (n) & 622 & 214 & 56 & 761 & 1653 & 740 \\
\hline par cultivateur & 3,8 & 4,0 & 4,3 & 3,2 & 3,5 & 2,5 \\
\hline bêtes à cornes (n) & 1798 & 716 & 171 & 2365 & 5050 & 1757 \\
\hline par cultivateur & 11,1 & 13,5 & 13,1 & 10,0 & 10,9 & 5,8 \\
\hline moutons (n) & 1862 & 609 & 177 & 2184 & 4832 & 2029 \\
\hline par cultivateur & 11,5 & 11,5 & 13,6 & 9,2 & 10,4 & 6,8 \\
\hline porcs (n) & 619 & 188 & 61 & 867 & 1735 & 865 \\
\hline par cultivateur & 3,8 & 3,5 & 4,7 & 3,6 & 3,7 & 2,9 \\
\hline total (n) & 4901 & 1727 & 465 & 6167 & 13270 & 5391 \\
\hline par cultivateur & 30,2 & 32,6 & 35,8 & 26,0 & 28,5 & 18,0 \\
\hline tués ou vendus (n) & 1535 & 651 & 151 & 2627 & 4964 & 1746 \\
\hline par cultivateur & 9,5 & 12,3 & 11,6 & 11,1 & 10,7 & 5,8 \\
\hline beurre (lbs) & 71785 & 24760 & 5965 & 99491 & 202091 & 51943 \\
\hline par cultivateur & 443,1 & 467,2 & 458,8 & 419,8 & 434,6 & 173,1 \\
\hline fromage (lbs) & 5300 & 19550 & 200 & 10605 & 35855 & 0 \\
\hline par cultivateur & 32,7 & 368,9 & 15,4 & 44,7 & 77,1 & \\
\hline laine (lbs) & 6930 & 2520 & 771 & 8487 & 17708 & 6660 \\
\hline par cultivateur & 42,8 & 47,5 & 59,3 & 35,8 & 38,1 & 22,0 \\
\hline flanelle (vgs) & 345 & 0 & $\mathbf{0}$ & 685 & 1030 & 531 \\
\hline par cultivateur & 2,1 & & & 2,9 & 2,2 & 1,8 \\
\hline
\end{tabular}

Sources: APC, Recensement nominatif de 1871, bobine 10010-10011. 
Les producteurs de grains et de racines les mieux intégrés à l'économie de marché étaient aussi ceux qui étaient à l'avant-garde en ce qui concerne l'élevage et la commercialisation des produits des animaux. Cela s'explique non seulement par le fait que ces producteurs avaient besoin d'une force de travail animale supérieure à celle des autres, mais aussi par le besoin d'accéder au marché par les viandes de boucherie, par la laine et par les produits laitiers. Cette réalité est fort bien décrite par le pourcentage des animaux tués pour consommation familiale ou pour vente et par le nombre d'animaux vivants vendus. Les chiffres à cet égard ne permettent pas de bien distinguer la consommation familiale de la portion commercialisée. Ils constituent cependant un bon indicateur de l'intensité des contacts avec le marché. Étant donné le nombre substantiel de tisserands, la plupart d'entre eux étant des femmes, et l'existence de moulins à fouler, on ne saurait être surpris de constater que la production domestique de flanelle et d'étoffe ait été si faible. Serait-ce que ces activités qui témoignent assez bien de la participation traditionnelle des femmes dans la production agricole étaient déjà en voie de se transformer sous l'effet du développement des villes et des industries textiles? Ainsi, depuis toujours, la préparation du beurre, en plus de celle des salaisons, faisait partie de leurs attributions en ce domaine, mais, chez les anglophones, le niveau de la production, quatre fois supérieur à celui des francophones, était tel qu'elles devaient nécessairement faire appel à la force de travail des jeunes garçons de la famille. Il en allait autrement de la fabrication du fromage qui était une activité pratiquée par seulement $5 \%$ des cultivateurs. À eux seuls, les Anglais contrôlaient $62 \%$ de cette production. Bien plus, 7 de ces 41 fabricants de fromage assumaient $82 \%$ de la production, deux d'entre eux étant responsables pour $15000 \mathrm{lbs}$, soit $43 \%$ du fromage fabriqué. Aucun Canadien français n'apparaît sous cet article dans le recensement. Comment 
peut-on, si cette situation est exemplaire, soutenir à la suite de Marjorie Cohen que l'émergence des beurreries et des fromageries était plus ou moins le fruit d'une conspiration masculine pour déposséder les femmes d'une de leurs responsabilités ${ }^{77}$ ? Ne faudrait-il pas, une fois de plus, y voir une manifestation de capitalisme agraire, dictée par la réponse d'une minorité affluente à la demande des marchés urbains et internationaux?

Ceci dit, on aura noté l'ampleur unique des inégalités entre anglophones et francophones dans toutes ces activités. Il existe cependant une autre polarisation qui ressort des données du recensement. Il s'agit de celle entre Irlandais catholiques et protestants. À ce sujet, Akenson, après avoir noté la surreprésentation des Irlandais catholiques parmi les travailleurs non qualifiés du village de Gananoque, écrit:

In the country, the Irish-born Protestants farmers were considerably better off than the average local farmers, but this caused no rural-village dissonance, as the Irish-Protestants immigrants in the village were above the average in the occupational profile. For the Irish-born Catholics, however, the situation was different: they comprised an elite sector in commercial farming in the countryside but were a somewhat disadvantaged group in the village ${ }^{78}$.

Cependant, à Hawkesbury et à Alfred, où ils étaient arrivés à la suite des autres anglophones, les Irlandais catholiques étaient un peu moins alphabétisés qu'eux. Leur surreprésentation parmi les journaliers du village était à peine visible. Par contre, ils se classaient après les Irlandais protestants, mais plus près de ceux-ci que des Canadiens français, quant aux performances agricoles.

\footnotetext{
${ }^{77}$ Marjorie Cohen, "The Decline of Women in Canadian Dairying», Histoire sociale/Social History, vol. 17, pp. 307-334.

${ }^{78}$ Akenson, op.cit., p. 331.
} 
TABLEAU 22

La place des cultivateurs irlandais (catholiques et protestants) parmi l'ensemble des cultivateurs des trois cantons

(en pourcentage)

\begin{tabular}{lccc}
\hline & \multicolumn{3}{c}{ Irlandais } \\
& catholiques & protestants & Ensemble \\
cultivateurs (\%) & 13,7 & 17,3 & 31,0 \\
grains et racines (\%) & 14,3 & 26,2 & 40,5 \\
foin (\%) & 13,0 & 23,6 & 36,6 \\
animaux (\%) & 11,8 & 21,2 & 33,0 \\
beurre (\%) & 15,5 & 23,7 & 39,2 \\
laine (\%) & 12,1 & 22,8 & 33,9 \\
\hline
\end{tabular}

Sources: APC, Recensement nominatif de 1871, bobine 10010-10011.

Dans son étude sur Plantagenet, Nicole Castéran s'est aussi intéressée aux hiérarchies entre les groupes ethniques dans les pratiques agricoles en partant de l'idée que " l'influence écologique est plus déterminante que celle du facteur ethnique sur la différenciation des groupes ${ }^{79} »$. Mais, un peu plus loin, sans doute pour affirmer la liberté de choix de l'agent économique collectif, sorte de garantie de sa rationalité face aux contraintes du milieu, elle se remet ellemême en question: "Sur un même type de sol, écrit-elle, différentes ethnies optent pour des stratégies différentes ${ }^{80}$.» Ainsi les Canadiens français étaient, selon elle, concentrés dans une proportion de $62 \%$ sur des sols argileux, sols qu'elle considère plus productifs mais aussi plus difficiles à travailler que les autres. Pourtant, ce ne sont pas eux qui figurent le mieux à son palmarès. Ce sont plutôt les Anglais, les Irlandais et les Écossais qui arrivent en tête. Les Anglais remportent la palme pour la productivité, même s'ils œuvraient dans une proportion de $87 \%$ sur des sols sablonneux. Quant aux Canadiens français, «en général, on les retrouve plus nombreux dans les deux groupes les moins productiff $^{81} \pitchfork$. En fait, ils obtiennent le dernier rang pour le

${ }^{79}$ Castéran, «Écologie et agriculture pré-industrielle...", Thèse de M.A., Université d'Ottawa, p. 81.

${ }^{80}$ Ibid., p. 90.

${ }^{81}$ Ibid., p. 92. 
volume de la récolte de grains et de racines, pour la dimension des troupeaux, pour l'équipement de la ferme, pour les rendements et la valeur de la propriété. Bien plus, leurs familles sont plus nombreuses et sont mieux représentées dans la population active; mais, comme les pères sont plus jeunes que les autres groupes, soit 42 ans en moyenne, "peu d'enfants ont atteint l'âge de participer à l'exploitation familiale», dit-elle ${ }^{82}$. Elle oublie cependant de rappeler que la moyenne d'âge des pères irlandais et anglais n'était que de 43 et 47 ans respectivement. Sans compter que les pères trop vieux avaient beaucoup perdu de leur vigueur.

À tout prendre, qu'il s'agisse de la production des grains et des racines, des animaux de ferme, de leurs produits, de l'équipement et des rendements, les polarisations entre les groupes ethniques qu'elle a obtenues à Plantagenet n'étaient pas tellement différentes, à part leurs amplitudes, de celles que nous avons relevées à Hawkesbury et, surtout, à Alfred où les conditions de vie, semble-t-il, se rapprochaient de celles qui prévalaient à Plantagenet. Dans nos trois cantons, les écarts entre anglophones et francophones en ce qui concerne l'équipement des fermes, se situaient entre $26 \%$ et $36 \%$ pour le nombre de granges et d'étables et de charrues par ferme. Ils atteignaient un niveau plus élevé dans le cas de la possession de moissonneuses, de rateaux à cheval, de batteuses et de cribles.

${ }^{82}$ Ibid., p. 104. 
TABLEAU 23

Rendements du blé, de la pomme de terre et du foin à l'acre à Hawkesbury et à Alfred

\begin{tabular}{lccc}
\hline & Blé (boisseaux) & Porme de terre (boisseaux) & Foin (tonnes) \\
Écossais & 10,4 & 180,0 & 0,92 \\
Anglais & 10,3 & 191,4 & 1,05 \\
Allemands & 9,5 & 150,0 & 0,92 \\
Irlandais & 10,3 & 310,9 & 1,03 \\
anglophones & 10,3 & 247,9 & 0,99 \\
C. français & 7,9 & 125,5 & 0,64 \\
\hline
\end{tabular}

Sources: APC, Recensement nominatif de 1871, bobine 10010-10011.

Bien que très importantes, les polarisations ethniques n'eurent jamais la force nécessaire, cela se comprend, pour prévenir l'émergence des classes sociales et des inégalités à l'intérieur de celles-ci. Ainsi, la paysannerie était ellemême divisée non seulement selon la quantité de terre possédée et améliorée mais aussi selon le niveau de la production agricole, le nombre d'animaux sur la ferme et leurs productions. Les cultivateurs qui produisaient de 100 à 399 boisseaux de grains et de racines résidaient depuis un peu moins longtemps dans la région que ceux qui récoltaient 400 boisseaux et plus. Ils étaient en plus moins alphabétisés, moins bien équipés et moins productifs. Ces deux derniers points ont aussi été bien documentés par W.L. Marr dans son étude sur le comté de York ${ }^{83}$. À Hawkesbury et à Alfred, ces différences entre gros et petits producteurs existaient dans tous les groupes ethniques mais elles n'avaient pas la même amplitude dans chacun d'eux. Ce qui ne veut pas dire, comme le laisse entendre Marr, que la dimension occupée et cultivée de la terre, liée qu'elle était au moment de l'arrivée en Ontario, suffisait à elle seule à rendre compte de ces variations. La situation dans Hawkesbury le confirme amplement. Ainsi, dans la partie de Hawkesbury-Est dénombrée par Samuel Arton,

\footnotetext{
${ }^{83}$ W.L. Marr, «Did Farm Size Matter? An 1871 Case Study», Papers in Rural History, vol. 6, Gananoque, 1988, pp. 279-300.
} 
$61 \%$ des cultivateurs qui produisaient 400 boisseaux et plus possédaient 100 acres et plus de terre, alors qu'un quart de ceux qui récoltaient entre 100 et 399 boisseaux se trouvaient dans la même situation. Ce qui ne veut pas dire que la dimension des terres n'était pas un élément capital, particulièrement dans le cas de ceux qui, comme les pionniers, accordaient beaucoup d'importance à la production du foin et à l'élevage des animaux. L'exemple des Irlandais démontre néanmoins qu'avec le temps et malgré un handicap persistant au plan de la dimension de la terre, les conséquences de l'entrée tardive dans la région pouvaient être résorbées en grande partie, sans pour autant être abolies.

TABLEAU 24

Le profil des cultivateurs

selon le moment de l'entrée en scène dans la région:

les pionniers, les Irlandais et les Canadiens français (en pourcentage)

\begin{tabular}{lcccc}
\hline & Pionniers & Irlandais & Canadiens trangais & Total \\
cultivateurs (nombre) & 29,8 & 31,0 & 39,2 & 100 \\
superficie occupée (acres) & 38,5 & 30,9 & 30,5 & 99,9 \\
superficie améliorée (acres) & 39,9 & 30,8 & 29,3 & 100 \\
grains et racines (boisseaux) & 38,9 & 40,5 & 20,5 & 99,9 \\
foin (tonnes) & 46,0 & 36,7 & 17,3 & 100 \\
animaux (nombre) & 38,0 & 33,1 & 28,9 & 100 \\
tués ou vendus (nombre) & 34,8 & 39,1 & 26,0 & 99,9 \\
beurre (lbs) & 40,4 & 39,2 & 20,4 & 100 \\
fromage (lbs) & 70,0 & 30,0 & 0 & 100 \\
laine (lbs) & 40,4 & 33,4 & 26,2 & 100 \\
\hline
\end{tabular}

Sources: APC, Recensement nominatif de 1871, bobine 10010-10011.

Ce qui voudrait dire, si on considère le cas des Canadiens français, que le degré de pauvreté initial, le niveau d'alphabétisation, le nombre d'enfants et le dynamisme personnel sont des facteurs qui entrent aussi en ligne de compte. 


\section{Fernand Ouellet}

\section{TABLEAU 25}

Les catégories de producteurs selon les années de résidence, le nombre d'enfants dans la famille et le niveau d'alphabétisation à Hawkesbury en 1871

\begin{tabular}{lcc}
\hline Récoltes (boisseaux) & Anglophones & Francophones \\
100-399 & 22,4 & \\
années de résidence & 3,5 & 10,8 \\
enfants (nombre) & 24,6 & 4,7 \\
ne sait lire (\%) & 30,9 & 79,6 \\
ne sait écrire (\%) & & 85,3 \\
Rendements & 6,7 & 7,2 \\
blé (boisseaux à l'acre) & 130,7 & 107,0 \\
pomme de terre (boisseaux à l'acre) & 0,81 & 0,65 \\
foin (tonnes à l'acre) & & \\
& & \\
400 et plus & 23,7 & 13,7 \\
années de résidence & 4,6 & 5,2 \\
nombre d'enfants & 3,1 & 70,9 \\
ne sait lire (\%) & 5,7 & 72,7 \\
ne sait écrire (\%) & & \\
Rendements & 12,8 & 9,3 \\
blé (boisseaux à l'acre) & 196,9 & 154,9 \\
pomme de terre (boisseaux à l'acre) & 0,94 & 0,73 \\
foin (tonne à l'acre) & \\
\hline
\end{tabular}

Sources: APC, Recensement nominatif de 1871, bobine 10010-10011.

Afin d'illustrer plus complètement les inégalités entre les ethnies et celles dans la classe agricole elle-même, nous avons regroupé les cultivateurs et leur participation à la production en trois catégories basées sur le niveau de production. 
InÉGALITÉS ETHNIQUeS À HaWKesbury et À ALFRed en 1871

TABLEAU 26

La répartition inégale des récoltes de grains et de racines entre cultivateurs à Hawkesbury et à Alfred selon les groupes ethniques

(en pourcentages)

\begin{tabular}{|c|c|c|c|c|c|}
\hline & Écossais & Anglais & Irlandais & Anglophones & C. franghais \\
\hline \multicolumn{6}{|l|}{ Récolte (boisseaux) } \\
\hline cultivateurs (\%) & 32,0 & 23,1 & 31,8 & 30,8 & 74,8 \\
\hline $\begin{array}{l}\text { production (\%) } \\
400-999\end{array}$ & 10,6 & 7,3 & 15,0 & 12,5 & 50,2 \\
\hline cultivateurs (\%) & 48,1 & 55,8 & 54,3 & 52,2 & 22,8 \\
\hline production (\%) & 39,9 & 56,5 & 52,7 & 48,3 & 39,2 \\
\hline \multicolumn{6}{|l|}{1000 et plus } \\
\hline cultivateurs (\%) & 19,9 & 21,1 & 13,9 & 16,9 & 2,4 \\
\hline production (\%) & 49,5 & 36,2 & 32,3 & 39,1 & 10,6 \\
\hline \multicolumn{6}{|l|}{ Total } \\
\hline cultivateurs (\%) & 100 & 100 & 100 & 99,9 & 100 \\
\hline production (\%) & 100 & 100 & 100 & 99,9 & 100 \\
\hline
\end{tabular}

Sources: APC, Recensement nominatif de 1871, bobine 10010-10011.

Ces catégories constituent des démarcations assez nettes entre les niveaux de richesse, d'aisance et de pauvreté des uns et des autres. Et cela, même si ces chiffres n'incluent pas les cultivateurs qui produisaient moins de 100 boisseaux de grains et de racines, beaucoup plus nombreux chez les Canadiens français que dans les autres ethnies. En effet, la proportion de ces agriculteurs s'élevait à $8 \%$ chez les anglophones et à $22 \%$ parmi les Canadiens français. Ce qui accentue encore le contraste entre les Canadiens français, en tant qu'ethnie marquée par la pauvreté et l'analphabétisme, et les autres fortement surreprésentés parmi les producteurs de 400 et 1000 boisseaux et plus. Beaucoup plus que la grandeur des terres, la production des grains et des racines, aussi confirmée par les chiffres sur l'élevage et les produits des animaux, révèle toute l'ampleur de la dépendance à l'égard de l'exploitation forestière et du travail agricole à la journée des cultivateurs canadiens-français produisant moins de 100 boisseaux et de ceux qui récoltaient de 100 à 399 boisseaux de grains et de racines. C'est 
sans doute pour compenser la faiblesse de leur activité agricole que tant de cultivateurs canadiens-français d'Alfred se livrèrent à de substantielles coupes du bois de chauffage pour le marché.

Comme cela était prévisible, les Canadiens français établis sur des terres avaient, entre autres, apporté dans leur bagage les traditions agricoles de leur milieu d'origine. $\mathrm{Si}$ nous n'avions pas exclu de nos calculs le $22 \%$ des producteurs de moins de 100 boisseaux, il serait plus facile de dire dans quelle mesure les fermes canadiennes-françaises de Hawkesbury et d'Alfred avaient pu reproduire l'agriculture de celles du Québec. Nous avons quand même réuni dans le même tableau les performances des Québécois et celles des cultivateurs canadiens-français de Hawkesbury et d'Alfred afin que le lecteur se fasse une idée approximative de ces parentés.

TABLEAU 27

Le profil de la ferme canadienne-française de Hawkesbury et d'Alfred comparé à celui de la ferme québécoise par districts en 1871

\begin{tabular}{lccccc}
\hline & $\begin{array}{c}\text { Grains et racines } \\
\text { (boissealux) }\end{array}$ & $\begin{array}{c}\text { Animaux } \\
\text { (nombre) }\end{array}$ & $\begin{array}{c}\text { Beume } \\
\text { (bs) }\end{array}$ & $\begin{array}{c}\text { Fromage } \\
\text { (bs) }\end{array}$ & $\begin{array}{c}\text { Laine } \\
\text { (bs) }\end{array}$ \\
district de Québec & 260 & 13,4 & 121 & 0,4 & 15,4 \\
district de Trois-Rivières & 230 & 13,6 & 101 & 0,9 & 15,8 \\
district de Montréal & 292 & 16,3 & 185 & 3,9 & 19,2 \\
province de Québec & 270 & 14,8 & 148 & 3,3 & 17,3 \\
Hawkesbury et Alfred & 299 & 18,0 & 173 & 0 & 22,0 \\
\hline
\end{tabular}

Sources: recensement de 1871 pour le Québec, ce qui inclut les anglophones; le recensement nominatif de 1871 pour les Canadiens français de Hawkesbury et d'Alfred.

En tout cas, les performances sont si rapprochées qu'une fois le tout ramené aux mêmes bases, les distances pourraient aisément s'expliquer par le caractère relativement récent de l'arrivée de ces Canadiens français en Ontario. Ainsi, les quelques livres de fromage par ferme inscrites au recensement à l'enseigne du producteur québécois sont trompeuses puisqu'elles avaient été fabriquées par des 
cultivateurs anglophones situés en grande majorité dans les cantons, surtout ceux de la région de Montréal ${ }^{84}$.

Au contraire, même si $8 \%$ des producteurs britanniques avaient été soustraits de nos chiffres faute de rencontrer la norme de 100 boisseaux et plus, il ne fait aucun doute que le cultivateur anglophone de ces cantons, surtout celui de Hawkesbury, avait une physionomie fort différente non seulement de celle des francophones de la région mais aussi de celle des cultivateurs du comté de Prescott, de l'est et du nord de l'Ontario. Pour être plus précis, il faudrait peut-être l'assimiler à la «middling-class» agricole du centre et du sud-ouest de l'Ontario, dont parle Gordon Darroch.

\section{TABLEAU 28}

Le profil de la ferme du cultivateur anglophone de Hawkesbury comparé au profil de celle du cultivateur moyen des différentes régions de l'Ontario en 1871

\begin{tabular}{|c|c|c|c|c|c|}
\hline & $\begin{array}{l}\text { Grains et racines } \\
\text { (boisseaux) }\end{array}$ & $\begin{array}{l}\text { Animaux } \\
\text { (nombre) }\end{array}$ & $\begin{array}{l}\text { Beurne } \\
\text { (lbs) }\end{array}$ & $\begin{array}{l}\text { Fromage } \\
\text { (lbs) }\end{array}$ & $\begin{array}{l}\text { Laine } \\
\text { (lbs) }\end{array}$ \\
\hline \multicolumn{6}{|l|}{ Ontario } \\
\hline Sud-Ouest & 416 & 19,0 & 153 & 22,0 & 28,4 \\
\hline Centre & 610 & 20,5 & 172 & 11,2 & 31,9 \\
\hline Est & 294 & 17,3 & 203 & 15,0 & 26,6 \\
\hline Nord & 176 & 5,9 & 54 & 0,3 & 3,3 \\
\hline province & 459 & 19,0 & 172 & 15,7 & 29,5 \\
\hline comté de Prescott & 288 & 13,5 & 172 & 17,3 & 17,0 \\
\hline \multicolumn{6}{|l|}{ Hawkesbury } \\
\hline anglophones & 784 & 29,5 & 456 & 85,8 & 39,9 \\
\hline francophones & 301 & 21,3 & 163 & 0 & 19,9 \\
\hline ensemble & 624 & 24,7 & 359 & 57,4 & 33,2 \\
\hline
\end{tabular}

Sources: le recensement de 1871 pour les producteurs agricoles des grandes régions et du comté de Prescott et le recensement nominatif de 1871 pour Hawkesbury.

En effet, le cultivateur anglophone de Hawkesbury n'est pas le producteur moyen du comté de Prescott. S'il fallait

${ }^{84}$ Ouellet, «Francophones et Franco-Ontariens dans l'univers agricole canadien...", Cahiers Charlevoix 1, Etudes franco-ontariennes, p. 320. 
trouver un canton représentatif de l'ensemble de ce territoire, Alfred avec ses terres pauvres, le faible volume de ses productions et de ses troupeaux serait, tant chez les francophones que chez les anglophones, un meilleur choix pour représenter ce comté. La production moyenne de grains et de racines y était de $47 \%$ inférieure à celle de Hawkesbury. Ce qui, évidemment, ne veut pas dire que les disparités entre francophones et anglophones n'existaient pas là comme ailleurs.

\section{Conclusion}

La colonisation des cantons de Hawkesbury et d'Alfred n'était donc qu'un aspect d'un vaste mouvement d'émigration, d'ampleur internationale, dirigé principalement vers l'Amérique du Nord, soit pour s'insérer dans les sociétés existantes, soit pour en créer de nouvelles. Elle avait surtout été réalisée dans un premier temps par des immigrants écossais, anglais et allemands qui avaient alors occupé une portion considérable du territoire. Puis les Irlandais protestants, suivis des Irlandais catholiques, étaient venus. Enfin, les Canadiens français, après avoir pénétré peu à peu dans la région en groupuscules depuis le début du siècle, arrivèrent en si grand nombre après 1855 qu'en 1871 ils constituaient déjà $54 \%$ de la population et $51 \%$ des chefs de maisonnée. Cette «invasion", comme on la qualifiera plus tard, avait été rendue possible par le déclin de l'immigration en provenance des îles Britanniques, particulièrement d'Irlande, par les grandes difficultés du monde rural québécois et par le besoin pressant qu'on avait des deux côtés de l'Outaouais d'une abondante main-d'œuvre à bon marché.

Ces Canadiens français étaient donc les derniers venus dans la région et ils étaient en quête de terres et d'emplois. En 1871, l'immense majorité de leurs chefs de maisonnée, soit $86 \%$ d'entre eux, étaient nés au Québec et ils habitaient 
l'Ontario depuis moins d'une décennie. Le pourcentage des anglophones nés ailleurs qu'en Ontario était de $64 \%$ et ils résidaient dans la province depuis une quinzaine d'années. Comme la grande majorité de tous ces immigrants établis dans ces cantons étaient déjà mariés et avaient eu des enfants avant de s'installer en Ontario, leurs épouses avaient surtout été choisies dans leurs provinces et leurs pays d'origine dans une proportion de $61 \%$ dans le cas des anglophones et de $77 \%$ dans celui des Canadiens français. Les fils de ces derniers, âgés d'environ 24 ans en 1871, qui avaient déclaré des occupations, étaient davantage ontariens de naissance (un rapport de deux sur cinq) que leurs pères ou grandspères, mais ils l'étaient beaucoup moins que les jeunes anglophones du même âge parmi lesquels huit sur dix étaient d'origine ontarienne. À ces divers points de vue, ces chefs de maisonnée canadiens-français étaient donc à la fois différents et semblables aux autres migrants, qu'ils s'agisse de ceux qui franchissaient l'Atlantique en toutes directions ou de ceux qui, au Québec, se déplaçaient à l'intérieur de la province, allaient aux États-Unis et ailleurs en Ontario. Comme eux, ils se déplaçaient le plus souvent en famille, incités qu'ils étaient à le faire autant, sinon plus, par des considérations socio-économiques que par le besoin de se reproduire. La nécessité d'avoir accès à la terre, de trouver du travail et de fonder une famille étaient des motifs qui animaient aussi les migrants célibataires, excepté que ceuxci étaient les moins nombreux.

Cette entrée presque massive des Canadiens français dans la région avait d'autant plus transformé son caractère qu'euxmêmes étaient catholiques dans une proportion de $99 \%$ et représentaient les deux tiers des chefs de maisonnée de cette Église dans une société culturellement diversifiée. Le contraste avec les autres ethnies était donc manifeste, puisque les Écossais étaient les seuls à être affiliés à une seule dénomination religieuse dans une proportion atteignant les 50\%, en l'occurrence l'Église presbytérienne. Il va 
sans dire qu'une telle variété dans les appartenances ethniques et religieuses, compliquée par de grandes différences dans la dimension des groupes eux-mêmes, ne pouvait que favoriser, contrairement à ce que raconte Gaffield, la multiplication des mariages interethniques et interconfessionnels. Ainsi $68 \%$ et $45 \%$ des chefs de maisonnée des groupes ethniques les moins nombreux, à savoir les Allemands et les Anglais, avaient contracté des mariages avec des épouses d'une autre ethnie ou d'une autre religion. Les Canadiens français catholiques, avec seulement $2 \%$ de mariages de ce genre, faisaient bande à part. Il n'est donc pas surprenant de constater qu'à la génération suivante le caractère catholique de la communauté francophone ait été renforcé au lieu d'être dilué.

Dans ces circonstances, peut-être peut-on parler d'une communauté irlandaise catholique, peut-être doit-on parler, sans doute avec bien des nuances, d'une communauté anglophone protestante. Il est certain, cependant, qu'une communauté canadienne-française unie autour de la langue et de la religion avait pris place en Ontario, d'autant plus qu'elle se distinguait aussi des autres par son dynamisme démographique. Ses taux de natalité surpassaient ceux des anglophones par une marge de $52 \%$, ceux de mortalité générale par une marge de $23 \%$ et ceux de mortalité infantile étaient 2,6 fois plus élevés que ceux des anglophones. En cela, comme en beaucoup d'autres choses, ces Canadiens français ne faisaient que reproduire les disparités qui existaient au Québec entre les francophones et les autres. Ce qui, en l'occurrence, leur était avantageux puisque, étant donné la baisse de l'immigration des îles Britanniques, la progression plus rapide du contrôle des naissances dans leur milieu et la faveur dont jouissaient les autres régions de l'Ontario auprès des immigrants, ces écarts, même en l'absence d'une émigration de Britanniques, auraient suffi à leur assurer une suprématie numérique croissante dans la région. 
L'originalité des Canadiens français se trouvait encore accentuée par le fait qu'ils étaient analphabètes dans des proportions qui les rendaient plus nettement différents du reste de la population locale. En effet, ils représentaient $90 \%$ des chefs de familles qui ne savaient lire et $86 \%$ de ceux qui ne pouvaient écrire. Leurs épouses leur étaient légèrement supérieures à cet égard puisqu'elles regroupaient $85 \%$ de celles qui étaient incapables de lire et $83 \%$ de celles qui étaient incapables d'écrire. Ces taux correspondaient à ceux qui avaient prévalu au Québec au moment où ils étaient d'âge scolaire, c'est-à-dire à l'époque où venait de s'engager la révolution présidée par l'État dans le domaine de l'éducation. Il est curieux de constater que, dans le livre de Chad Gaffield, il ne soit pas question de cet aspect capital du développement culturel de cette région.

Sur ce plan, les francophones nés en Ontario n'étaient pas du tout en retard sur ceux qui étaient nés au Québec. D'ailleurs, dans les deux cas, les enfants d'âge scolaire fréquentaient davantage l'école que leurs parents. Aussi les fils de ces chefs de maisonnée, nés en Ontario et au Québec, étaient-ils beaucoup plus alphabétisés que leurs parents. Mais, comme leurs enfants, relativement aux anglophones, étaient sous-inscrits dans les écoles (seulement $43 \%$ des enfants d'âge scolaire) et que leurs instituteurs étaient sous-représentés dans cette profession (seulement $16 \%$ des effectifs), les Canadiens français ne se trouvaient pas dans une situation susceptible de réduire rapidement l'écart qui existait entre eux et les autres. En fait, derrière ces différences entre les groupes ethniques, il y avait des réseaux d'inégalités qui avaient en grande partie leurs racines dans leur passé respectif et dans les conditions socio-économiques et culturelles actuelles des migrants.

Même si la dernière vague d'immigration avait été constituée de Canadiens français catholiques, leur arrivée en grand nombre n'avait suscité ni perturbations ni mouvements de 
protestation parmi les membres des ethnies en place. C'est que, pour faire fonctionner une structure économique fondée sur l'agriculture et la forêt, on avait alors eu besoin d'immigrants non seulement pour prendre en charge les terres disponibles mais aussi, à travers eux, d'un abondant réservoir de main-d'œuvre à bon marché qui puisse contribuer aux travaux forestiers et agricoles. La chose était d'autant plus importante que les premiers immigrants anglophones, qui avaient largement choisi de s'établir sur des fermes et y avaient le plus souvent prospéré, avaient eu de moins en moins besoin de s'impliquer dans le travail en forêt. Il faut dire qu'arrivés les premiers, ils avaient eu plus facilement accès à la terre et à la propriété que ceux qui étaient venus par la suite.

C'est un fait que conteste Gordon Darroch à propos du Centre de l'Ontario. Pourtant, comme l'ont justement montré Akenson et plusieurs autres, il est tout à fait raisonnable de croire, sans pour autant exclure les autres facteurs, que l'arrivée tardive dans une région peut avoir eu des effets significatifs, souvent permanents, sur l'accès à la propriété, voire sur la dimension des parcelles et leur degré de développement. En tout cas, il est certain qu'ici comme dans Leeds et Lansdowne, ce facteur, aussi bien que le degré de pauvreté et le niveau d'alphabétisation des immigrants, a influé sur le statut des nouveaux colons. Ce n'est certainement pas un hasard si les deux tiers des locataires de ces trois cantons étaient des Canadiens français qui, il va sans dire, payaient un loyer à leurs prédécesseurs. Pour être plus précis, le fait d'être locataire constituait dans la plupart des cas la grande démarcation entre le statut de journalier et celui de cultivateur.

Aucun doute à ce sujet, la communauté canadiennefrançaise de Hawkesbury et d'Alfred faisait, en 1871, figure de société défavorisée. Plus de la moitié de la population et des chefs de maisonnée s'y rattachaient, mais seulement $29 \%$ des hommes et des femmes de professions et des gens 
d'affaires en faisaient partie. Ce qui veut dire que le pouvoir économique édifié dans l'Outaouais depuis le début du siècle, relié aux villes et aux marchés impériaux, dont les frères Hamilton étaient les plus éminents représentants, était essentiellement concentré entre les mains des anglophones. Au point que, même si les Canadiens français possédaient $39 \%$ des établissements où se déroulaient des activités artisanales et industrielles, ils ne contribuaient que pour moins de $4 \%$ à la valeur de leur production. Si on exclut la participation des frères Hamilton à ce chapitre, leur part ne s'élève qu'à $13 \%$.

Il est évident, quoi qu'en disent Darroch et Ornstein, qu'il existait une hiérarchie à la fois ethnique et sociale dans la région. La représentation marginale des Canadiens français parmi les classes dirigeantes, à peine compensée par le fait que les artisans d'origine française étaient en nombre à peu près suffisant pour desservir adéquatement leur communauté, avait sa confirmation dans leur énorme sur-représentation au bas de l'échelle sociale parmi les journaliers. En effet, les Canadiens français monopolisaient $80 \%$ des effectifs de la classe des journaliers de la région. Tout cela éclaire non seulement les rapports de dépendance qui existaient entre les prolétaires francophones et les employeurs anglophones, mais aussi les inégalités qui imprégnaient la société canadienne-française elle-même. Mis ensemble, les artisans et les journaliers de langue anglaise représentaient $23 \%$ des chefs de maisonnée de même origine, alors que ceux d'origine française représentaient $48 \%$ des leurs. Cette situation n'était pas spécifique à l'Ontario puisqu'elle existait aussi dans le canton de Hull en 1842 et dans la seigneurie de la Petite-Nation en $1851^{85}$. De même, dans les quatre paroisses de la région de SaintEustache, en 1831, les Canadiens français constituaient 91\% des chefs de maisonnée, $98 \%$ des journaliers, $89 \%$

${ }^{85}$ Chad Gaffield (dir.), Histoire de l'Outaouais, Québec, IQRC, 1994, pp. 205s.; Claude Baribeau, op. cit., pp. 122-124. 
des cultivateurs et seulement $69 \%$ des professionnels et des gens d'affaires ${ }^{86}$. La sous-représentation des Canadiens français, à peu près partout très marquée au Québec au sommet de la hiérarchie des occupations, l'était davantage à Hawkesbury et à Alfred, même parmi les cultivateurs qui ne constituaient que $43 \%$ des agriculteurs de ces trois cantons.

Ainsi, à Hawkesbury et à Alfred, il existait aussi une hiérarchie de la terre. Plusieurs historiens ont prétendu, à la suite du géographe Cartwright, qu'un déterminisme culturel avait présidé à l'occupation du sol. Les anglophones auraient par atavisme privilégié les sites élevés et les terres sablonneuses, alors que les Canadiens français auraient pour les mêmes raisons préféré les basses terres argileuses et marécageuses. Ce schéma n'a aucun fondement historique puisque partout, lorsque les individus en avaient eu l'occasion, ils avaient misé sur la qualité des sols et les facilités d'accès à leur site par voie d'eau ou de terre. Si les anglophones avaient pu sembler manifester une certaine prédilection pour certains types de sols, c'est qu'ils accordaient plus d'importance à la culture de la pomme de terre que les Canadiens français. La répartition des groupes ethniques par concession démontre que les Canadiens français, même s'ils arrivèrent plus tard que les autres, ne furent pas strictement confinés à certains endroits. Elle suggère plutôt que les choix individuels furent conditionnés par la nature de leurs occupations, par leur degré de pauvreté et leurs préférences, compte tenu des terres disponibles et de leurs notions sur la hiérarchie des cultures. Comme de raison, les pionniers, c'est-à-dire les Écossais, les Anglais et les Allemands, occupèrent d'abord les neuf premières concessions, surtout les six premières, et s'y taillèrent souvent de petits domaines. Puis, à mesure que

${ }^{86}$ Monique Benoît, «La Formation d'une région. La marche du peuplement de Saint-Eustache à Saint-Jérôme et le problème des subsistances", Thèse de Maîtrise, Université d'Ottawa, 1980, p. 110. 
se fit la diversification sociale, ils furent capables d'accommoder à même leurs larges possessions les non-cultivateurs qui se trouvèrent partout rassemblés dans les mêmes concessions près du front, non seulement dans le village de Hawkesbury-Ouest mais à Hawkesbury-Est et à Alfred. Le même processus joua pour ceux qui désiraient des terres pour fins agricoles. Les Irlandais, arrivés en second lieu, furent davantage concentrés dans les trois premières concessions que dans les suivantes alors que leurs successeurs canadiens-français, les plus nombreux et les plus répandus sur l'ensemble du territoire, le furent davantage dans les concessions quatre à six que partout ailleurs. Le résultat de toutes ces transactions, dont bénéficièrent largement les pionniers, fut que ces derniers, même après s'être départis d'une portion de leurs propriétés, étaient encore plus largement dotés en 1871 que les autres: 141 acres en moyenne, dont 68 améliorées. Arrivés à leur suite, les Irlandais disposaient de 104 acres, dont 48 améliorées et, enfin, les Canadiens français, de 64 acres, dont 30 améliorées. Qui oserait dire, à la suite de Gordon Darroch, que le moment de l'entrée sur le marché foncier n'a pas d'effet, au moins temporaire, sur l'émergence des inégalités entre les groupes ethniques et entre les individus euxmêmes quant à la dimension des fermes et à leur développement?

À Hawkesbury et à Alfred, ce n'était pas seulement la moitié des fermiers qui possédaient entre 70 et 167 acres comme c'était le cas dans le centre de l'Ontario échantillonné par Darroch, mais $76 \%$ des fermiers écossais, anglais et allemands, $60 \%$ des Irlandais et seulement $26 \%$ des Canadiens français qui s'étaient appropriés 100 acres et plus. Les premiers contrôlaient $89 \%$ de la superficie occupée dans leur groupe, les seconds $79 \%$ et les troisièmes $47 \%$. Ce qui confirme amplement l'existence d'une hiérarchie de la terre occupée à cet endroit qui s'étendait aussi à la surface améliorée. En effet, $36 \%$ des pionniers, 
$53 \%$ des Irlandais et $78 \%$ des Canadiens français se classaient dans la catégorie de ceux dont la portion améliorée était inférieure à 50 acres.

Les Canadiens français, les derniers arrivants et les plus pauvres, se trouvaient donc au dernier rang quant à l'étendue de leurs possessions foncières. Ils l'étaient plus encore quant à leurs performances agricoles. En effet, en mesurant l'activité agricole, nous avons d'abord exclu de la statistique tous ceux qui, tout en se déclarant cultivateurs, récoltaient moins de 100 boisseaux de grains et de racines: c'est-à-dire $7 \%$ des pionniers, $8 \%$ des Irlandais et $22 \%$ des Canadiens français. Parmi les autres, nous avons distingué ceux qui produisaient de 100 à 399 boisseaux de ceux qui récoltaient davantage qu'eux. Dans la catégorie de ceux qui produisaient 100 à 399 boisseaux, il y avait $30 \%$ de pionniers qui n'étaient responsables que pour $10 \%$ de la récolte dans leur groupe, $32 \%$ d'Irlandais qui n'étaient responsables que pour $15 \%$ de la récolte de leur groupe et $75 \%$ de Canadiens français qui étaient responsables de la moitié de leur propre production.

Ainsi, l'élite agricole, celle qui appartenait à la catégorie des producteurs de 400 boisseaux et plus et qui assumait une proportion encore plus élevée de la production, se recrutait pour l'essentiel chez les pionniers et les Irlandais. Même si, à cet égard, il existait des disparités entre les Irlandais protestants et les catholiques, ces écarts n'avaient rien de comparables à ceux qui existaient entre les Canadiens français et l'ensemble des anglophones.

Cette marginalité des producteurs canadiens-français s'étendait à tous les aspects de l'activité agricole. Quatre cultivateurs sur dix de la région étaient d'origine française, ils possédaient $30 \%$ de l'espace occupé et amélioré, mais ils récoltaient seulement $20 \%$ des grains et des racines, $17 \%$ du foin, possédaient $29 \%$ des animaux et produisaient seulement $20 \%$ du beurre, aucun fromage et $26 \%$ 
de la laine. Ils étaient aussi au dernier rang pour les rendements et l'équipement des fermes. Encore ici, la situation n'était pas si différente que cela de celle qui prévalait dans les dix paroisses de la région de Saint-Eustache en 1851 où la marge entre les producteurs canadiens-français et les anglophones en ce qui concerne les grains et les racines, d'une part, et le nombre des animaux de la ferme, d'autre part, était d'environ $40 \%{ }^{87}$. Dans la seigneurie de la PetiteNation en $1842,76 \%$ des producteurs anglophones de grains et de racines récoltaient 100 minots et plus alors que seulement $32 \%$ des censitaires canadiens-français appartenaient à cette catégorie ${ }^{88}$.

Ces disparités entre les groupes ethniques et à l'intérieur de chacun d'eux, en ce qui regarde la culture du sol, s'expliquent incontestablement par la chronologie de l'immigration, mais seulement en partie. Comme le démontre le cas des Irlandais protestants et catholiques, cet écart pouvait partiellement être comblé avec le temps. Cependant, les différences dans la dimension de la terre, qui résultent, pour une part, de l'arrivée tardive, ne peuvent rendre compte de tous les écarts. Car de nombreux propriétaires de terres de 100 acres et plus, le plus souvent classés parmi les producteurs de 400 boisseaux et plus, appartenaient aussi à la catégorie des cultivateurs qui ne récoltaient que de 100 à 399 boisseaux des grains et de racines. Ce qui ne veut pas dire qu'une bonne part des différences entre les Irlandais protestants et les pionniers relativement à la production du foin et à l'élevage des animaux ne s'expliquent pas largement par le fait que leurs terres étaient plus petites que celles des pionniers. D'ailleurs, en tout ceci, on ne saurait sous-estimer le degré de pauvreté des individus, le niveau d'alphabétisme et le dynamisme des individus qui, comme la durée de la résidence dans la région, contribuaient à départager les petits et les gros cultivateurs.

\footnotetext{
${ }^{87}$ Ibid., p. 159.

${ }^{88}$ Baribeau, op. cit., p. 92.
} 
Dans cette hiérarchie de la terre, qui allait des pionniers, aux Irlandais protestants, aux Irlandais catholiques et aux Canadiens français, ceux-ci se situaient au bas de l'échelle, loin derrière les autres. Incontestablement, leurs fermiers étaient les plus pauvres, les moins alphabétisés et une proportion considérable d'entre eux, à part les $22 \%$ de ceux qui récoltaient moins de 100 boisseaux de grains et de racines, dépendaient eux-mêmes ou leurs fils du travail saisonnier en forêt ou ailleurs pour vivre. Comme ils composaient en plus $80 \%$ de la classe des journaliers, on peut alors se faire une idée de l'ampleur de la situation marginale qui était la leur. D'autant plus qu'ils étaient fortement sous-représentés au sommet de la société et ne contribuaient que pour $4 \%$ à la valeur des produits fabriqués par les entrepreneurs et les artisans. Pourtant, cette majorité de pauvres gens venus du Québec, qu'ils avaient quitté avec l'espoir d'améliorer leur sort, persévérèrent dans la région et même renforcèrent leur position majoritaire même si leurs gains immédiats furent modestes. Pendant ce temps, les anglophones qui jouissaient de tant d'avantages, la quittaient doucement. Il serait intéressant de savoir dans quelle mesure chacun de ces groupes a pu être affecté par la récession des années 1873-1878, par le déplacement du centre de l'exploitation forestière vers l'Ouest et le Nord, et par les changements structuraux de la fin du siècle. 